FINAL REPORT

\title{
ZnO PN Junctions for Highly-Efficient, Low-Cost Light Emitting Diodes
}

\author{
$\underline{\text { Principal Investigator }}$ \\ David P. Norton \\ Professor \\ University of Florida \\ Department of Materials Science and Engineering \\ 106 Rhines Hall \\ P. O. Box 116400 \\ Gainesville, FL 32611-6400 \\ Phone: (352) 846-0525 \\ Fax: (352) 846-1182 \\ E-mail: $\underline{\operatorname{dnort} @ \text { mse.ufl.edu }}$ \\ $\underline{\text { Co-Principal Investigators }}$ \\ Stephen Pearton \\ Professor \\ University of Florida \\ Department of Materials Science and Engineering \\ 106 Rhines Hall \\ P. O. Box 116400 \\ Gainesville, FL 32611-6400 \\ Fan Ren \\ Professor \\ University of Florida \\ Department of Chemical Engineering \\ 106 Rhines Hall \\ P. O. Box 116400 \\ Gainesville, FL 32611-6400 \\ Work Performed Under Agreement: \\ DE-FC26-04NT42271 \\ U. S. Department of Energy \\ National Energy Technology Laboratory \\ COR: Ryan Egidi \\ E-Mail: Ryan.Egidi@netl.doe.gov
}

\section{Scope of Work:}

By 2015, the US Department of Energy has set as a goal the development of advanced solid state lighting technologies that are more energy efficient, longer lasting, and more cost-effective than current technology. One approach that is most attractive is to utilize light-emitting diode technologies. Although III-V compound semiconductors have been the primary focus in pursuing this objective, $\mathrm{ZnO}$-based materials present some distinct advantages that could yield success in meeting this objective. As with the nitrides, $\mathrm{ZnO}$ is a direct bandgap semiconductor whose gap energy $(3.2 \mathrm{eV})$ can be tuned from 3.0 to $4 \mathrm{eV}$ with substitution of $\mathrm{Mg}$ for higher bandgap, $\mathrm{Cd}$ for lower bandgap. $\mathrm{ZnO}$ has an exciton binding energy of $60 \mathrm{meV}$, which is larger that that for the nitrides, indicating that it should be a superior light emitting semiconductor. Furthermore, $\mathrm{ZnO}$ thin films can be deposited at temperatures on the order of $400-600^{\circ} \mathrm{C}$, which is significantly lower that that for the nitrides and should lead to lower manufacturing costs. It has also been demonstrated that functional $\mathrm{ZnO}$ electronic devices can be fabricated on inexpensive substrates, such as glass. Therefore, for the large-area photonic application of solid state lighting, $\mathrm{ZnO}$ holds unique potential. A significant impediment to exploiting $\mathrm{ZnO}$ in light-emitting applications has been the absence of effective p-type carrier doping. However, the recent realization of acceptor-doped $\mathrm{ZnO}$ material overcomes this impediment, opening the door to $\mathrm{ZnO}$ light emitting diode development

In this project, the synthesis and properties of $\mathrm{ZnO}$-based pn junctions for light emitting diodes was 


\section{DISCLAIMER}

This report was prepared as an account of work sponsored by an agency of the United States Government. Neither the United States Government nor any agency thereof, nor any of their employees, makes any warranty, express or implied, or assumes any legal liability or responsibility for the accuracy, completeness, or usefulness of any information, apparatus, product, or process disclosed, or represents that its use would not infringe privately owned rights. Reference herein to any specific commercial product, process, or service by trade name, trademark, manufacturer, or otherwise does not necessarily constitute or imply its endorsement, recommendation, or favoring by the United States Government or any agency thereof. The views and opinions of authors expressed herein do not necessarily state or reflect those of the United States Government or any agency thereof. 
investigated. The focus was on three issues most pertinent to realizing a ZnO-based solid state lighting technology, namely (1) achieving high p-type carrier concentrations in epitaxial and polycrystalline films, (2) realizing band edge emission from pn homojunctions, and (3) investigating pn heterojunction constructs that should yield efficient light emission. The project engaged established expertise at the University of Florida in $\mathrm{ZnO}$ film growth (D. Norton), device fabrication (F. Ren) and wide bandgap photonics (S. Pearton). It addressed p-type doping and junction formation in $(\mathrm{Zn}, \mathrm{Mg}) \mathrm{O}$ alloy thin films. The project employed pulsed laser deposition for film growth. The p-type dopant of interest was primarily phosphorus, given the recent results in our laboratory and elsewhere that this anions can yield p-type $\mathrm{ZnO}$-based materials. The role of $\mathrm{Zn}$ interstitials, oxygen vacancies, and/or hydrogen complexes in forming compensating shallow donor levels imposes the need to simultaneously consider the role of in situ and post-growth processing conditions. Temperature-dependent Hall, Seebeck, C-V, and resistivity measurements was used to determine conduction mechanisms, carrier type, and doping. Temperature-dependent photoluminescence was used to determine the location of the acceptor level, injection efficiency, and optical properties of the structures. X-ray diffraction will used to characterize film crystallinity. Using these materials, the fabrication and characterization of $(\mathrm{Zn}, \mathrm{Mg}) \mathrm{O}$ pn homojunction and heterojunction devices was pursued. Electrical characterization of the junction capacitance and I-V behavior was used to extract junction profile and minority carrier lifetime. Electroluminescence from biased junctions was the primary property of interest.

\section{Summary of Tasks Performed:}

\section{$\underline{\text { Task } 1 \text { - Growth of High Hole Density p-type (Zn,Mg)O Thin Films }}$}

\subsection{Synthesis and characterization of phosphorus-doped $\mathrm{ZnO}$ and (Zn,Mg)O thin films via pulsed laser deposition}

Summary: The transport and optical properties of phosphorus-doped $(\mathrm{Zn}, \mathrm{Mg}) \mathrm{O}$ thin films grown via pulsed laser deposition (PLD) are studied. The carrier type of as-deposited ( $\mathrm{Zn}, \mathrm{Mg}$ )O:P films converts from n-type to p-type with increasing oxygen partial pressure. All the films exhibit good crystallinity with c-axis orientation. This result indicates the importance of oxidation conditions in realizing p-type $(\mathrm{Zn}, \mathrm{Mg}) \mathrm{O}: \mathrm{P}$ films. The as-deposited $\mathrm{ZnO}: \mathrm{P}$ film properties show a strong dependence on the deposition ambient at different growth temperatures. The resistivity of the samples deposited in $\mathrm{O}_{3} / \mathrm{O}_{2}$ mixture is two orders of magnitude higher than the films grown in oxygen and $\mathrm{O}_{2} / \mathrm{Ar} / \mathrm{H}_{2}$ mixture. The room temperature photoluminescence (PL) of the as-deposited films has been shown that growing in the $\mathrm{O}_{2} / \mathrm{Ar} / \mathrm{H}_{2}$ mixture ambient significantly increases the band edge emission while inhibiting the visible emission. The enhanced UV emission in the films grown in $\mathrm{O}_{2} / \mathrm{Ar} / \mathrm{H}_{2}$ mixture may result from hydrogen passivation of the deep level emission centers. The annealed $\mathrm{ZnO}: \mathrm{P}$ films are $\mathrm{n}$-type with nonlinear dependence of resistivity on annealing temperature. The resistivity increases in the films with annealing at $800 \mathrm{C}$ while decreasing with further increasing annealing temperature. Strong visible light emission is observed from the $\mathrm{ZnO}: \mathrm{P}$ films annealed in oxygen.

\section{Introduction:}

One of the significant issues remaining in p-type doping of $\mathrm{ZnO}$ and related alloys is to achieve reproducible ptype conduction. The p-type behavior is highly dependent on the growth process and annealing conditions. Since $\mathrm{Zn}$ interstitials, $\mathrm{O}$ vacancies, and/or hydrogen complexes have been reported as contributors to compensating electrons, understanding the role of oxidizing species in yielding low native defect thin-film materials is needed. The background impurity density during growth also needs to be minimized so as to observe the presence of acceptors in transport measurements. In this work, $(\mathrm{Zn}, \mathrm{Mg}) \mathrm{O}$ doped with phosphorus films were synthesized via PLD under different oxygen partial pressures. A positive Hall coefficient is reported in as-deposited $(\mathrm{Zn}, \mathrm{Mg}) \mathrm{O}: \mathrm{P}$ films grown at higher oxygen pressure. The systematic study of the relationship of growth condition and post-annealing process with the properties of phosphorus-doped $\mathrm{ZnO}$ thin films is also discussed.

\section{Experimental procedures:}

Pulsed laser deposition was used to deposit phosphorus-doped $\mathrm{ZnO}$ and $(\mathrm{Zn}, \mathrm{Mg}) \mathrm{O}$ epitaxial films on c-plane sapphire substrates. The targets were fabricated using high-purity $\mathrm{ZnO}(99.995 \%)$ with or without $\mathrm{MgO}(99.998 \%)$, mixing with $\mathrm{P}_{2} \mathrm{O}_{5}(99.998 \%)$ as the doping agent. The targets were pressed and sintered at $1000^{\circ} \mathrm{C}$ for $12 \mathrm{~h}$ in air. The phosphorus doping levels in the $(\mathrm{Zn}, \mathrm{Mg}) \mathrm{O}: \mathrm{P}$ and $\mathrm{ZnO}: \mathrm{P}$ targets were 2 and 0.2 at $\%$, respectively. $\mathrm{A} \mathrm{KrF}$ excimer laser with a wavelength of $248 \mathrm{~nm}$ was used as the ablation source. A laser repetition rate of $1 \mathrm{~Hz}$ was used, with a target to substrate distance of $4 \mathrm{~cm}$ and a laser pulse energy density of $1-3 \mathrm{~J} / \mathrm{cm}^{2}$. Sapphire substrates were 
ultrasonically cleaned with trichloroethylene (TCE), acetone and methanol for 5 min and dried in $\mathrm{N}_{2}$ prior to loading into the growth chamber. The growth chamber base pressure was $2 \times 10^{-7}$ Torr. Film thickness was in the range of $400-500 \mathrm{~nm}$. An undoped $\mathrm{ZnO}$ buffer layer $(\sim 50 \mathrm{~nm})$ was initially deposited at $400^{\circ} \mathrm{C}$ and $20 \mathrm{mTorr}$ oxygen partial pressure before the growth of P-doped $\left(\mathrm{Zn}_{0.9} \mathrm{Mg}_{0.1}\right) \mathrm{O}$ films. Introducing a nucleation layer grown at lower temperature on sapphire prior to growing the active layer improves reproducibility and crystallinity. The undoped $\mathrm{ZnO}$ buffer layer was post-annealed at $650^{\circ} \mathrm{C}$ in flowing $\mathrm{O}_{2}$ for $1 \mathrm{~h}$ in order to decrease the electron conductivity. A semi-insulating buffer layer is preferable in order to perform Hall measurements without influence from buffer layer conduction. The P-doped $\left(\mathrm{Zn}_{0.9} \mathrm{Mg}_{0.1}\right) \mathrm{O}$ films were then deposited on the annealed $\mathrm{ZnO}$ buffer layer at a substrate temperature of $500^{\circ} \mathrm{C}$ at oxygen partial pressure ranging from $20 \mathrm{mTorr}$ to $200 \mathrm{mTorr}$. ZnO:P films were deposited under different oxidizing conditions such as in oxygen and $4 \% \mathrm{H}_{2} / \mathrm{Ar}$ mixture, pure oxygen and ozone/oxygen mixture. The partial pressure ratio of oxygen and $\mathrm{Ar} / \mathrm{H}_{2}$ in the gas mixture was 1:1. The nitrogen-free plasma discharge ozone generator yielded an $\mathrm{O}_{3} / \mathrm{O}_{2}$ ratio on the order of 1-3\%. The same total growth pressure was maintained at $60 \mathrm{mTorr}$ for the different ambients. The growth temperature ranged from $600^{\circ} \mathrm{C}$ to $800^{\circ} \mathrm{C}$. Annealing was carried out at temperatures ranging from $800^{\circ} \mathrm{C}$ to $1100^{\circ} \mathrm{C}$ in a flowing $\mathrm{O}_{2}$ ambient for $1 \mathrm{hr}$. The transport properties of the as-grown and annealed films were determined using four-point Van der Pauw Hall measurements at room temperature. The photoluminescence properties of the films were also measured at room temperature using a He-Cd laser $(325 \mathrm{~nm})$. The film crystallinity and surface morphology were investigated using X-ray Diffraction (XRD) and atomic force microscopy (AFM).

Results and discussion:

There are two motivations for examining phosphorus doping in Mg-doped ZnO. First, p-type (Zn,Mg)O will be necessary for LED heterostructures in which carrier confinement for efficient electron-hole recombination is needed. Second, the addition of $\mathrm{Mg}$ shifts the conduction band edge to higher energy, perhaps increasing the activation energy of the defect donor states. Previous results on P-doped $\left(\mathrm{Zn}_{0.9} \mathrm{Mg}_{0.1}\right) \mathrm{O}$, in particular $\mathrm{C}-\mathrm{V}$ and $\mathrm{I}-\mathrm{V}$ characteristics of device structures, indicate that phosphorus yields an acceptor state and p-type behavior. However, these materials did not show an unambiguous positive Hall voltage, presumably due to the low mobility and high carrier compensation. In this study, the effect of oxygen partial pressure on the transport properties of as-deposited $\left(\mathrm{Zn}_{0.9} \mathrm{Mg}_{0.1}\right) \mathrm{O}: \mathrm{P}_{0.02}$ films were examined systematically. Figure 1.1.1 shows the carrier concentration and carrier type as a function of oxygen pressure. The samples were maintained in the dark for $12 \mathrm{~h}$ prior to performing the Hall measurements in order to eliminate the photoconductivity relaxation effect. The error bars represent the maximum deviation from the average deduced from over twenty measurements. It has been shown that the films deposited at the oxygen partial pressure lower than 100 mTorr show n-type. With increasing oxygen pressure, the hole concentration increases while the electron density continuously decreases. The films grown at 150 mTorr oxygen pressure show consistent p-type conduction with a hole concentration of $\sim 2.7 \times 10^{16} \mathrm{~cm}^{-3}$. For the films grown at 100 , 120 and 200 mTorr oxygen partial pressures, unambiguous conduction type is not observed due to the nearequivalent concentrations of holes and electrons in the films. Figure 1.1.2 shows the carrier mobility of P-doped $\left(\mathrm{Zn}_{0.9} \mathrm{Mg}_{0.1}\right) \mathrm{O}$ films as a function of oxygen pressure. The indeterminate carrier type films yield large standard deviations compared to those with unipolar conduction type. The p-type films show an average hole mobility of 8.2 $\mathrm{cm}^{2} / \mathrm{Vs}$ at room temperature. The stability of the Hall measurements is largely dependence on exposure to ambient light. Irradiation yielded persistent photoconductivity that had to be accounted for in the measurement procedure. In addition, it is known that surface conduction can mask the transport properties of low carrier density films. This will certainly be dependent on the ambient atmosphere. We did not examine measurements in different ambients. The measurements reported were largely reproducible with time.

The transport properties of P-doped $\left(\mathrm{Zn}_{0.9} \mathrm{Mg}_{0.1}\right) \mathrm{O}$ films indicate that the oxidation conditions play an important role in p-type doping of $\mathrm{ZnO}$. There have been several experimental and theoretical studies which focus on the effect of the oxidation conditions for the p-type doping of $\mathrm{ZnO}$. Limitations to p-type doping may be overcome by adjusting the growth conditions according to the doping rules proposed by A. Zunger. Chemical potential calculations suggest that the enthalpy of forming anion vacancies (oxygen vacancies) decreases under cation-rich (zinc-rich) conditions. The use of the host anion-rich growth conditions can inhibit the formation of compensation defects. In the present study, the host anion condition is optimized to obtain p-type P-doped $\left(\mathrm{Zn}_{0.9} \mathrm{Mg}_{0.1}\right) \mathrm{O}$ films.

X-ray diffraction patterns of the P-doped $\left(\mathrm{Zn}_{0.9} \mathrm{Mg}_{0.1}\right) \mathrm{O}$ films show only $\mathrm{ZnO}(000 l)$ and substrate peaks, indicating that the films have good crystallinity with $c$-axis orientation. The surface morphology of the films grown 
in various oxygen pressures is shown in Figure 1.1.3. The scan area is $2 \times 2 \mu \mathrm{m}^{2}$. As the oxygen pressure increased, the surface roughness increased. The Root-Mean-Square (RMS) roughness is 2.6 and $12.8 \mathrm{~nm}$ for the films grown in 20 mTorr and 200 mTorr oxygen pressure, respectively.

In addition to $(\mathrm{Zn}, \mathrm{Mg}) \mathrm{O}: \mathrm{P}$, this work also explored $\mathrm{P}$-doped $\mathrm{ZnO}$ thin films via PLD. Based on the bulk phase diagram for $\mathrm{ZnO}-\mathrm{P}_{2} \mathrm{O}_{5}$, the solid solubility of phosphorus in $\mathrm{ZnO}$ should be limited. Previous X-ray diffraction data showed a decrease in diffraction intensity as the phosphorus content increased from 1-5 at $\%$. In particular, the diffraction intensity of the $\mathrm{ZnO}(0002)$ peak for the 2 and 5 at\% P-doped films is measurably lower than that for the 1 at $\%$ doped films. ${ }^{53}$ This degradation in crystallinity may indicate that the phosphorus-doping levels are exceeding the solid solubility limit. Therefore, initial studies in this work focused on the effect of growth conditions on the properties of $\mathrm{ZnO}$ doped with $0.2 \mathrm{at} \% \mathrm{P}$. Figure 1.1.4 shows the resistivity as a function of deposition temperature for films grown under different ambient. There is little change in resistivity as the deposition temperature increased from $600^{\circ} \mathrm{C}$ to $800^{\circ} \mathrm{C}$ for the films grown in pure oxygen and $\mathrm{O}_{2} / \mathrm{Ar} / \mathrm{H}_{2}$ mixture. In contrast, for films grown in ozone/oxygen mixture, the resistivity increases from $2.2 \times 10^{-2} \Omega$-cm to $3.5 \Omega$-cm with increasing growth temperature. However, the resistivity is within an order of magnitude for the films grown under different ambient at the lower growth temperature of $600^{\circ} \mathrm{C}$. Hall measurements suggest that the increased resistivity with growth temperature is due to a reduction in carrier density with slight change in mobility. Figure 1.1.5 shows the carrier density and Hall mobility for $\mathrm{ZnO}: \mathrm{P}_{0.002}$ films over a temperature range of $600^{\circ} \mathrm{C}$ to $800^{\circ} \mathrm{C}$. The Hall coefficients are negative in sign, indicating that as-deposited films are n-type. Note that the Hall mobility for samples grown under pure oxygen and $\mathrm{O}_{2} / \mathrm{Ar} / \mathrm{H}_{2}$ mixture increases with increasing growth temperature. For the films grown in ozone/oxygen mixture, the decrease in the carrier density as the growth temperature increases suggests that the donor defect may be relatively unstable. Similar results have been shown in $\mathrm{ZnO}$ doped with $1-5 \mathrm{at} \% \mathrm{P}$ films after annealing at $600^{\circ} \mathrm{C}$ or higher temperature. Compared with the $\mathrm{O}_{2} / \mathrm{Ar} / \mathrm{H}_{2}$ mixture and pure $\mathrm{O}_{2}$, the ozone/oxygen ambient presents a stronger oxidizing species because of the weaker $\mathrm{O}-\mathrm{O}$ bonds in $\mathrm{O}_{3}$. According to the theoretical calculations from chemical potentials, the anion-rich (oxygen-rich) growth conditions could inhibit the formation of compensating defects in ptype doping of $\mathrm{ZnO}$. In this work, the as-deposited $\mathrm{ZnO}: \mathrm{P}$ films grown in ozone/oxygen condition shows significantly lower electron density with increasing growth temperature.

In order to further delineate the characteristics of 0.2 at $\%$ P-doped $\mathrm{ZnO}$ films, room temperature photoluminescence was investigated. Figure 1.1.6 shows the PL spectra taken for the as-deposited $\mathrm{ZnO}: \mathrm{P}_{0.002}$ films at various growth conditions. A strong dependence on growth ambient and temperatures has been demonstrated. The films grown in $\mathrm{O}_{2} / \mathrm{Ar} / \mathrm{H}_{2}$ mixture show the strongest peak for the near band-edge emission at $\sim 3.29 \mathrm{eV}$ when grown at $800^{\circ} \mathrm{C}$. Decreasing the deposition temperature significantly reduces the near band-edge PL intensity. Broadband visible (VIS) emission that peaks at $\sim 1.87 \mathrm{eV}$ is observed in the films grown in pure $\mathrm{O}_{2}$. The films grown at $700^{\circ} \mathrm{C}$ show the highest VIS emission intensity. Note that for the films grown under both conditions, the peak in the near band-edge emission shifts to slightly lower energy with the growth temperature. This shift in PL may reflect a MossBurstein type effect on the optical gap, in which a high density of electrons in the conduction band increases the optical gap. This is consistent with the Hall results as shown in Figure 1.1.5, in which the carrier density decreases with the growth temperature. On the contrary, the intensity of the near band-edge peak is very low for the films grown in $\mathrm{O}_{3} / \mathrm{O}_{2}$ mixture, almost quenched entirely with the growth temperature as shown in the inset of Figure 1.1.6 (c). The orange-red luminescence shows much stronger intensity, which increases rapidly as the growth temperature increases. Previous annealing studies of undoped $\mathrm{ZnO}$ have shown a similar dependence of PL on the annealing ambient, with a decrease in near-edge emission and an increase in visible defect-related luminescence as $\mathrm{ZnO}$ is annealed in an oxidizing environment. Annealing in the hydrogen ambient increases the band edge emission while subsequently decreasing the visible emission. In the present study, the growth temperature also plays an important role in the near band-edge emission. Increasing the deposition temperature could improve the UV emission due to a reduction in the structural defects, although the opposite effect is shown for the films grown in $\mathrm{O}_{3} / \mathrm{O}_{2}$ mixture. The optical response of the $\mathrm{ZnO}: \mathrm{P}_{0.002}$ films is correlated to the transport properties. There is an inverse correlation between the intensity of the VIS emission and the carrier density. The luminescence intensity increases as the conductivity is decreased due to the high temperature growth in oxidizing ambient. This behavior is consistent with radiative recombination involving a deep acceptor level. As the electron carrier density was reduced via growth at high temperature in $\mathrm{O}_{3} / \mathrm{O}_{2}$ mixture, the unoccupied deep-level trap states are increased. This would enhance the VIS radiative recombination of electrons in the conduction band. For the films grown in $\mathrm{O}_{2} / \mathrm{Ar} / \mathrm{H}_{2}$ mixture, the near band-edge emission efficiency improvement may reflect passivation of the deep acceptor-related levels by hydrogen, which also yields the passivation of the VIS emission. 
In an effort to reduce electron density and elucidate the phosphorus doping in $\mathrm{ZnO}$, the effect of annealing process on the properties of the $\mathrm{ZnO}: \mathrm{P}_{0.002}$ films grown under different ambients was examined. The as-grown films were annealed in flowing oxygen for $1 \mathrm{hr}$ at temperatures ranging from $800^{\circ} \mathrm{C}$ to $1100^{\circ} \mathrm{C}$. Figure 1.1 .7 shows the resistivity of the samples annealed at different temperatures and ambients as a function of growth temperature. First, there is a significant increase in resistivity as samples are subjected to an annealing temperature of $800^{\circ} \mathrm{C}$. With increasing annealing temperature the resistivity starts to decrease. Figure 1.1.8 and 1.1.9 shows the carrier density and Hall mobility for annealed $\mathrm{ZnO}: \mathrm{P}_{0.002}$ films over a temperature range of $800^{\circ} \mathrm{C}$ to $1100^{\circ} \mathrm{C}$. The Hall

measurements indicate that annealed $\mathrm{ZnO}: \mathrm{P}_{0.002}$ films are also n-type. Note also that carrier density shows a similar dependence on annealing temperature. However, the mobility of annealed films generally increases as annealing temperature increases. It is unclear why this transport behavior is observed and is being further investigated. Room temperature PL results show strong VIS emission for the annealed samples grown in different conditions. On the contrary, very low intensity of the near band-edge emission is observed from the samples annealed in oxygen at different temperatures.

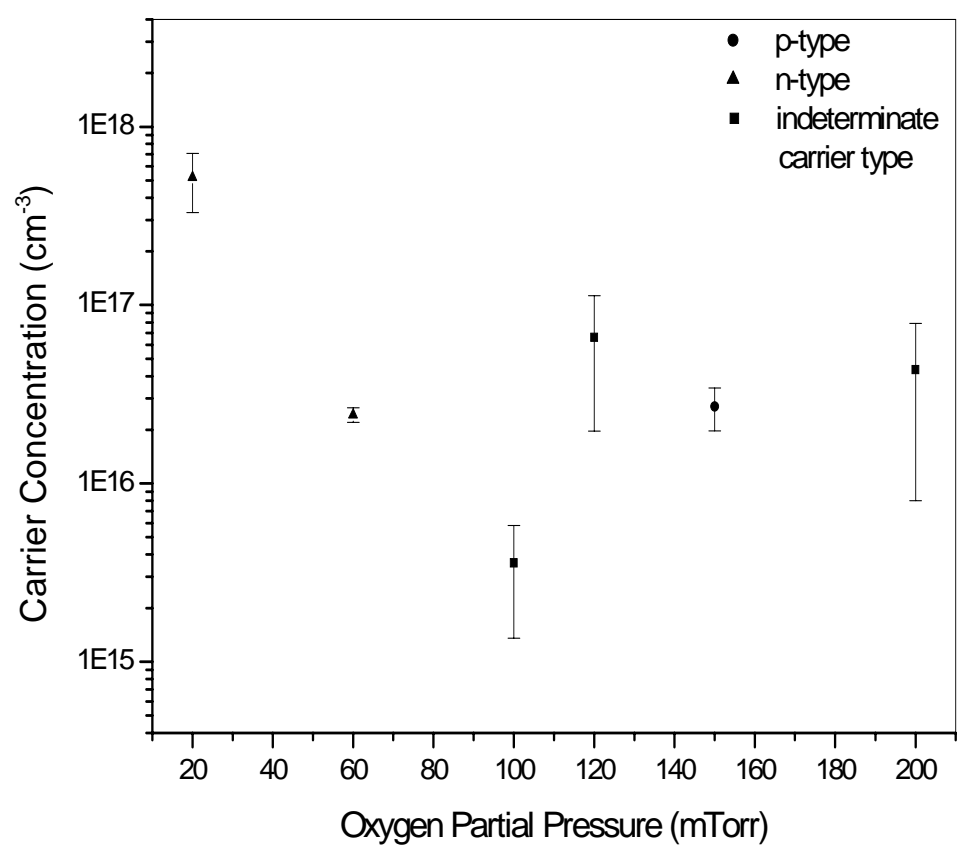

Figure 1.1.1 Carrier concentration and type in P-doped $\left(\mathrm{Zn}_{0.9} \mathrm{Mg}_{0.1}\right) \mathrm{O}$ films as a function of oxygen partial pressure. 


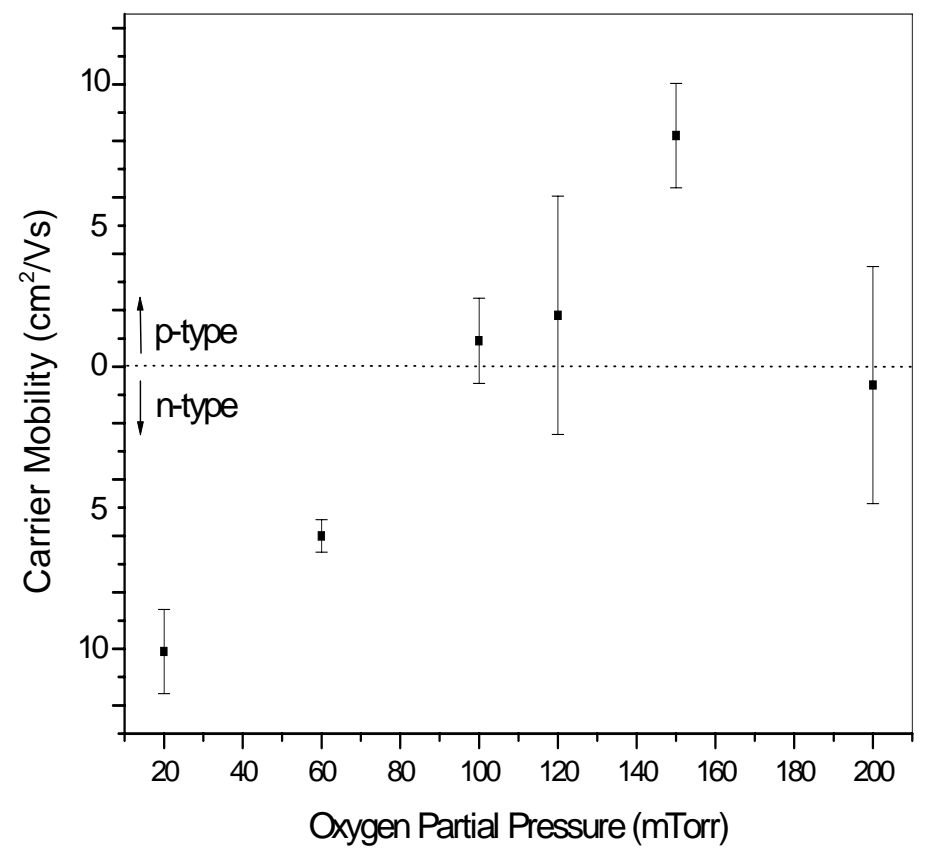

Figure 1.1.2 Effect of oxygen partial pressure on carrier mobility of P-doped $\left(\mathrm{Zn}_{0.9} \mathrm{Mg}_{0.1}\right) \mathrm{O}$ films. 

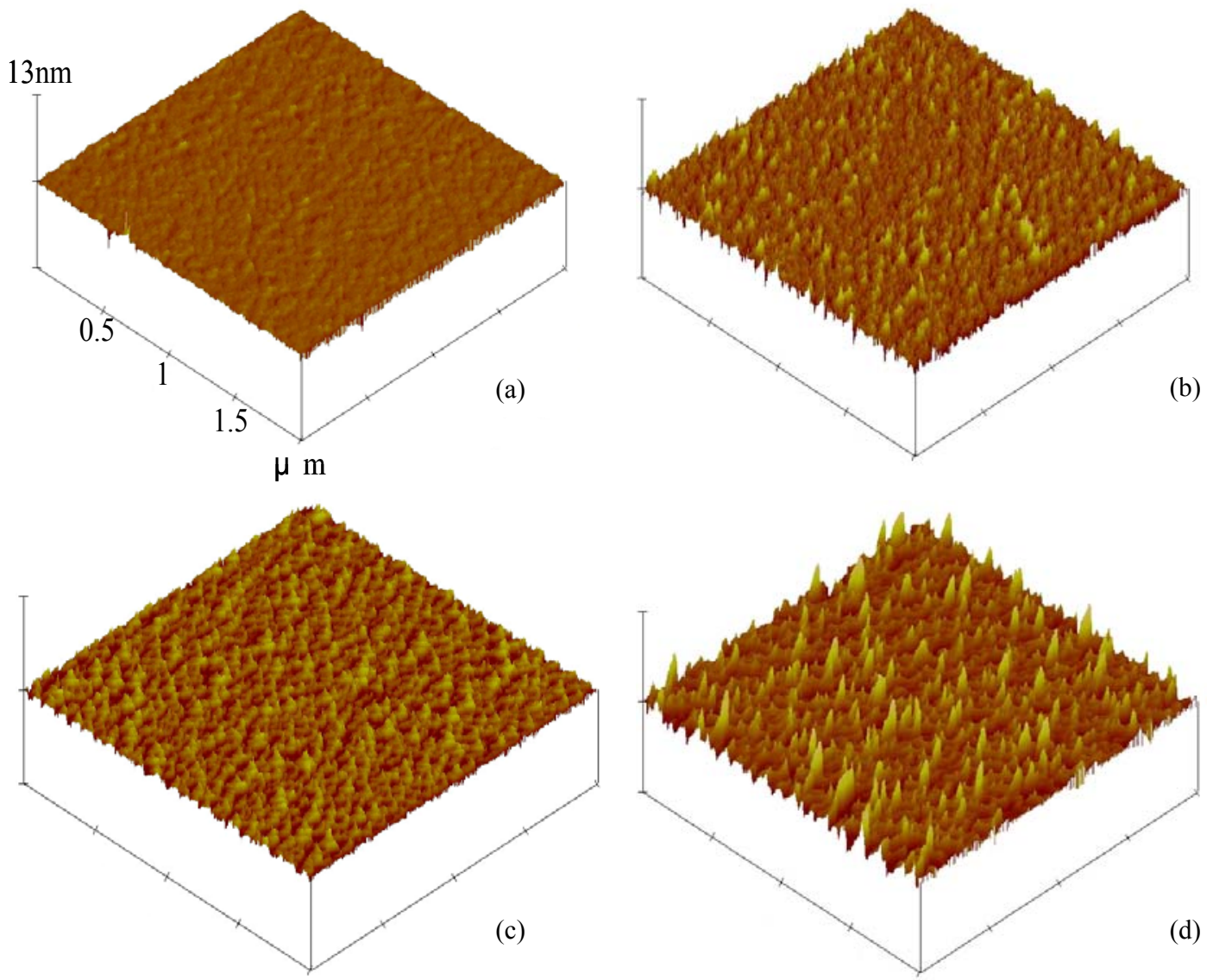

Figure 1.1.3 AFM images of the as-deposited P-doped $\left(\mathrm{Zn}_{0.9} \mathrm{Mg}_{0.1}\right) \mathrm{O}$ films grown at different oxygen pressures: (a) 20; (b) 100; (c) 150; (d) 200 mTorr. The scale bar applies to all the images. 


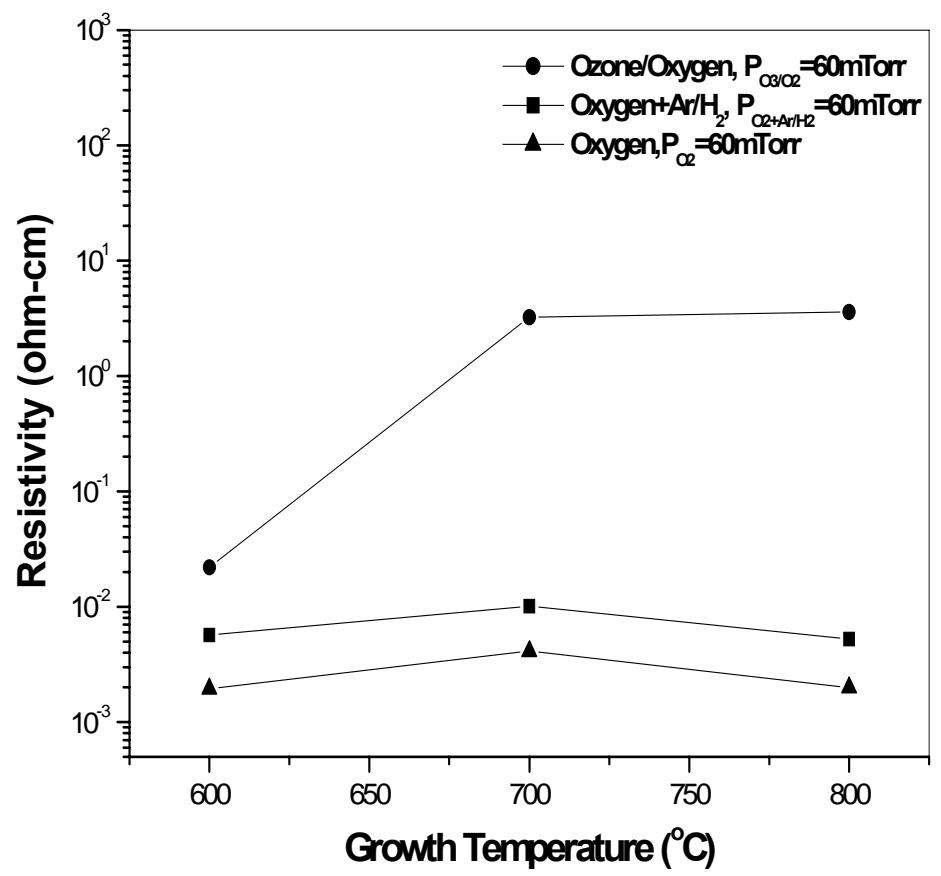

Figure 1.1.4 Resistivity as a function of growth temperature for $\mathrm{ZnO}: \mathrm{P}_{0.002}$ films grown in different gas ambient. 

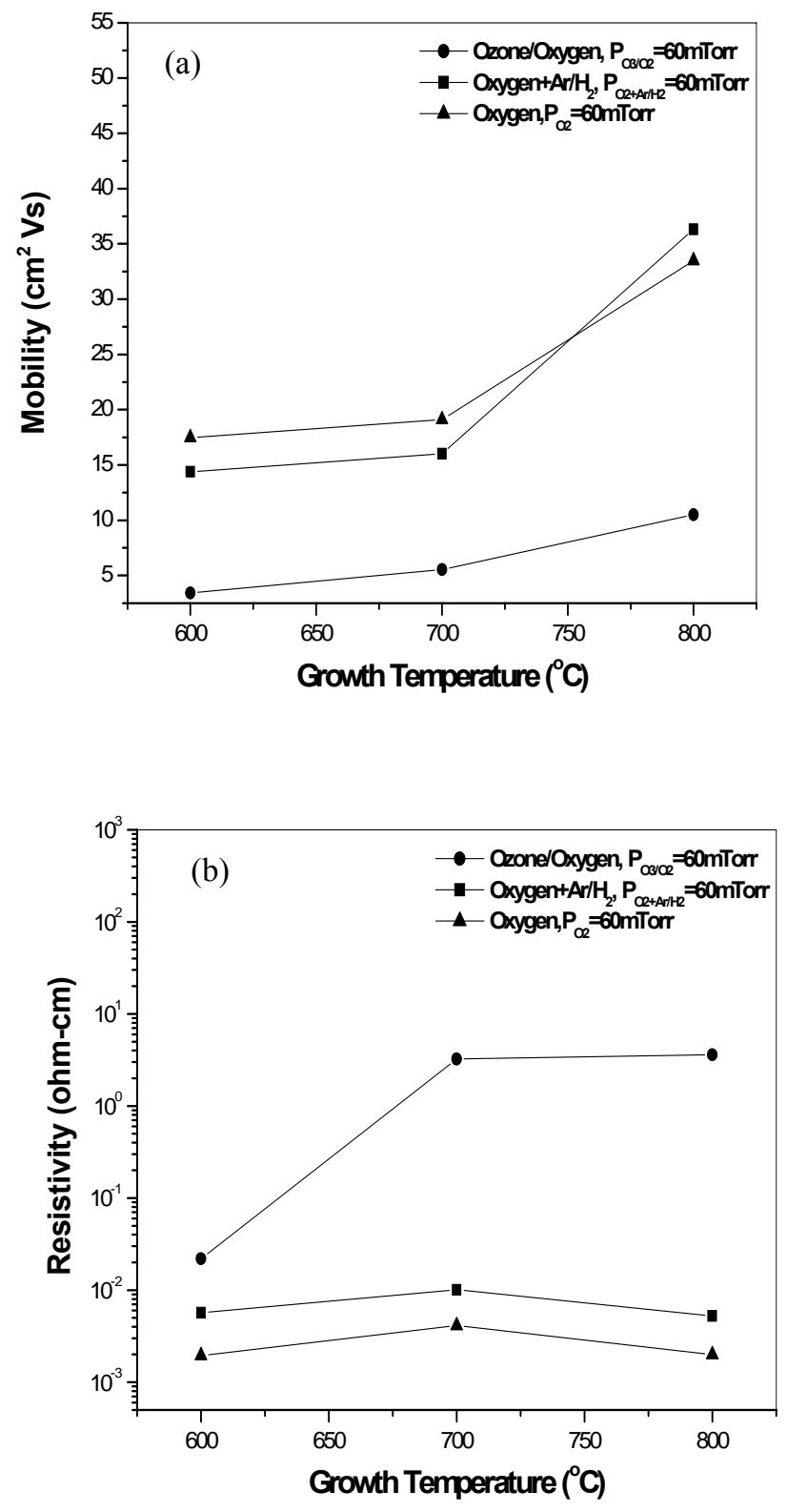

Figure 1.1.5

Carrier density (a) and Hall mobility (b) for $\mathrm{ZnO}: \mathrm{P}_{0.002}$ films as a function of growth temperature. 

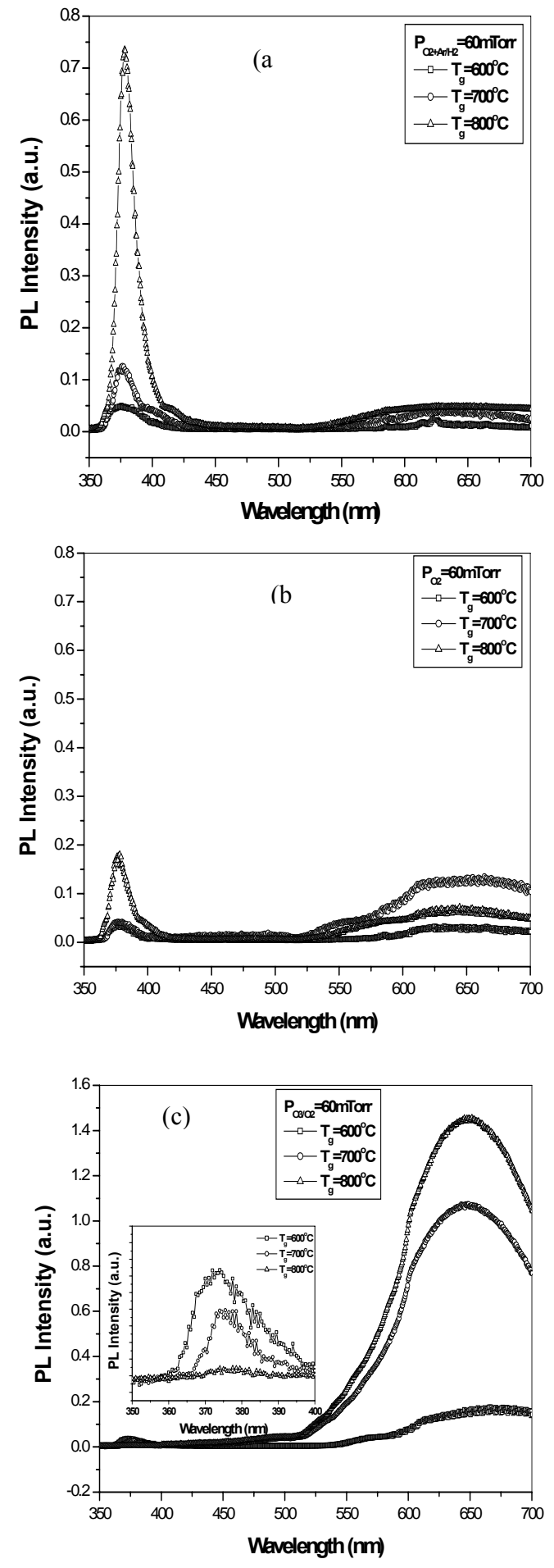

Figure 1.1.6 Room-temperature PL spectra of 0.2 at $\%$ P-doped $\mathrm{ZnO}$ films grown at different temperatures in (a) $\mathrm{O}_{2} / \mathrm{Ar} / \mathrm{H}_{2}$ mixture; (b) pure $\mathrm{O}_{2}$; (c) $\mathrm{O}_{3} / \mathrm{O}_{2}$, the inset shows the near band-edge emission peaks of the films. 

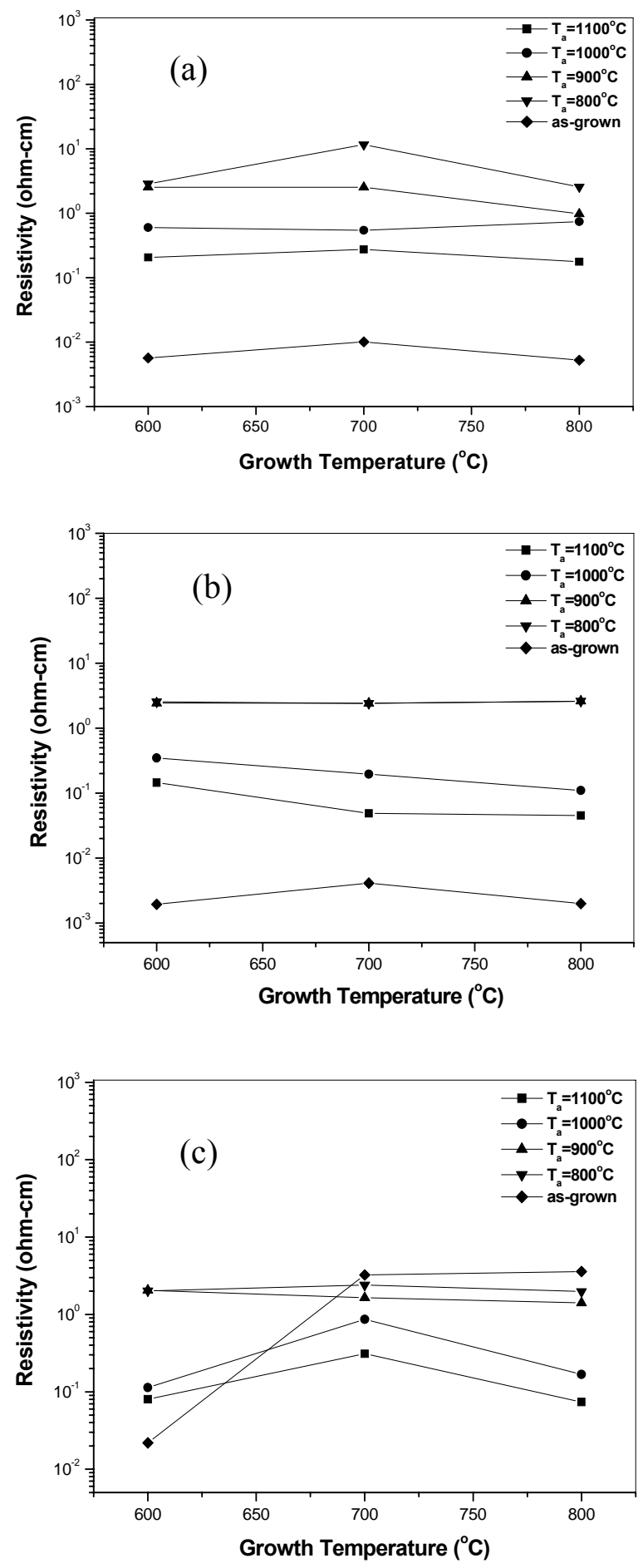

Figure 1.1.7 Resistivity of annealed $\mathrm{ZnO}: \mathrm{P}_{0.002}$ films as a function of annealing temperature grown in (a) $\mathrm{O}_{2} / \mathrm{Ar} / \mathrm{H}_{2}$ mixture; (b) pure $\mathrm{O}_{2}$; (c) $\mathrm{O}_{3} / \mathrm{O}_{2}$. 

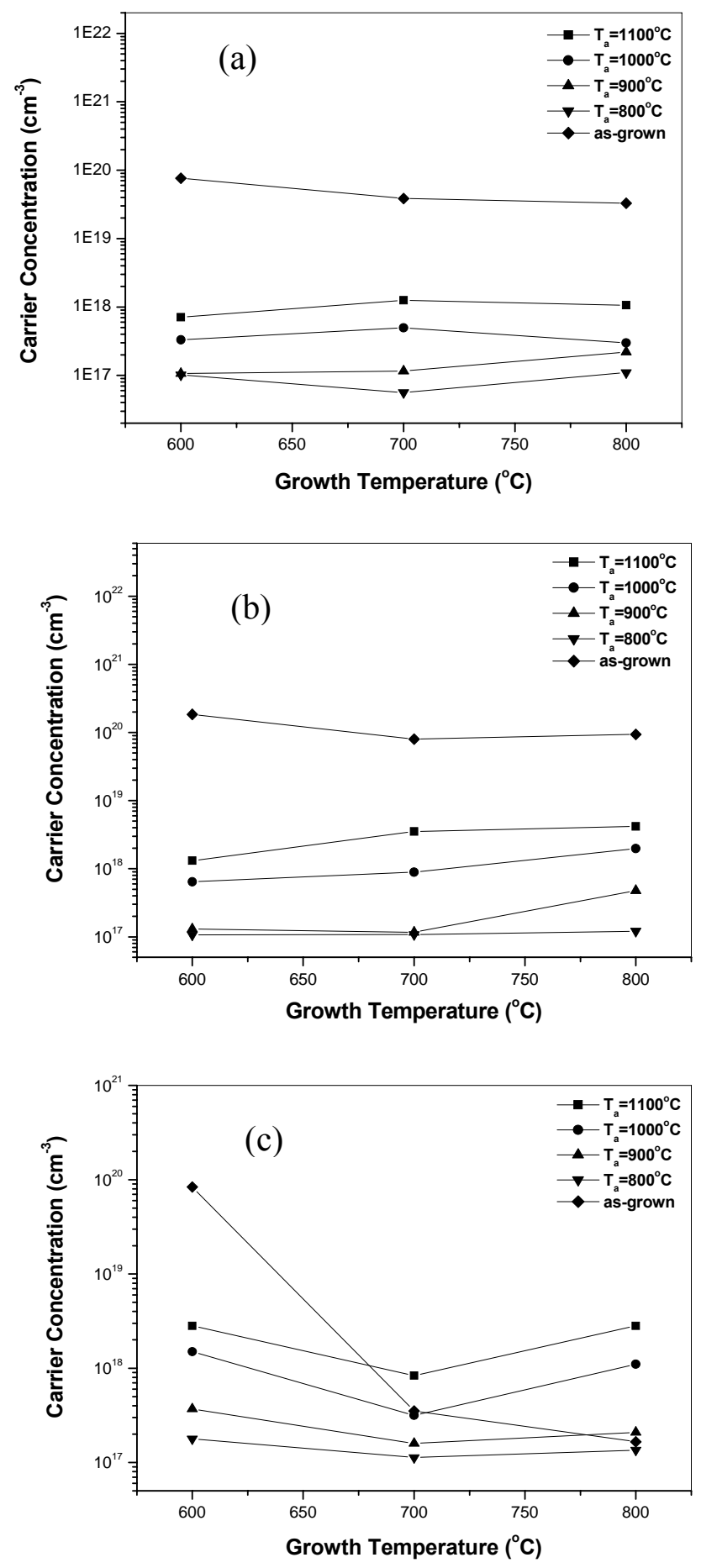

Figure 1.1.8 Carrier density of annealed $\mathrm{ZnO}: \mathrm{P}_{0.002}$ tilms as a function of annealing temperature grown in (a) $\mathrm{O}_{2} / \mathrm{Ar} / \mathrm{H}_{2}$ mixture; (b) pure $\mathrm{O}_{2} ;$ (c) $\mathrm{O}_{3} / \mathrm{O}_{2}$. 

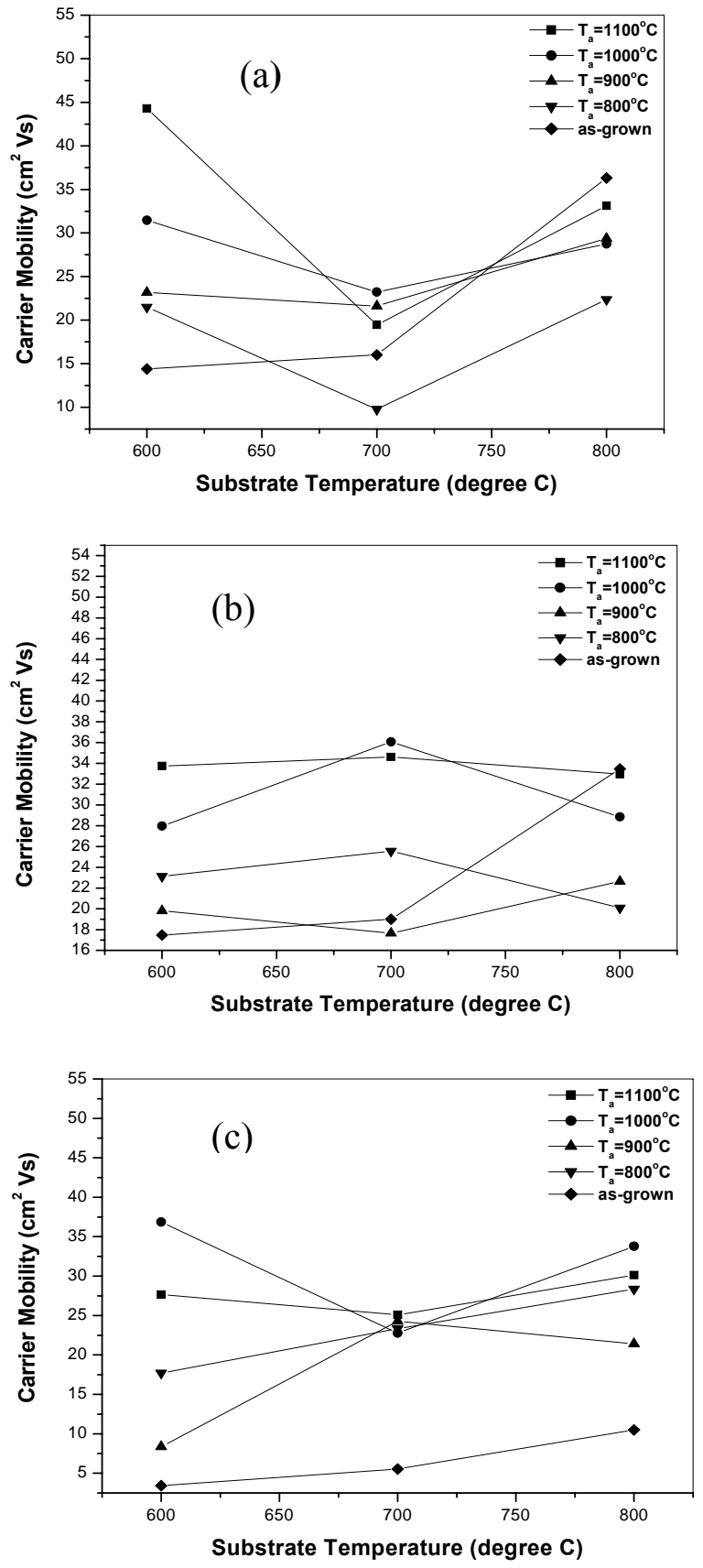

Figure 1.1.9 Mobility of annealed $\mathrm{ZnO}: \mathrm{P}_{0.002}$ films as a function of annealing temperature grown in (a) $\mathrm{O}_{2} / \mathrm{Ar} / \mathrm{H}_{2}$ mixture; (b) pure $\mathrm{O}_{2}$; (c) $\mathrm{O}_{3} / \mathrm{O}_{2}$. 


\subsection{Behavior of Rapid Thermal Annealed ZnO:P films Grown by Pulsed Laser Deposition}

Summary: The transport properties of as-deposited and rapid thermal annealed phosphorus-doped $\mathrm{ZnO}$ films grown by pulsed laser deposition are reported. As-grown $\mathrm{ZnO}: \mathrm{P}$ samples showed n-type characteristics, presumably due to the formation of anti-site $\mathrm{P}_{\mathrm{Zn}}$ defects. Rapid thermal annealing yielded a carrier type conversion from $\mathrm{n}$ - to $\mathrm{p}$-type for the $\mathrm{ZnO}: \mathrm{P}$ films grown at 700 ; samples grown at substantially lower or higher temperatures tended to remain $\mathrm{n}-$ type even after thermal annealing process. The properties and behavior of the $n$-to-p conversion is most consistent with the formation of $\mathrm{P}_{\mathrm{Zn}}-2 \mathrm{~V}_{\mathrm{Zn}}$ as the active acceptor state. Variable magnetic field Hall measurements confirmed the p-type behavior. Phosphorus doping concentrations in the range of 0.5-1.0 at, $\%$ were considered, with evidence for P segregation in the higher phosphorus concentrations.

Introduction:

By far, the most studied p-type dopants for $\mathrm{ZnO}$ are the group $\mathrm{V}$ anions, motivated by the obvious opportunity to hole dope via substituting -3 anions for the -2 oxygen sites. Unfortunately, theoretical arguments suggest that substituting $\mathrm{Sb}, \mathrm{As}$, or $\mathrm{P}$ on the oxygen site should yield deep acceptors rather than shallow levels and thus may be inefficient in contributing to p-type conduction. The principle driver for this is size mismatch. For example, the ionic radius of phosphorus $(2.12 \AA)$ is significantly larger than that for oxygen $(1.38 \AA)$. Due to this large size mismatch, these group $\mathrm{V}$ anions are predicted to favor antisite defects to alleviate lattice strain. These antisite defects should play the role of acceptor-compensating donors. Despite these apparent limitations, there have been multiple reports of p-type $\mathrm{ZnO}$ doping with phosphorus, realizing both rectifying and light-emitting junctions. Theoretical studies suggest that these anions may act as acceptors, not through substitution on the oxygen site, but by forming an antisite complex (e.g. $\mathrm{P}_{\mathrm{Zn}}-2 \mathrm{~V}_{\mathrm{Zn}}$ ). Obviously, for $\mathrm{P}, \mathrm{As}$, and $\mathrm{Sb}$, there are open questions regarding the specific doping mechanism as well as processing conditions necessary to activate the acceptor states.

In this section, the behavior of $\mathrm{P}$ in $\mathrm{ZnO}$ is examined, in particular characterizing the effect of processing on the transport properties for $\mathrm{ZnO}: \mathrm{P}$ films grown by pulsed laser deposition, followed by rapid thermal annealing. Focus is given to understanding the sensitivity of carrier-type conversion on deposition and annealing conditions for postannealed P-doped $\mathrm{ZnO}$ films. The film properties are used to extrapolate the behavior of the phosphorus dopant in the process-dependent creation of effective acceptor states.

Experimental procedure:

The $\mathrm{ZnO}: \mathrm{P}$ films were grown on sapphire (0001) by pulsed laser deposition at substrate temperatures in the range of 500 $800{ }^{\circ} \mathrm{C}$ in an oxygen partial pressure of 30-150 mTorr, followed by post thermal annealing at temperatures ranging from 500 to $950^{\circ} \mathrm{C}$ under oxygen ambient. Prior to $\mathrm{ZnO}: \mathrm{P}$ deposition, an undoped $\mathrm{ZnO}$ buffer layer was deposited on the sapphire at $400^{\circ} \mathrm{C}$ in $20 \mathrm{mTorr}$. This served as a nucleation layer for $\mathrm{ZnO}: \mathrm{P}$ growth, greatly improving surface morphology and reproducibility in the transport properties. The buffer layer was annealed at 650 ${ }^{\circ} \mathrm{C}$ in an oxygen ambient prior to $\mathrm{ZnO}: \mathrm{P}$ deposition. This pre-anneal increased the resistivity of the buffer layer, thus decreasing its impact on the subsequent Hall measurements of the $\mathrm{ZnO}: \mathrm{P}$ films.

Phosphorus-doped $\mathrm{ZnO}$ targets were fabricated using high purity (99.9995\%) $\mathrm{ZnO}$ mixed with $\mathrm{P}_{2} \mathrm{O}_{5}(99.998 \%$ \%)

as the doping agent. The targets were sintered at $1000^{\circ} \mathrm{C}$ for $12 \mathrm{~h}$ in air. The phosphorus doping levels chosen for this study were 0.5 and 1 at \%. The target was ablated by a $\mathrm{KrF}$ excimer laser with the laser frequency of $1 \mathrm{~Hz}$ and energy density of approximately $1.5 \mathrm{~J} / \mathrm{cm}^{2}$. The film thickness was approximately $400 \mathrm{~nm}$ for the $\mathrm{ZnO}: \mathrm{P}$ layer and $100 \mathrm{~nm}$ for the undoped $\mathrm{ZnO}$ buffer layer. The room temperature electrical properties were investigated by Hall measurements using the four-point van der Pauw method with a commercial LakeShore Hall measurement system. In order to minimize the influence of persistent photoconductivity often seen in acceptor-doped $\mathrm{ZnO}$, the samples were maintained in the dark for $12 \mathrm{~h}$ prior to Hall measurements. Typical room-temperature decay times for persistent photoconductivity in $\mathrm{P}$-doped $\mathrm{ZnO}$ can be on the order of $10^{4}$ seconds as reported elsewhere. The magnetic field strength ranged from -1 tesla to +1 tesla.

Results and Discussion:

Experimental efforts examined the structural and transport properties of as-deposited and post-annealed $\mathrm{ZnO}$ films doped with 0.5 and 1.0 at.\% phosphorus. In general, phosphorus doping at the high concentrations considered in this study leads to a degradation in crystalline quality of the epitaxial films. Figure 1.2.1 shows the X-ray diffraction rocking curves for $\mathrm{ZnO}$ films that are undoped, as well as doped with 0.5 and 1.0 at.\% P. These films were grown at $700^{\circ} \mathrm{C}$ in $150 \mathrm{mTorr}$ oxygen, using the same $\mathrm{ZnO}$ buffer nucleation layer as described earlier. The 
rocking curve full-width half-maximum (FWHM) was $0.80^{\circ}$ for the undoped film, $1.79^{\circ}$ for 0.5 at. $\% \mathrm{P}$, and $3.21^{\circ}$ for the film doped with 1 at. $\%$ P. This large increase in the $\mathrm{x}$-ray diffraction rocking curve with $\mathrm{P}$ doping indicates a high density of defects and lattice strain associated with high phosphorus doping. Based on these results, one might anticipate superior semiconductor material properties in the 0.5 at.\% P-doped material as compared to the 1.0 at.\% P-doped $\mathrm{ZnO}$. As will be seen, the results for the 0.5 at.\% P-doped films were more systematic. As such, the majority of the discussion will center on the behavior of the 0.5 at.\% P-doped films. However, the results for the 1.0 at.\% P-doped $\mathrm{ZnO}$ films will also be presented for comparison.

The processing window for achieving $\mathrm{p}$-type conduction in $\mathrm{P}$-doped $\mathrm{ZnO}$ films was relatively narrow, requiring high temperature in situ growth followed by rapid thermal annealing (RTA) treatment. Before examining the specific conditions for p-type conversion, it is useful to consider the generic behavior of the P-doped $\mathrm{ZnO}$ thin films. First, the as-deposited ZnO:P films were n-type, with electron concentrations ranging from $10^{17}$ to $10^{19} \mathrm{~cm}^{-3}$ depending on the deposition temperature, pressure, and phosphorus concentration. Figure 1.2.2 shows the carrier density of the as-grown $\mathrm{ZnO}: \mathrm{P}$ films that were deposited at different substrate temperatures and phosphorus doping levels. All as-deposited samples show n-type conductivity regardless of the growth temperature and phosphorus doping level. For the growth conditions selected, the 1 at $\%$ phosphorus-doped $\mathrm{ZnO}$ films generally showed lower donor density as compared to the 0.5 at $\%$ phosphorus-doped $\mathrm{ZnO}$ films. The lowest donor density for the asdeposited films in Fig. 1.2.2 was 1.1x $10^{17} / \mathrm{cm}^{3}$, observed for the 1 at. $\%$ P doped film grown at $600{ }^{\circ} \mathrm{C}$. The n-type conductivity of as-grown P-doped films reflects an amphoteric doping behavior for phosphorus in $\mathrm{ZnO}$ in yielding either donor or acceptor states. The dominant P-related donor is assumed to be the $\mathrm{P}_{\mathrm{Zn}}$ antisite defect. Previous work on P-doped $\mathrm{ZnO}$ films as-grown at moderate temperatures showed a slight decrease in d-spacing with phosphorus doping. Substitution of a large anion (phosphorus) on the smaller oxygen site should yield an increase in lattice spacing. The observed decrease in lattice spacing is inconsistent with substitution on the $\mathrm{O}$ site, but suggestive of an alternative location for the $\mathrm{P}$, possibly as an antisite $\mathrm{P}_{\mathrm{Zn}}$ defect. This would be consistent with these films being $\mathrm{n}$ type, given that $\mathrm{P}_{\mathrm{Zn}}$ is presumed to be a donor, albeit relatively deep. Note that these films were deposited in relatively O-rich (oxygen pressure equals $150 \mathrm{mTorr}$ ) growth condition. The formation of zinc vacancies and oxygen interstitials is also possible based on their estimated formation energy in O-rich conditions even though residual and antisite donor defects are dominant in transport.

Regarding the P-related defects, both P-related donors $\left(\mathrm{P}_{\mathrm{Zn}}\right.$ and $\left.\mathrm{P}_{\mathrm{Zn}}-\mathrm{V}_{\mathrm{Zn}}\right)$ and acceptors $\left(\mathrm{P}_{\mathrm{Zn}}-2 \mathrm{~V}_{\mathrm{Zn}}\right.$ complex and $\left.\mathrm{P}_{\mathrm{O}}\right)$ appear to coexist, with their relative ratio likely dependent on the growth conditions and its effect on the amphoteric nature of phosphorus. The coexistence of donor and acceptor states associated with phosphorus doping is consistent with the low-temperature photoluminescence (PL) data shown in Figure 1.2.3 for a P-doped ZnO films. In this case, the P-doped $\mathrm{ZnO}$ sample was shown to be n-type via Hall effect measurements, yet displayed a PL peak that has previously been attributed to an acceptor state in group- $\mathrm{V}$ doped $\mathrm{ZnO}$ materials. One also might expect that the oxygen rich growth conditions used in this study would suppress the formation of $\mathrm{P}_{O}$ and promote the generation of anti-site $\mathrm{P}_{\mathrm{Zn}}$ donors. The anti-site $\mathrm{P}_{\mathrm{Zn}}$ defects could combine with a double acceptor, $\mathrm{V}_{\mathrm{Zn}}$, which is a favorable native defect in O-rich growth condition, and generate $\mathrm{P}_{\mathrm{Zn}}-2 \mathrm{~V}_{\mathrm{Zn}}$ complexes. This complex is predicted to be a shallow acceptor. The lower carrier density seen in the 1 at.\% $\mathrm{P}$ doped film (as compared to the 0.5 at.\%) suggests a higher density of acceptors. (e.g. $\mathrm{P}_{\mathrm{O}}$ or $\mathrm{P}_{\mathrm{Zn}}-2 \mathrm{~V}_{\mathrm{Zn}}$ ) yielding a lower donor density. Note that the low temperature growth also yields an O-rich growth condition by suppressing oxygen liberation.

Returning to the data in Figure 1.1.2, it is interesting to consider the inflection in both resistivity and carrier density at a growth temperature of $650-700^{\circ} \mathrm{C}$. For the sample doped with 0.5 at. $\% \mathrm{P}$, the electron carrier density initially increases, then steadily decreases with increasing growth temperature. This might be explained in one of two ways. First, the increased growth temperature may initiate the generation of compensating acceptor states $\left(\mathrm{P}_{\mathrm{O}}\right.$ or $\mathrm{P}_{\mathrm{Zn}}-2 \mathrm{~V}_{\mathrm{Zn}}$ ), thus yielding a decrease in electron concentration. Alternatively, the decrease in electron concentration could reflect a reduction in overall $\mathrm{P}$ content (and associated donors) due to $\mathrm{P}$ evaporation. However, this second possibility would not explain the lower electron density observed for the 1 at.\% P-doped $\mathrm{ZnO}$ films grown under identical conditions. Thus, the most logical explanation is that, at $\mathrm{T} \geq 650^{\circ} \mathrm{C}$, acceptor states are generated with increasing density relative to the donor concentration that dominates transport for films grown at lower temperature. Note that, in previous work involving P-doped films grown at lower temperatures, higher P concentrations yielded higher donor density. Annealing at higher temperature in $\mathrm{O}_{2}$ resulted in a significant decrease in donor concentration. In the present study, increasing the growth temperature to $700 \mathrm{C}$ decreases the donor density. This suggests that, at temperatures higher than $700 \mathrm{C}$, the formation of acceptor states become a significant contribution for $\mathrm{P}$-doped $\mathrm{ZnO}$. This could involve $\mathrm{P}$ substitution on the oxygen site, or formation of $\mathrm{P}_{\mathrm{Zn}}$ $2 \mathrm{~V}_{\mathrm{Zn}}$ complexes, as has been theoretically predicted. In either case, the results suggest that donors (perhaps $\mathrm{P}_{\mathrm{Zn}}$ ) are predominantly formed at the growth temperature of $600 \mathrm{C}$, while acceptor formation $\left(\mathrm{P}_{\mathrm{O}}\right.$ or $\left.\mathrm{P}_{\mathrm{Zn}}-2 \mathrm{~V}_{\mathrm{Zn}}\right)$ is observed at 
$700 \mathrm{C}$ or higher.

While there is evidence for acceptor formation for growth above $700 \mathrm{C}$, it is interesting to note that the donor density of $1 \mathrm{at} \%$ phosphorus-doped $\mathrm{ZnO}$ films generally increases with the growth temperature while that of 0.5 at $\%$ phosphorus-doped $\mathrm{ZnO}$ films decreases. This may reflect a segregation of phosphorus for high deposition temperature and higher phosphorus doping level. Indirect evidence for phosphorus segregation at the higher temperatures can be seen in the atomic force microscopy (AFM) images shown in Fig. 1.2.4, where a significant modification in surface morphology is observed for the P-doped $\mathrm{ZnO}$ film grown at $800^{\circ} \mathrm{C}$ as compared to $650^{\circ} \mathrm{C}$. In the high temperature region, there will be a competition between the formation of $\mathrm{P}_{\mathrm{O}}$ or $\mathrm{P}_{\mathrm{Zn}}-2 \mathrm{~V}_{\mathrm{Zn}}$ acceptors, the formation of $\mathrm{P}_{\mathrm{Zn}}-\mathrm{V}_{\mathrm{Zn}}, \mathrm{P}_{\mathrm{Zn}}$, and/or native defect donor states, and segregation of phosphorus. The carrier type and density of the phosphorus-doped $\mathrm{ZnO}$ is determined by both native defects and amphoteric phosphorus doping behavior.

For growth in the temperature range of $500-800^{\circ} \mathrm{C}$, and oxygen pressure range of $1-150 \mathrm{mTorr}$, all $\mathrm{ZnO}: \mathrm{P}$ films examined in this study were n-type. However, p-type conversion of the as-deposited P-doped $\mathrm{ZnO}$ films was achieved via post-growth annealing. First note that the effects of post-growth annealing depend on whether the anneal is steady-state (furnace anneal) or short transient (rapid thermal annealing). As reported earlier, steady state annealing of $\mathrm{ZnO}: \mathrm{P}$ in oxygen yielded an increase in resistivity without conversion to p-type, often resulting in semi-insulating behavior. In contrast, a short (2-3 min) rapid thermal anneal (RTA) in oxygen could produce a decrease in resistivity and conversion to p-type conduction. First consider the generic behavior of P-doped $\mathrm{ZnO}$ subjected to an RTA anneal. Figure 1.2.5 shows the generic behavior for $\mathrm{ZnO}: \mathrm{P}$ films subjected to a 2 min oxygen anneal at various temperatures. These 0.5 at.\% P-doped $\mathrm{ZnO}$ films were grown at $700^{\circ} \mathrm{C}$ in 50 or $150 \mathrm{mTorr}_{2}$. Note that, for the sample set in figure 1.2.5, most of these films remained n-type and did not show conversion with annealing, due largely to experimental uncertainty in the thermal transients for the particular RTA system employed. Nevertheless, the overall behavior of the films considered in Figure 1.2.5 is instructive. First, the initial increase in resistivity with rapid thermal annealing in $1 \mathrm{~atm} \mathrm{O}_{2}$ likely reflects a decrease in surface conductivity and/or oxygen vacancy-related defects associated with cooling the as-grown films in low (50-150 mTorr) oxygen pressure. Note, however, that an inflection in the resistivity ( and carrier concentration) with annealing temperature is observed for both sample sets. This behavior is typical for a compensated semiconductor in which the relative ratio of activated donor and acceptors is changing with annealing temperature. Again, for films considered in Figure 1.2.5, type conversion was not observed for most samples. However, the annealing temperature dependence of resistivity with RTA treatment was common to P-doped $\mathrm{ZnO}$ films subjected to annealing. It is also interesting to note that the inflections in resistivity and carrier concentration for these annealed P-doped $\mathrm{ZnO}$ films in the temperature range of $800-950^{\circ} \mathrm{C}$ is similar in nature to the inflection seen in the as-grown films for the growth temperature range of 600$750^{\circ} \mathrm{C}$ as discussed for Fig. 1.2.2. This is consistent with a model in lower temperature processing favors P-related donor formation, while high temperatures activate P-related acceptor states. The fact that this behavior is observed at lower temperatures for epitaxial films as compared to post-annealed activation is not unexpected, given that crystallization in epitaxy occurs on a free surface.

Through improved control of thermal transients during the annealing cycles, p-type conversion was achieved via post-growth rapid thermal annealing. Table 1.2.1 shows the Hall measurement results for a series of 0.5 at. \% Pdoped films deposited in 150 mTorr at various substrate growth temperatures, then RTA annealed in oxygen for the temperature range 850 950C. Table 1.2.2 shows similar results for the 1 at.\% P-doped $\mathrm{ZnO}$. Interestingly, for the 0.5 at. $\% \mathrm{P}$ doped films, only the films grown at $700-750 \mathrm{C}$ showed reproducible p-type conversion upon annealing, while the samples grown at other temperatures generally remained n-type even after the thermal annealing process. Figure 1.2.6 shows the resistivity and carrier density as a function of annealing temperature for the 0.5 and 1.0 at.\% P-doped $\mathrm{ZnO}$ films, along with an undoped film for comparison. First note that an RTA peak temperature at or above $900^{\circ} \mathrm{C}$ was needed in order to achieve p-type conversion. Second, note that the resistivity remained relatively high for samples annealed at $850^{\circ} \mathrm{C}$, a temperature just below that needed for p-type conversion. Most importantly, the background electron density remained low enough such that type conversion with moderate hole concentrations was possible. Also note that large changes in carrier density were not observed for the undoped $\mathrm{ZnO}$ film subjected to the same annealing cycle.

The mobility of the $\mathrm{ZnO}: \mathrm{P}$ films was also determined. For 0.5 and 1.0 at.\% doping levels, the mobility decreases until type conversion occurs. It increases again after converting to p-type. The ZnO:P films grown with a higher P contents shows a higher mobility over the entire range. In general, p-type ZnO:P films have a low carrier mobility, typically less than $1 \mathrm{~cm}^{2} / \mathrm{V}$-s.

Given the multi-carrier type conductance due to the presence of compensating donors and acceptors, along with the low carrier mobility for holes in P-doped $\mathrm{ZnO}$, it is useful to examine the actual Hall voltages used to extract 
carrier type and density. For these samples, the Hall measurements were performed at multiple magnetic field, namely 2000, 4000, 6000, 8000, and 10,000 Gauss. As a reminder, Hall measurements using a van der Pauw method are performed using a four-point configuration (illustrated in inset for Fig. 1.2.7) in which current is passed through one sample diagonal (e.g contacts 1 and 3 ) with voltage measured across the transverse diagonal (contacts 2 and 4) while simultaneously applying a magnetic filed perpendicular to the sample surface. The same measurement is then made for the same current/voltage configuration but with the magnetic field reversed. The Hall voltage can then be distinguished from other signal sources (noise, offset, magnetoresistance) by taking the difference between the two measurements described above. The van der Pauw approach involves extracting the magnetic field dependent voltage difference for the two possible voltage contact choices along with the two possible current polarities. Thus, a van der Pauw measurement generates four voltage-pair differences, each of which indicates the carrier type based on the sign of the voltage difference. Figure 1.2.7 shows a plot of these four voltage pairs for the 0.5 at.\% P-doped $\mathrm{ZnO}$ film grown at $700^{\circ} \mathrm{C}$ in $150 \mathrm{mTorr}$ oxygen, followed by rapid thermal annealing at $900^{\circ} \mathrm{C}$.

The voltage pair polarities were selected such that a positive voltage difference indicates p-type, a negative voltage difference n-type. For measurements taken at the five magnetic fields considered, all voltage pairs for this sample are consistent with p-type majority carrier conduction. This was routinely seen for samples reported as being p-type in this study.

In examining the Hall data in Tables 1.2.1 and 1.2.2 for the 0.5 and 1.0 at.\% P-doped films, it becomes apparent that the results for the 1.0 at.\% P-doped films are less systematic with higher variability in the measured parameters as compared to the 0.5 at.\% samples. As mentioned earlier, the x-ray diffraction results indicate that the 1.0 at. $\%$ Pdoped samples are highly defective as compared to the 0.5 at.\% P-doped films. This is also reflected in the room temperature photoluminescence data for RTA processed, p-type ZnO:P films. The room temperature photoluminescence characteristics for the RTA annealed p-type films are shown in Fig. 1.2.8. The photoluminescence for the 1 at.\% P-doped sample shows a near band edge emission with significant visible emission commonly attributed to defects. The film with 0.5 at.\% $\mathrm{P}$ shows significantly higher intensity at the near band edge emission with little mid-gap emission. Clearly, the semiconducting properties are better for lower $\mathrm{P}$ concentrations.

Given the results presented in this study, it is possible to postulate on the specific defect structures that yield ntype behavior in the as-grown films, while yielding p-type conduction upon annealing. In previous studies, Kim et al. have also reported carrier type conversion in sputter deposited $\mathrm{ZnO}: \mathrm{P}$ films by using rapid thermal annealing. Hwang et al. claimed that phosphorus atoms act as an acceptor by occupying oxygen sites in the $\mathrm{ZnO}$ during the RTA process. However, the $\mathrm{P}_{\mathrm{O}}$ acceptor is predicted to be deep while the $\mathrm{P}_{\mathrm{Zn}}-2 \mathrm{~V}_{\mathrm{Zn}}$ complex is predicted to have a low formation energy and act as a shallow acceptor. Furthermore, the O-rich growth and annealing conditions used in the present study should favor $\mathrm{P}_{\mathrm{Zn}}-2 \mathrm{~V}_{\mathrm{Zn}}$ formation and suppress the formation of $\mathrm{P}_{\mathrm{O}}$. It may be that both $\mathrm{P}_{\mathrm{Zn}}-2 \mathrm{~V}_{\mathrm{Zn}}$ and $\mathrm{P}_{\mathrm{O}}$ defects are present in these films. However, given the consistency with $\mathrm{P}_{\mathrm{Zn}}$ formation in the as-grown films, it is reasonable to assume that the high-temperature formation of the associated complex $\mathrm{P}_{\mathrm{Zn}}-2 \mathrm{~V}_{\mathrm{Zn}}$ is the source of $\mathrm{p}$ type behavior seen in post-annealed films. A key aspect in activating p-type conversion is in limiting the donor density that must be overcome for majority carrier p-type behavior to be observed. 

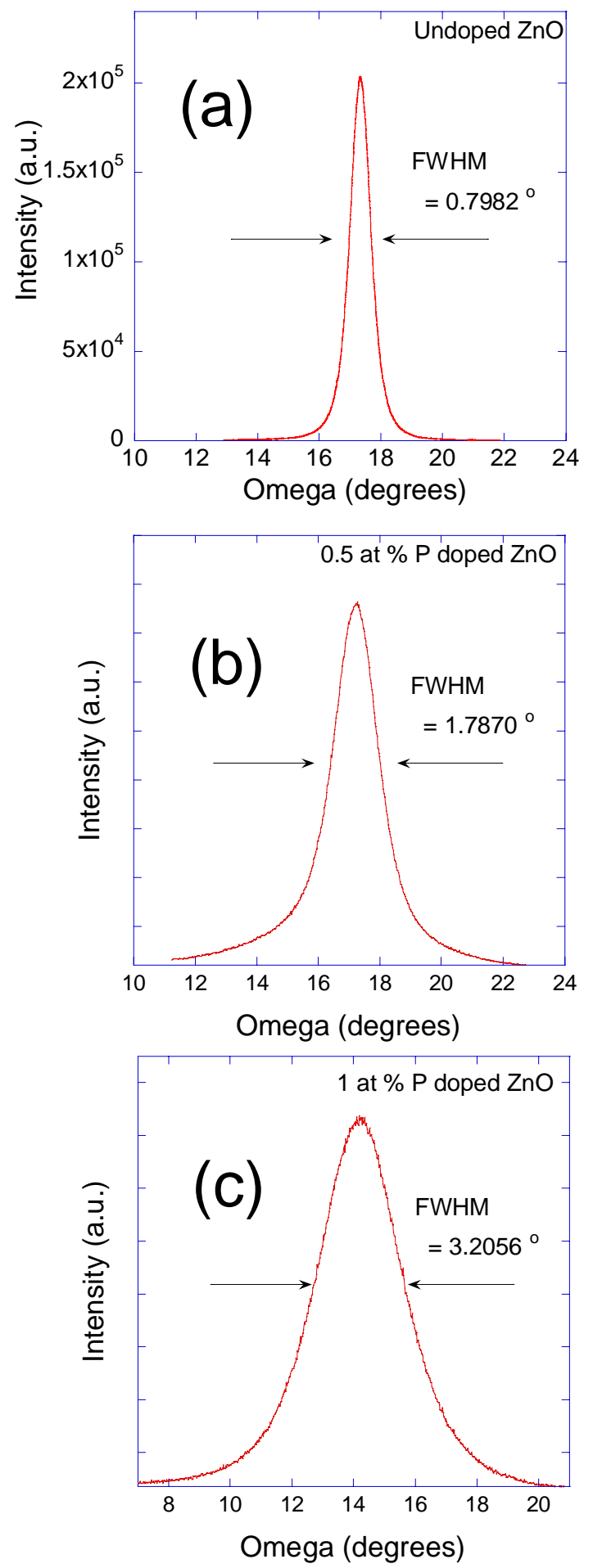

Figure 1.2.1. X-ray diffraction omega rocking curves for a) undoped, b) 0.5 at.\% P-doped, and c) 1.0 at.\% doped $\mathrm{ZnO}$ films grown by pulsed laser deposition. Growth conditions were $700^{\circ} \mathrm{C}$ and $150 \mathrm{mTorr}$ oxygen. 

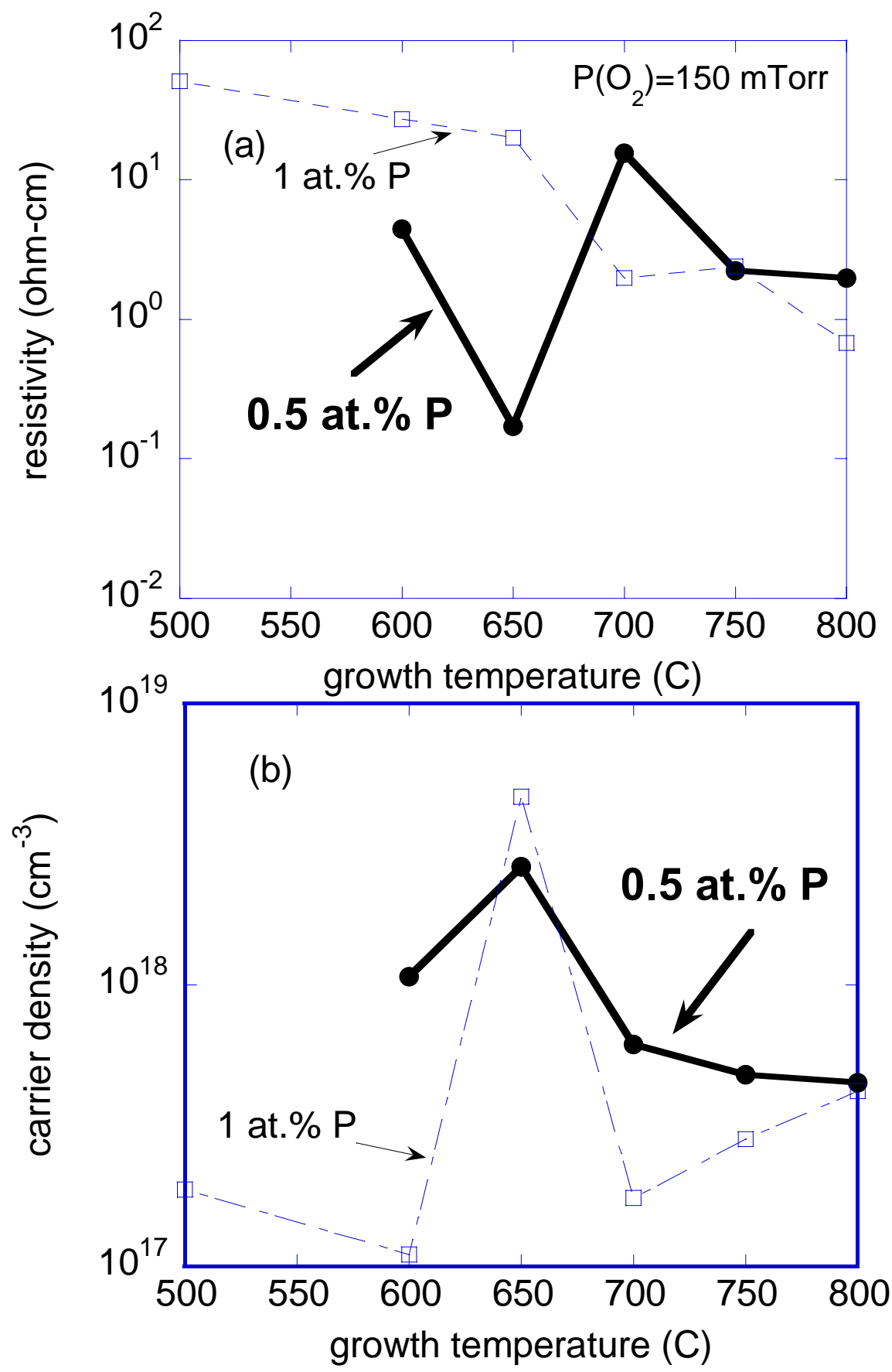

Figure 1.2.2. Hall data for as-deposited ZnO:P films, showing a) resistivity and b) carrier density. All films in this figure are n-type. 


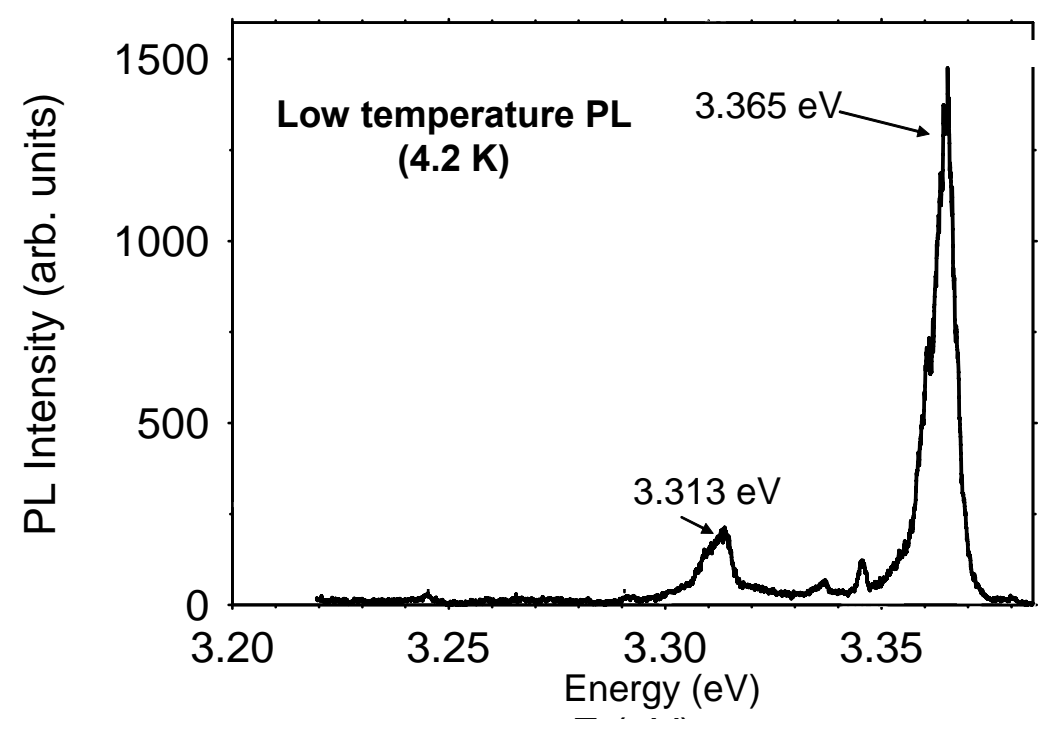

Figure 1.2.3. Low temperature photoluminescence (PL) for a $\mathrm{ZnO}: \mathrm{P}$ film showing an acceptor-associated peak at $3.313 \mathrm{eV}$. 


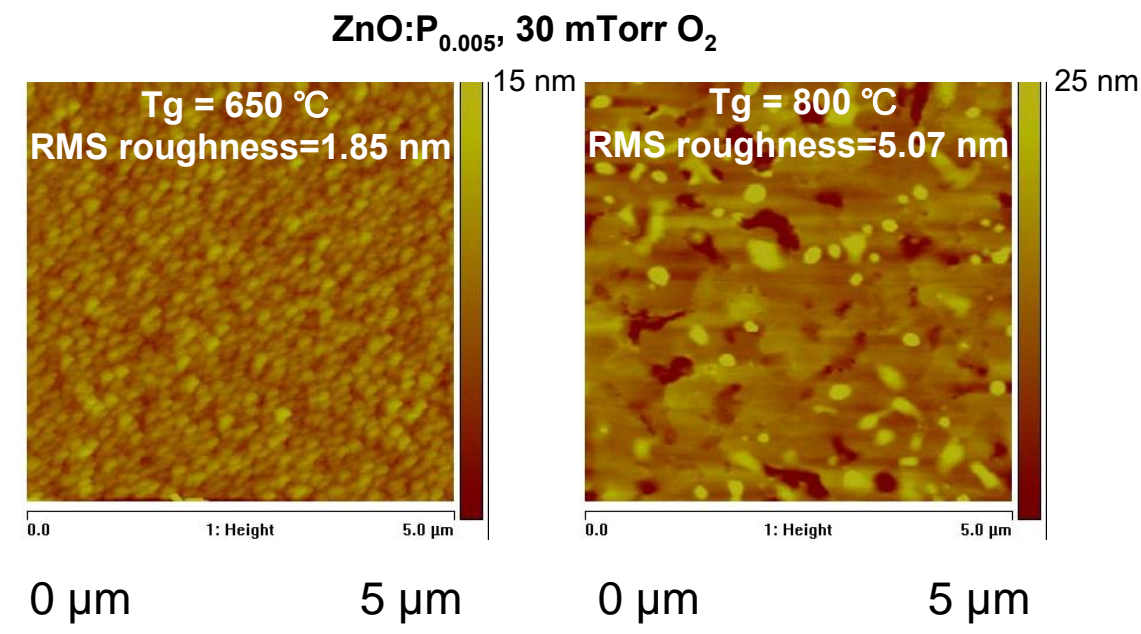

Figure 1.2.4. Atomic force microscopy images for 05 at.\% P-doped $\mathrm{ZnO}$ films grown at different substrate temperatures 


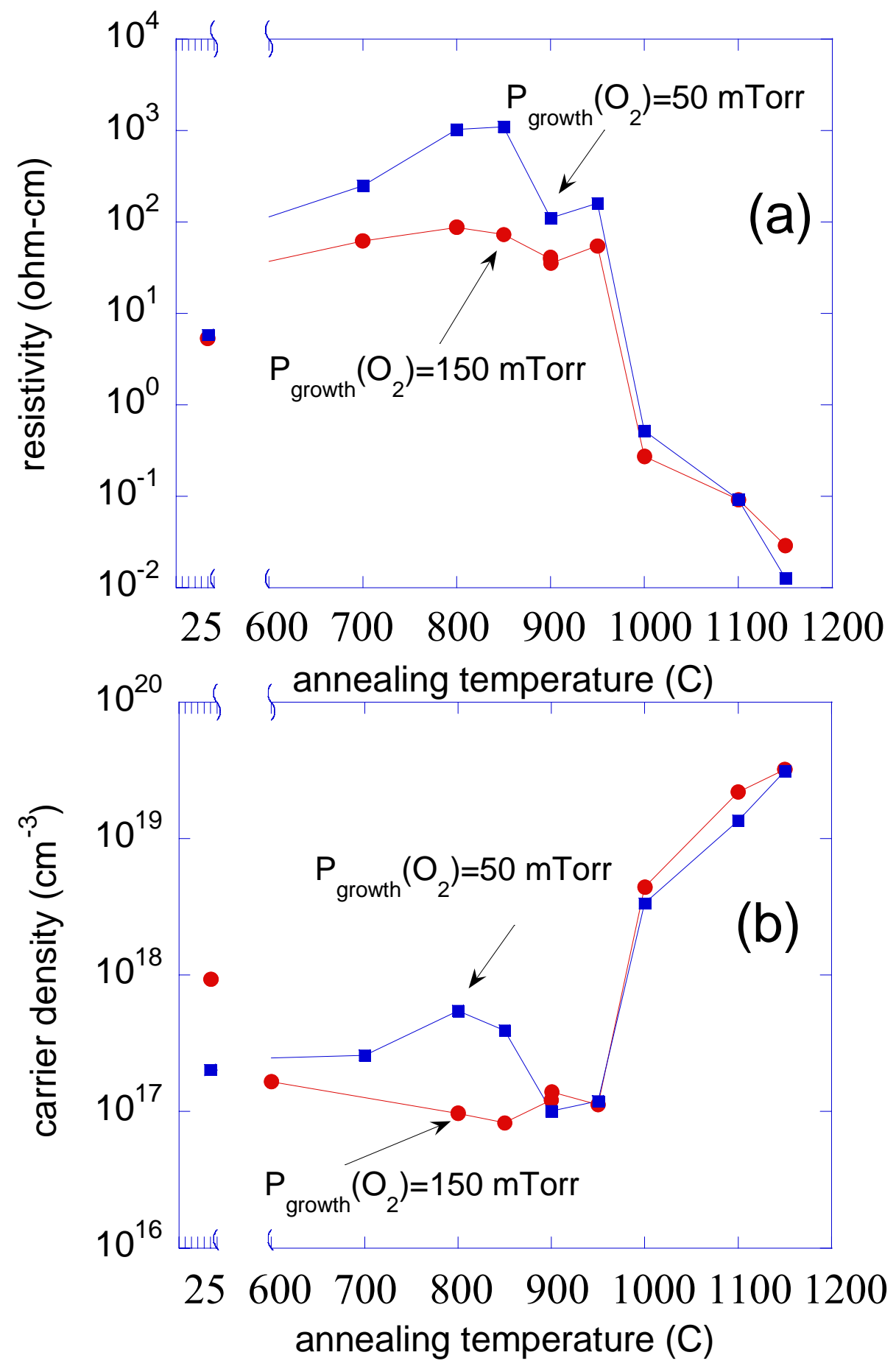

Figure 1.2.5 Hall data for rapid thermal annealed $\mathrm{ZnO}$ films doped with 0.5 at.\% $\mathrm{P}$, grown at $700^{\circ} \mathrm{C}$, showing a) resistivity and b) carrier density as a function of annealing temperature. Most films in this figure were n-type. 


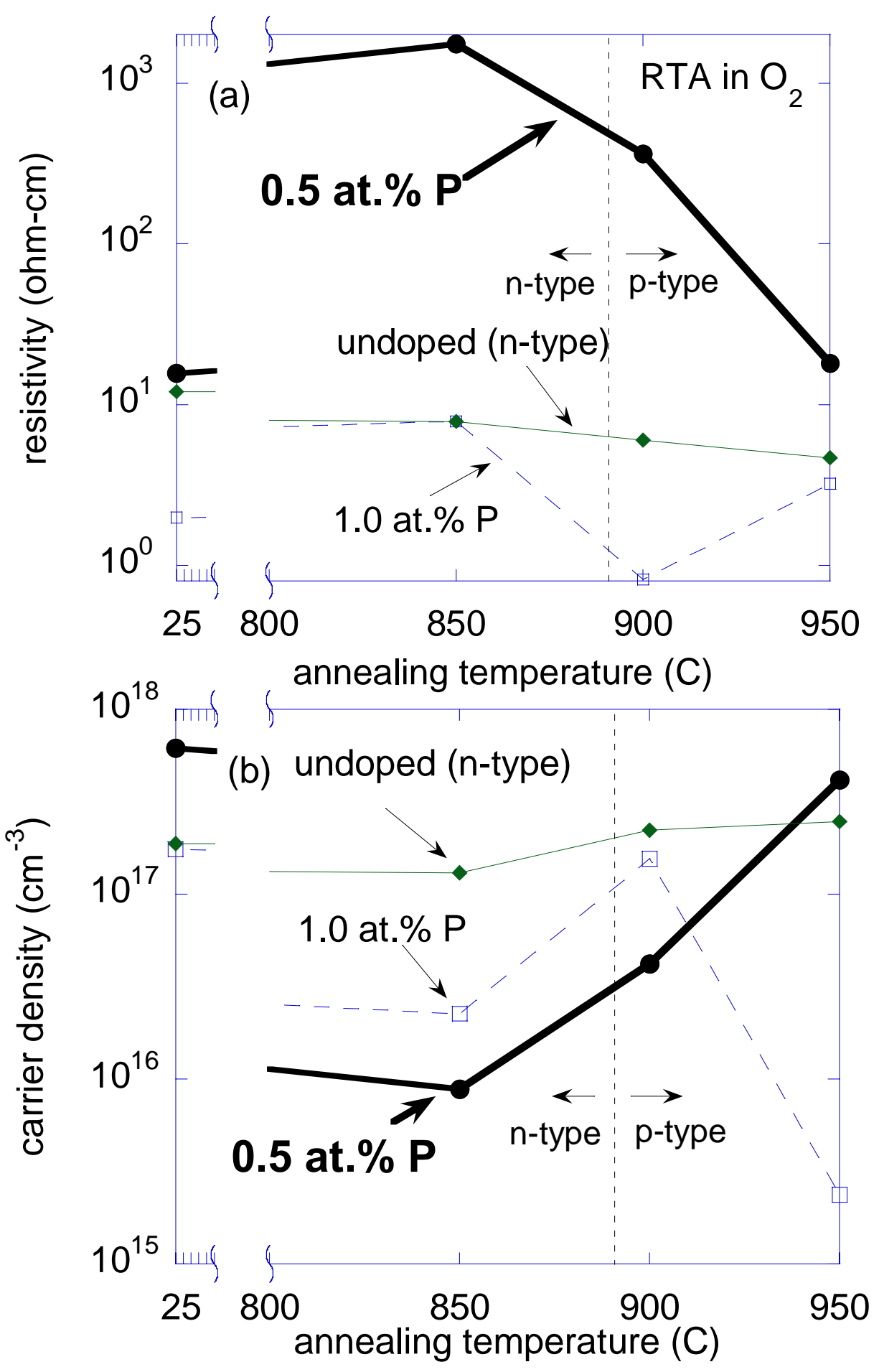

Figure 1.2.6 Hall data for rapid thermal annealed $\mathrm{ZnO}$ films doped with 0.5 and 1.0 at.\% $\mathrm{P}$, grown at $700^{\circ} \mathrm{C}$, 150 mTorr oxygen, showing a) resistivity and b) carrier density as a function of annealing temperature. 


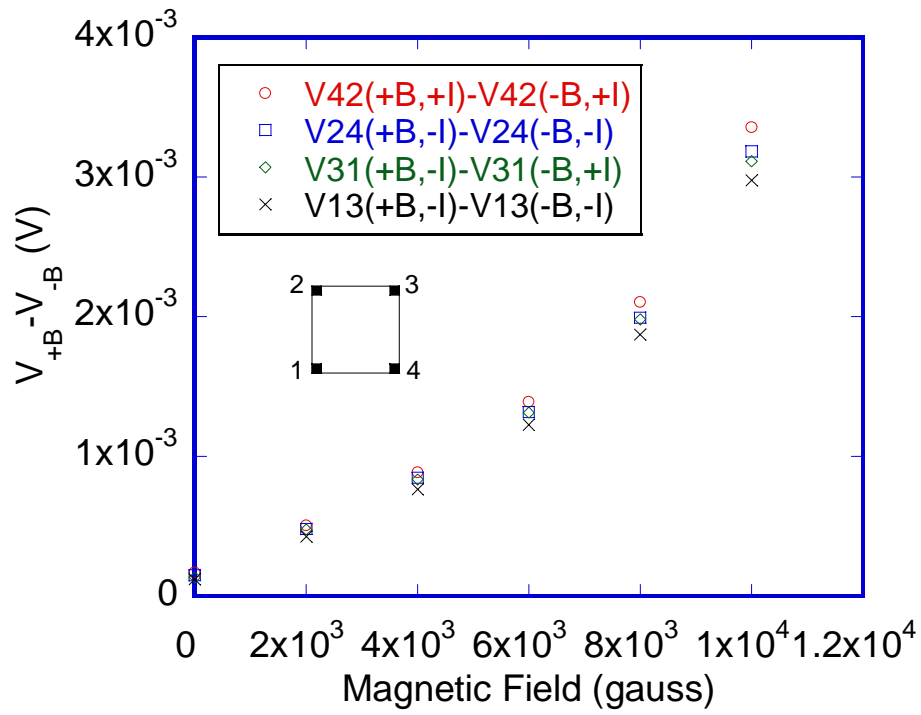

Figure 1.2.7 Plot of van der Pauw Hall voltage differences for a p-type 0.5 at.\% P-doped $\mathrm{ZnO}$ film subjected to a $900^{\circ} \mathrm{C}$ RTA process. The voltage difference polarity for all measurements are consistent with p-type conduction. 

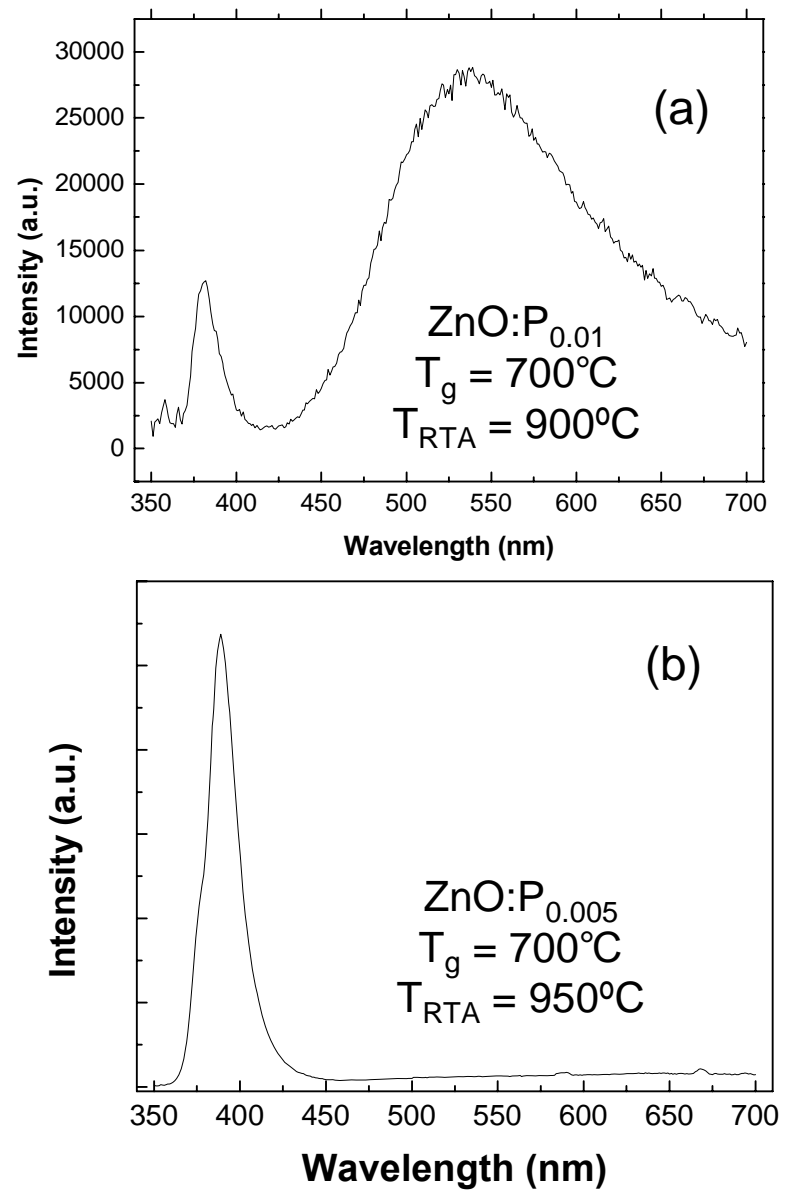

Figure 1.2.8 Room temperature photoluminescence data for a) 1.0 at. $\%$ and b) 0.5 at. $\%$ P-doped $\mathrm{ZnO}$ films that were post-annealed and p-type 


\begin{tabular}{|c|c|c|c|c|}
\hline \multirow{2}{*}{$\begin{array}{c}\text { Growth } \\
\text { Temp }\left({ }^{\circ} \mathrm{C}\right)\end{array}$} & \multirow{2}{*}{ As grown } & \multicolumn{3}{|c|}{$\begin{array}{c}\left(\mathrm{ZnO}: \mathrm{P}_{0.005}\right) \text { - Hall data }(150 \text { mTorr growth pressure }) \\
\text { RTA temperature }\left({ }^{\circ} \mathrm{C}\right) /(\text { anneal time }=2 \mathrm{~min})\end{array}$} \\
\hline & & 850 & 900 & 950 \\
\hline 600 & & $\begin{array}{l}4400 \Omega-\mathrm{cm} \\
3.9 \mathrm{E}+16 \mathrm{~cm}^{-3} \\
0.037 \mathrm{~cm}^{2} / \mathrm{Vs} \\
\text { N-type }\end{array}$ & $\begin{array}{l}140 \Omega-\mathrm{cm} \\
1.2 \mathrm{E}+17 \mathrm{~cm}^{-3} \\
0.37 \mathrm{~cm}^{2} / \mathrm{Vs} \\
N \text {-type }\end{array}$ & $\begin{array}{l}1.1 \Omega-\mathrm{cm} \\
4.9 \mathrm{E}+18 \mathrm{~cm}^{-3} \\
1.2 \mathrm{~cm}^{2} / \mathrm{Vs} \\
N \text {-type }\end{array}$ \\
\hline 650 & & $\begin{array}{l}1700 \Omega-\mathrm{cm} \\
2.9 \mathrm{E}+15 \mathrm{~cm}^{-3} \\
1.3 \mathrm{~cm}^{2} / \mathrm{Vs} \\
\text { N-type }\end{array}$ & $\begin{array}{l}70 \Omega-\mathrm{cm} \\
4.3 \mathrm{E}+17 \mathrm{~cm}^{-3} \\
0.20 \mathrm{~cm}^{2} / \mathrm{Vs} \\
\mathrm{N} \text {-type }\end{array}$ & $\begin{array}{l}6.3 \Omega-\mathrm{cm} \\
2.7 \mathrm{E}+18 \mathrm{~cm}^{-3} \\
0.36 \mathrm{~cm}^{2} / \mathrm{Vs} \\
\text { N-type }\end{array}$ \\
\hline 700 & $\begin{array}{l}15.59 \Omega-\mathrm{cm} \\
6.2 \mathrm{E}+17 \mathrm{~cm}^{-3} \\
0.98 \mathrm{~cm}^{2} / \mathrm{Vs} \\
\text { N-type }\end{array}$ & $\begin{array}{l}3400 \Omega-\mathrm{cm} \\
3.9 \mathrm{E}+15 \mathrm{~cm}^{-3} \\
0.47 \mathrm{~cm}^{2} / \mathrm{Vs} \\
\text { N-type }\end{array}$ & $\begin{array}{l}360 \Omega-\mathrm{cm} \\
4.2 \mathrm{E}+16 \mathrm{~cm}^{-3} \\
0.40 \mathrm{~cm}^{2} / \mathrm{Vs} \\
P \text {-type }\end{array}$ & $\begin{array}{l}19 \Omega-\mathrm{cm} \\
4.1 \mathrm{E}+17 \mathrm{~cm}^{-3} \\
0.80 \mathrm{~cm}^{2} / \mathrm{Vs} \\
\underline{P \text {-type }}\end{array}$ \\
\hline 750 & $\begin{array}{l}2.2 \Omega-\mathrm{cm} \\
4.8 \mathrm{E}+17 \mathrm{~cm}^{-3} \\
5.8 \mathrm{~cm}^{2} / \mathrm{Vs} \\
\text { N-type }\end{array}$ & $\begin{array}{l}630 \Omega-\mathrm{cm} \\
1.4 \mathrm{E}+16 \mathrm{~cm}^{-3} \\
0.68 \mathrm{~cm}^{2} / \mathrm{Vs} \\
\text { N-type }\end{array}$ & $\begin{array}{l}140 \Omega-\mathrm{cm} \\
2.2 \mathrm{E}+17 \mathrm{~cm}^{-3} \\
0.21 \mathrm{~cm}^{2} / \mathrm{Vs} \\
N \text {-type }\end{array}$ & $\begin{array}{l}21 \Omega-\mathrm{cm}^{-3} \\
9.5 \mathrm{E}+17 \mathrm{~cm}^{-3} \\
0.30 \mathrm{~cm}^{2} / \mathrm{Vs} \\
\text { P-type }\end{array}$ \\
\hline 800 & $\begin{array}{l}2.0 \Omega-\mathrm{cm} \\
4.5 \mathrm{E}+17 \mathrm{~cm}^{-3} \\
7.1 \mathrm{~cm}^{2} / \mathrm{Vs} \\
\text { N-type }\end{array}$ & $\begin{array}{l}360 \Omega-\mathrm{cm} \\
2.6 \mathrm{E}+16 \mathrm{~cm}^{-3} \\
0.66 \mathrm{~cm}^{2} / \mathrm{Vs} \\
\mathrm{N} \text {-type }\end{array}$ & $\begin{array}{l}100 \Omega-\mathrm{cm} \\
2.6 \mathrm{E}+16 \mathrm{~cm}^{-3} \\
2.4 \mathrm{~cm}^{2} / \mathrm{Vs} \\
N \text {-type }\end{array}$ & $\begin{array}{l}4.5 \Omega-\mathrm{cm} \\
3.7 \mathrm{E}+18 \mathrm{~cm}^{-3} \\
0.38 \mathrm{~cm}^{2} / \mathrm{Vs} \\
\text { N-type }\end{array}$ \\
\hline
\end{tabular}

Table 1.2.1. Hall data of 0.5 at.\% P-doped films grown at various temperatures and subjected to various postannealing temperatures. 


\begin{tabular}{|c|c|c|c|c|}
\hline \multirow{2}{*}{$\begin{array}{c}\text { Growth } \\
\text { Temp }\left({ }^{\circ} \mathrm{C}\right)\end{array}$} & \multirow[t]{2}{*}{ As grown } & \multicolumn{3}{|c|}{$\begin{array}{l}\left(\mathrm{ZnO}: \mathrm{P}_{0.01}\right) \text { - Hall data }(150 \text { mTorr growth pressure }) \\
\text { RTA temperature }\left({ }^{\circ} \mathrm{C}\right) /(\text { anneal time }=2 \mathrm{~min})\end{array}$} \\
\hline & & 850 & 900 & 950 \\
\hline 600 & $\begin{array}{l}27.34 \Omega-\mathrm{cm} \\
1.1 \mathrm{E}+17 \mathrm{~cm}^{-3} \\
2.06 \mathrm{~cm}^{2} / \mathrm{V}-\mathrm{s} \\
N \text {-type }\end{array}$ & $\begin{array}{l}32.2 \Omega-\mathrm{cm} \\
2.57 \mathrm{E}+16 \mathrm{~cm}^{-3} \\
7.55 \mathrm{~cm}^{2} / \mathrm{V}-\mathrm{s} \\
N \text {-type }\end{array}$ & $\begin{array}{l}24.5 \Omega-\mathrm{cm} \\
1.06 \mathrm{e}+18 \mathrm{~cm}^{-3} \\
0.24 \mathrm{~cm}^{2} / \mathrm{V}-\mathrm{s} \\
N \text {-type }\end{array}$ & $\begin{array}{l}77.7 \Omega-\mathrm{cm} \\
1.61 \mathrm{E}+17 \mathrm{~cm}^{-3} \\
0.5 \mathrm{~cm}^{2} / \mathrm{V}-\mathrm{s} \\
P \text {-type }\end{array}$ \\
\hline 650 & $\begin{array}{l}20.1 \Omega-\mathrm{cm} \\
4.67 \mathrm{E}+18 \mathrm{~cm}^{-3} \\
0.067 \mathrm{~cm}^{2} / \mathrm{N}-\mathrm{s} \\
\text { N-type }\end{array}$ & $\begin{array}{l}10400 \Omega-\mathrm{cm} \\
6.7 \mathrm{E}+16 \mathrm{~cm}^{-3} \\
0.009 \mathrm{~cm}^{2} / \mathrm{V}-\mathrm{s} \\
N \text {-type }\end{array}$ & $\begin{array}{l}38.6 \Omega-\mathrm{cm}^{-3} \\
3.7 \mathrm{E}+18 \mathrm{~cm}^{-3} \\
0.044 \mathrm{~cm}^{2} \mathrm{~N}-\mathrm{s} \\
\text { N-type }\end{array}$ & $\begin{array}{l}1.91 \Omega-\mathrm{cm} \\
3.17 \mathrm{E}+18 \mathrm{~cm}^{-3} \\
1.03 \mathrm{~cm}^{2} / \mathrm{V}-\mathrm{s} \\
N \text {-type }\end{array}$ \\
\hline 700 & $\begin{array}{l}1.98 \Omega-\mathrm{cm} \\
1.75 \mathrm{E}+17 \mathrm{~cm}^{-3} \\
18.1 \mathrm{~cm}^{2} / \mathrm{V}-\mathrm{s} \\
\text { N-type }\end{array}$ & $\begin{array}{l}35.2 \Omega-\mathrm{cm} \\
2.26 \mathrm{E}+16 \mathrm{~cm}^{-3} \\
7.80 \mathrm{~cm}^{2} / \mathrm{V}-\mathrm{s} \\
\text { N-type }\end{array}$ & $\begin{array}{l}48.8 \Omega-\mathrm{cm} \\
1.55 \mathrm{E}+17 \mathrm{~cm}^{-3} \\
0.814 \mathrm{~cm}^{2} / \mathrm{V}-\mathrm{s} \\
\text { P-type }\end{array}$ & $\begin{array}{l}801 \Omega-\mathrm{cm} \\
2.37 \mathrm{E}+15 \mathrm{~cm}^{-3} \\
3.2 \mathrm{~cm}^{2} / \mathrm{V}-\mathrm{s} \\
\text { P-type }\end{array}$ \\
\hline 750 & $\begin{array}{l}2.41 \Omega-\mathrm{cm} \\
2.83 \mathrm{E}+17 \mathrm{~cm}^{-3} \\
9.18 \mathrm{~cm}^{2} / \mathrm{N}-\mathrm{s} \\
\text { N-type }\end{array}$ & $\begin{array}{l}22.0 \Omega-\mathrm{cm} \\
5.90 \mathrm{E}+16 \mathrm{~cm}^{-3} \\
4.8 \mathrm{~cm}^{2} / \mathrm{V}-\mathrm{s} \\
\text { N-type }\end{array}$ & $\begin{array}{l}4.36 \Omega-\mathrm{cm} \\
1.82 \mathrm{E}+18 \mathrm{~cm}^{-3} \\
0.787 \mathrm{~cm}^{2} / \mathrm{V}-\mathrm{s} \\
\text { N-type }\end{array}$ & $\begin{array}{l}2.33 \Omega-\mathrm{cm} \\
3.30 \mathrm{E}+18 \mathrm{~cm}^{-3} \\
0.81 \mathrm{~cm}^{2} / \mathrm{V}-\mathrm{s} \\
N \text {-type }\end{array}$ \\
\hline 800 & $\begin{array}{l}0.68 \Omega-\mathrm{cm} \\
4.2 \mathrm{E}+17 \mathrm{~cm}^{-3} \\
22.1 \mathrm{~cm}^{2} / \mathrm{V}-\mathrm{s} \\
\text { N-type }\end{array}$ & $\begin{array}{l}34.1 \Omega-\mathrm{cm} \\
5.73 \mathrm{E}+16 \mathrm{~cm}^{-3} \\
3.19 \mathrm{~cm}^{2} / \mathrm{V}-\mathrm{s} \\
\text { N-type }\end{array}$ & $\begin{array}{l}46 \Omega-\mathrm{cm} \\
1.98 \mathrm{E}+17 \mathrm{~cm}^{-3} \\
0.68 \mathrm{~cm}^{2} / \mathrm{V}-\mathrm{s} \\
\text { P-type }\end{array}$ & $\begin{array}{l}6300 \Omega-\mathrm{cm} \\
5.18 \mathrm{E}+15 \mathrm{~cm}^{-3} \\
0.19 \mathrm{~cm}^{2} / \mathrm{V}-\mathrm{s} \\
N \text {-type }\end{array}$ \\
\hline 850 & $\begin{array}{l}0.027 \Omega-\mathrm{cm} \\
1.06 \mathrm{E}+19 \mathrm{~cm}^{-3} \\
22 \mathrm{~cm}^{2} / \mathrm{V}-\mathrm{s} \\
\text { N-type }\end{array}$ & $\begin{array}{l}7 \Omega-\mathrm{cm} \\
7.47 \mathrm{E}+17 \mathrm{~cm}^{-3} \\
\text { (M) } 1.2 \mathrm{~cm}^{2} / \mathrm{V}-\mathrm{s} \\
N \text {-type }\end{array}$ & $\begin{array}{l}8.11 \Omega-\mathrm{cm} \\
1.54 \mathrm{E}+18 \mathrm{~cm}^{-3} \\
0.49 \mathrm{~cm}^{2} / \mathrm{V}-\mathrm{s} \\
\text { N-type }\end{array}$ & $\begin{array}{l}1.51 \Omega-\mathrm{cm} \\
2.48 \mathrm{E}+18 \mathrm{~cm}^{-3} \\
1.65 \mathrm{~cm}^{2} / \mathrm{V}-\mathrm{s} \\
\mathrm{N} \text {-type }\end{array}$ \\
\hline
\end{tabular}

Table 1.2.2. Hall data of 1.0 at.\% P-doped films grown at various temperatures and subjected to various postannealing temperatures. 
Task 2 - Fabrication of ZnO-based pn Homojunctions

\subsection{Low Specific Contact Resistance Ti/Au Contacts on ZnO}

Summary: $\quad \mathrm{Ti} / \mathrm{Au}$ Ohmic contacts on heavily Al-doped $\left(\mathrm{n} \sim 10^{19} \mathrm{~cm}^{-3}\right) \mathrm{n}-\mathrm{ZnO}$ produce low specific contact resistivity of $2.4 \times 10^{-7} \Omega \mathrm{cm}^{2}$ in the as-deposited condition and extremely low minimum values of $6 \times 10^{-8} \Omega \mathrm{cm}^{2}$ after annealing at $300^{\circ} \mathrm{C}$. The contact resistance is independent of measurement temperature after low temperature anneals, suggesting that tunneling is the dominant transport mechanism in the contacts. The contact morphology roughens after annealing at $150^{\circ} \mathrm{C}$ and Auger Electron Spectroscopy depth profiling shows Zn outdiffusion through the metal and intermixing of Au and Ti. However, the morphology does not significantly worsen after anneals at $450^{\circ} \mathrm{C}$. This metallization scheme looks very attractive for the n-electrode of $\mathrm{ZnO}$-based light-emitting diode structures.

Introduction: A key component of any $\mathrm{ZnO}$-based light emitter is the availability of low resistance Ohmic contacts to both $\mathrm{n}$ - and $\mathrm{p}$-type layers. If the high contact resistance occurs between metal and semiconductors, device performance can be degraded through thermal stress or contact failure. It is essential to achieve Ohmic contacts that have both low resistance and are thermally stable and reliable. This can be achieved either through surface preparation to reduce the metal semiconductor barrier height, increasing carrier tunneling probability, or by increasing the effective carrier concentration of the surface by mechanisms such as oxygen loss or the indiffusion of zinc. Ti/Au on $\mathrm{n}-\mathrm{ZnO}$ shows a specific contact resistance in the $10^{-4} \Omega \cdot \mathrm{cm}^{2}$ after annealing at $300 \mathrm{C}^{(10,11)}$ and a value of $3.9 \times 10^{-7} \Omega . \mathrm{cm}^{2}$ with insertion of $\mathrm{Al} / \mathrm{Pt}$ layers between the Ti and Au.Other schemes based on $\mathrm{Zn} / \mathrm{Au}, \mathrm{Al}, \mathrm{Al} / \mathrm{Pt}$ , Re/Ti/Au, Ru and Pt/Ga have shown specific contact resistances in the range $10^{-4}-10^{-7} \mathrm{~cm}^{2}$ on n-type $\mathrm{ZnO}$. In this letter we show that Ti/Au on heavily Al-doped ZnO grown by Pulsed Laser Deposition (PLD) exhibit extremely low specific contact resistance in the as-deposited state and are stable to anneal temperatures of at least $450^{\circ} \mathrm{C}$.

The films were grown by PLD on $\mathrm{MgO}$ buffers on c-plane $\mathrm{Al}_{2} \mathrm{O}_{3}$ substrates. The ablation targets were fabricated with an $\mathrm{Al}$ doping level of 0.01 at. \% and a $\mathrm{KrF}$ excimer laser with a repetition rate of $1 \mathrm{~Hz}$ and pulse energy density of $\sim 3 \mathrm{~J} / \mathrm{cm}^{2}$ was used as the ablation source. The target to substrate distance was $4 \mathrm{~cm}$. The $\mathrm{ZnO}$ growth chamber exhibits a base pressure of $10^{-6}$ Torr. Film growth was performed at $800{ }^{\circ} \mathrm{C}$ in an oxygen pressure of 20-50 mTorr. The films were $\sim 0.5-\mu \mathrm{m}$ thick with an electron concentration of $9 \times 10^{18}-1.3 \times 10^{19} \mathrm{~cm}^{-3}$ and mobility $50-61 \mathrm{~cm}^{2} \mathrm{~V}^{-1} \mathrm{~s}^{-1}$ at room temperature, as determined from van der Pauw Hall measurements. The fullwidth-at-half maximum (FWHM) for the $\mathrm{ZnO}(002)$ peak of $0.26-0.64^{\circ}$. The layers exhibited strong band edge photoluminescence at $\sim 370 \mathrm{~nm}$ at room temperature . Contact metallurgy of either $\operatorname{Ti}(200 \AA) / \mathrm{Au}(800 \AA)$ was deposited by electron-beam evaporation and patterned by resist lift-off to form a transmission line pattern (TLM) with $100 \mu \mathrm{m}$ pads spaced from 2 to $16 \mu \mathrm{m}$. The samples were annealed for $1 \mathrm{~min}$ at temperatures up to $450^{\circ} \mathrm{C}$ in $\mathrm{O}_{2}$ and the current-voltage (I-V) characteristics recorded on an Agilent 4156B parameter analyzer. Auger Electron Spectroscopy (AES) depth profiling was performed on a Physical Electronics 660 Scanning Auger Microprobe. The electron beam conditions were $10 \mathrm{keV}, 0.3 \mu \mathrm{A}$ beam current at $30^{\circ}$ from sample normal. For depth profiling, the ion beam conditions were $3 \mathrm{keV} \mathrm{Ar}{ }^{+}, 2.0 \mu \mathrm{A}, 4 \mathrm{~mm}^{2}$ raster, with measured sputter rate of $88 \AA /$ minute.

Figure 2.1.1 shows the specific contact resistance of the $\mathrm{Ti} / \mathrm{Au}$ contacts on $\mathrm{Al}$-doped $\mathrm{ZnO}$ of two different electron concentrations. The latter were obtained by altering the oxygen pressure during growth of the $\mathrm{ZnO}$. The minimum specific contact resistivity of $6 \times 10^{-8} \Omega \cdot \mathrm{cm}^{2}$ was obtained at $300^{\circ} \mathrm{C}$ for Ti/Au, which is the lowest reported for $\mathrm{n}$-Ohmic contacts on $\mathrm{ZnO}$. Note that even the as-deposited contacts exhibit a very low specific contact resistivity of $2.4 \times 10^{-7} \Omega . \mathrm{cm}^{2}$ for the layer doped at $1.3 \times 10^{19} \mathrm{~cm}^{-3}$.

The morphology of the contacts was a strong function of the annealing temperature, as shown in Figure 2.1.2. The smooth and flat metal surface in the as-deposited condition for Ti/Au (a root-mean-square(RMS) roughness of $3.3 \mathrm{~nm}$ as measured by Atomic Force Microscopy over a $5 \times 5 \mathrm{~m}^{2}$ area) became rougher even after $150^{\circ} \mathrm{C}$ annealing(RMS roughness of $2.4 \mathrm{~nm}$ ). However, the surface did not become measurably rougher for anneals up to $450^{\circ} \mathrm{C}$ annealing. As annealing temperature increases, Ti and Au start to form intermetallic compounds and oxygen is predominantly removed from the $\mathrm{ZnO}$ surface leading to decomposition of the $\mathrm{ZnO}$. These reactions are likely to play a strong role in the roughening of the contact morphology.

To determine the dominant current transport mechanism in the contacts, the specific contact resistivity was obtained as a function of the measurement temperature. Given the high doping level in the $\mathrm{ZnO}$ layer is moderately doped, we would expect tunneling to be the main mechanism. As shown in Figure 2.1.3, the Ti/Au contacts annealed at $150^{\circ} \mathrm{C}$ exhibited almost constant specific contact resistance in the temperature range from $25-225^{\circ} \mathrm{C}$, indicating that current flow is dominated by tunneling. Similar results were obtained for the contacts annealed from $150-300^{\circ} \mathrm{C}$. Under these conditions, the specific contact resistivity $\left(\mathrm{R}_{\mathrm{SCR}}\right)$ is a strong function of dependent doping concentration 
through the relation

$$
R_{S C R} \propto \exp \left[\frac{2 \sqrt{\varepsilon_{S} m_{e}^{*}}}{\hbar}\left(\frac{\phi_{B}}{\sqrt{N_{D}}}\right)\right],
$$

where $\varepsilon_{\mathrm{S}}$ the semiconductor permittivity $\left(\varepsilon_{\mathrm{S}, \mathrm{ZnO}}=8.5\right), m_{e}^{*}$ the effective mass of electrons, $\hbar$ the Planck's constant , $\phi_{\mathrm{B}}$ is the barrier height, and $\mathrm{N}_{\mathrm{D}}$ is the donor concentration in the semiconductor. Both the calculated and experimental barrier heights for $\mathrm{Ti}$ on $\mathrm{ZnO}$ are very low $(0.02-0.04 \mathrm{eV})$. Previous reports have also shown that thin titanium oxide layers may be formed at the metal/ZnO interface even in as-deposited condition since titanium has a higher affinity with oxygen than does $\mathrm{Zn}$ ( the respective enthalpies of reaction are $\Delta \mathrm{H}_{\mathrm{f}}^{\mathrm{o}}\left(\mathrm{Ti}_{3} \mathrm{O}_{5}\right)=-2459.1 \mathrm{~kJ} / \mathrm{mol}$, $\Delta \mathrm{H}_{\mathrm{f}}^{\mathrm{o}}\left(\mathrm{Ti}_{2} \mathrm{O}_{3}\right)=-1520.9 \mathrm{~kJ} / \mathrm{mol}, \Delta \mathrm{H}_{\mathrm{f}}{ }^{0} \quad\left(\mathrm{TiO}_{2}\right)=-944 \mathrm{~kJ} / \mathrm{mol}, \Delta \mathrm{H}_{\mathrm{f}}{ }^{\mathrm{o}} \quad(\mathrm{TiO})=-542.7 \mathrm{~kJ} / \mathrm{mol} \quad v s . \Delta \mathrm{H}_{\mathrm{f}}{ }^{0} \quad(\mathrm{ZnO})=-$ $350 \mathrm{~kJ} / \mathrm{mol}$ ). The formation of titanium oxide produces oxygen vacancies, which as effective mass donors in $\mathrm{ZnO}$ further increase the carrier concentration near the $\mathrm{ZnO}$ surface and increase the tunneling probability. Note that since the as-deposited contacts are also Ohmic, tunneling is also the main mechanism even without the formation of the oxygen vacancies.

AES depth profiles from the Ti/Au contacts are shown in Figure 2.1.4 both before and after annealing at $250^{\circ} \mathrm{C}$. $\mathrm{Zn}$ and $\mathrm{Ti}$ outdiffusion to the surface are clearly evident at $250^{\circ} \mathrm{C}$. The possible formation of a $\mathrm{TiO}_{\mathrm{x}}$ interfacial region is inconclusive from this data although we have seen more clear evidence in previous work on $\mathrm{Ti} / \mathrm{Au}$ and $\mathrm{Ti} / \mathrm{Al} / \mathrm{Pt} / \mathrm{Au}$ Ohmic contacts on $\mathrm{n}$-type $\mathrm{Zn}_{0.05} \mathrm{Cd}_{0.95} \mathrm{O}$ layers grown on $\mathrm{ZnO}$ buffer layers 


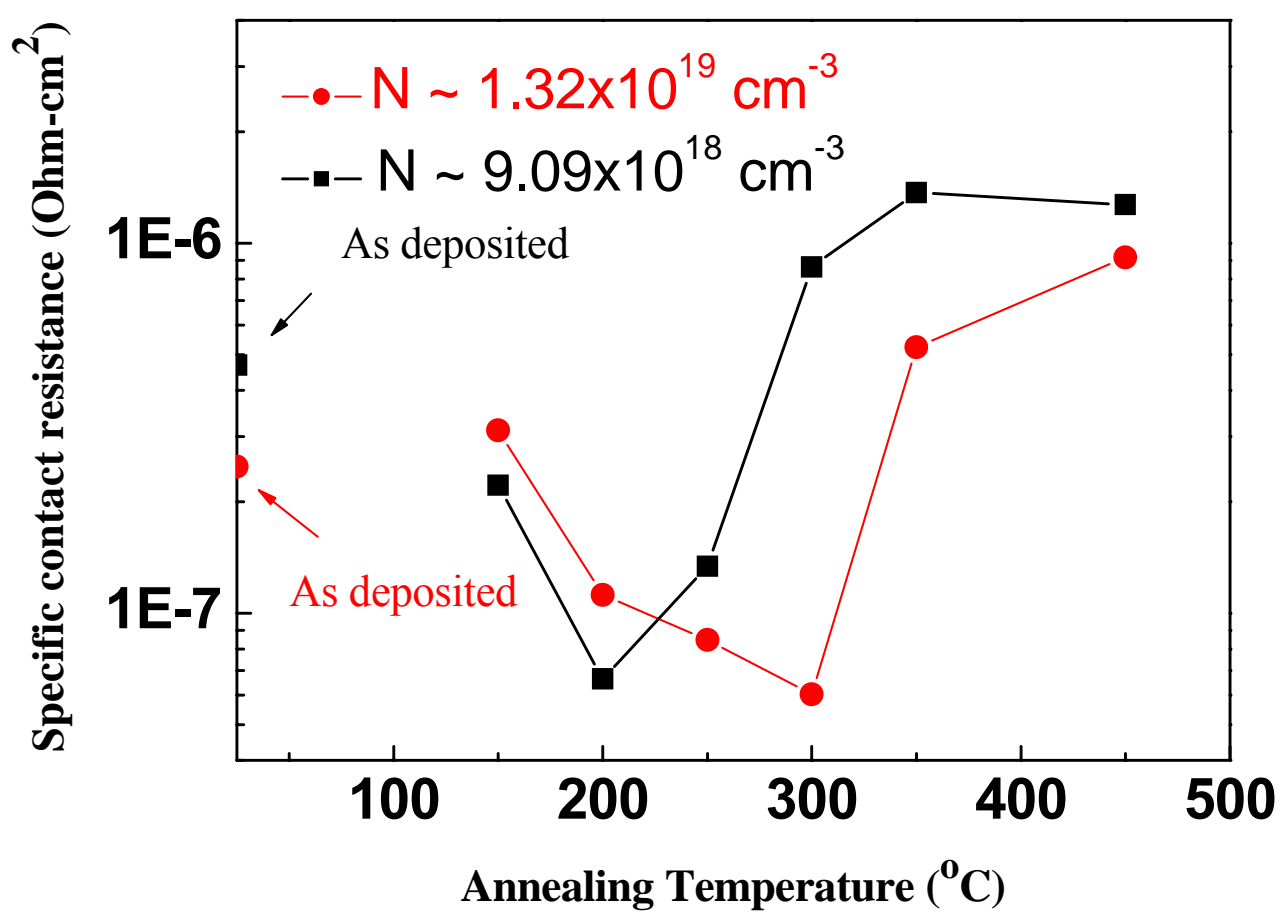

Figure 2.1.1. Specific contact resistivity as a function of annealing temperature for $\mathrm{Ti} / \mathrm{Au}$ contacts on $\mathrm{Al}$-doped $\mathrm{ZnO}$ of two different carrier concentrations. 

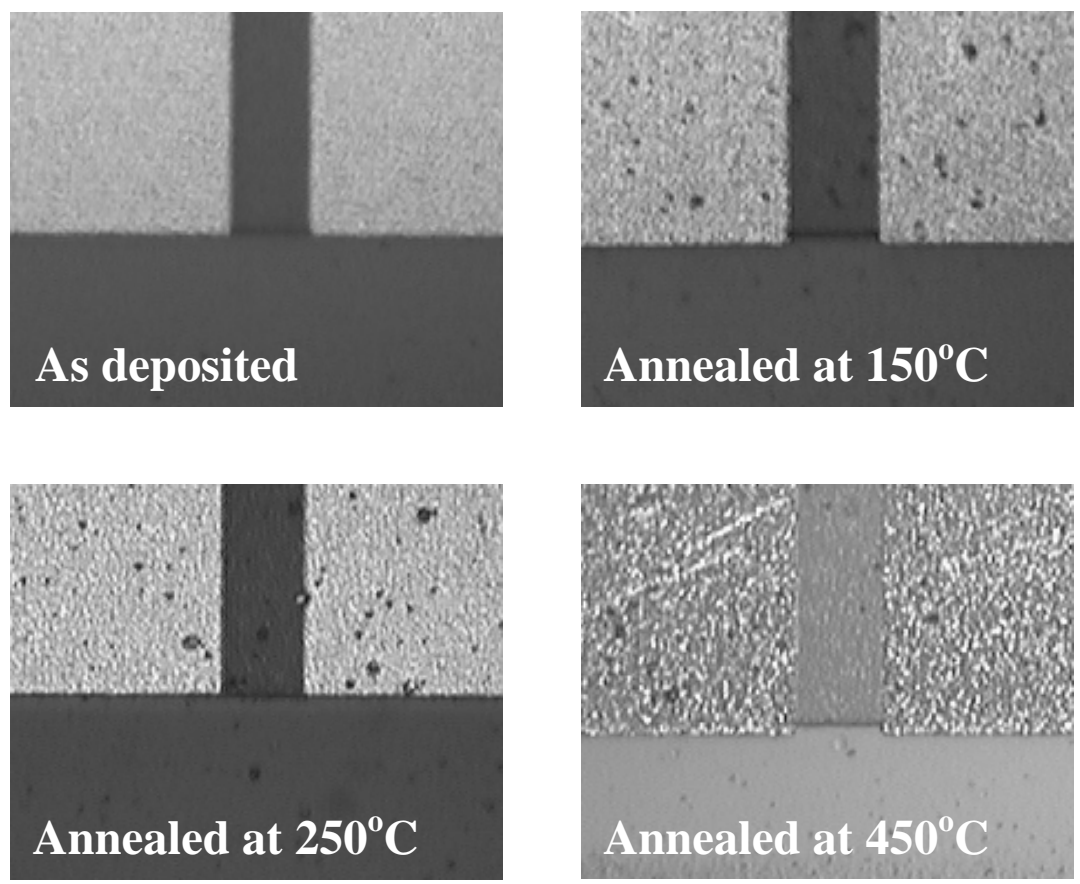

Figure 2.1.2.Optical microscopy images of $\mathrm{Ti} / \mathrm{Au}$ contacts on $\mathrm{ZnO}$ annealed at different temperatures. The contact pads are $100 \times 100 \mu \mathrm{m}^{2}$. 


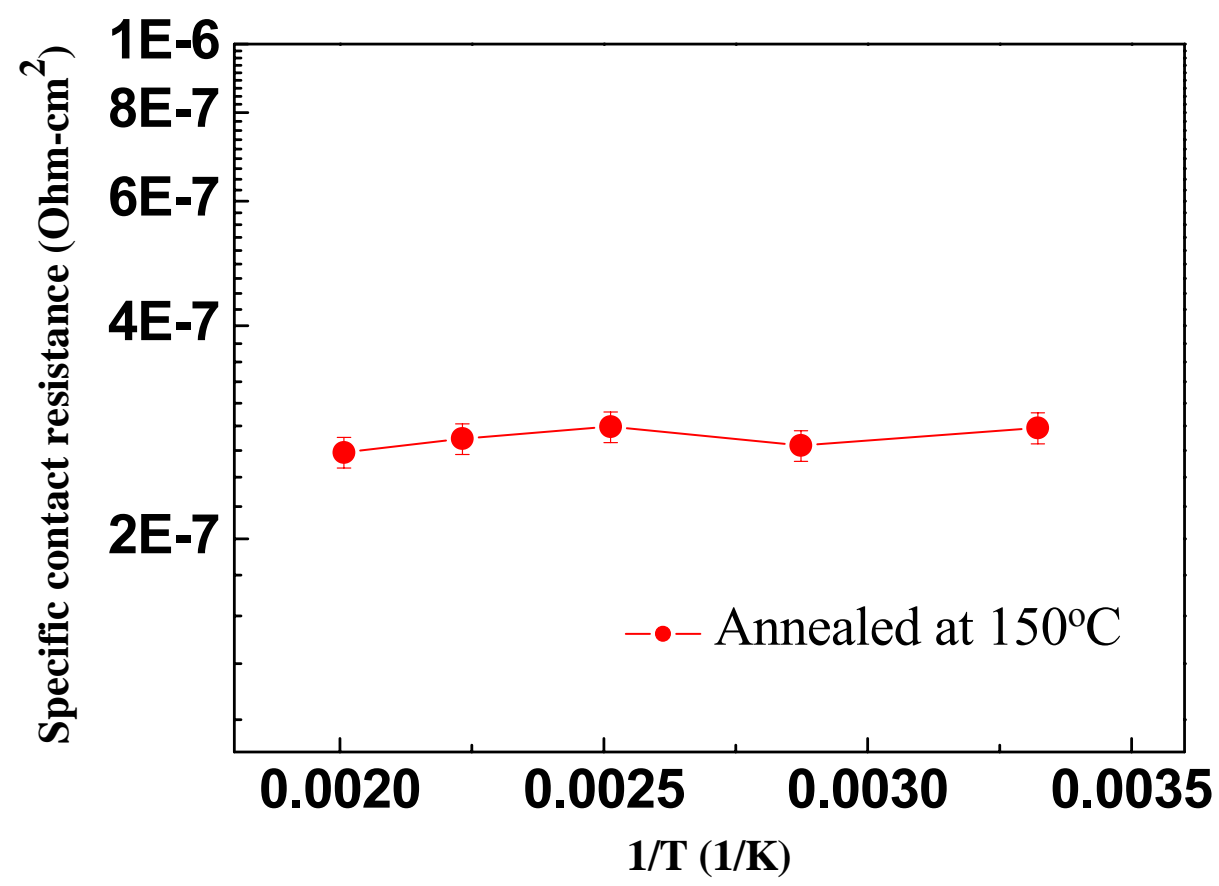

Figure 2.1.3. Arrhenius plot of specific contact resistance for $\mathrm{Ti} / \mathrm{Au}$ on $\mathrm{ZnO}$ annealed at $150^{\circ} \mathrm{C}$. 


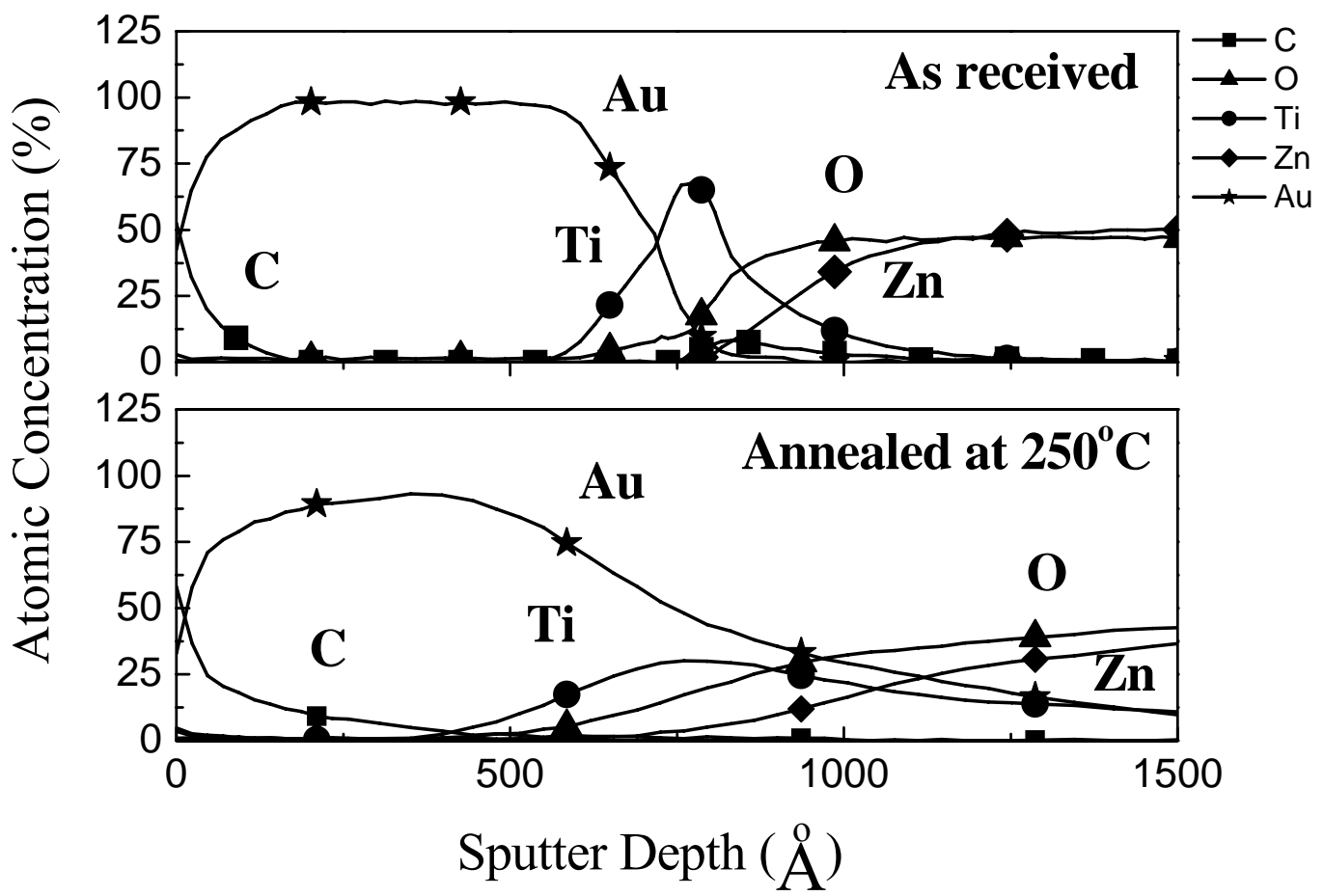

Figure 2.1.4. AES depth profiles on $\mathrm{Ti} / \mathrm{Au}$ contacts on $\mathrm{ZnO}$ as-received (top), after annealing at $250^{\circ} \mathrm{C}$ (bottom). 
Summary: $\quad$ Wet etch rates at $25^{\circ} \mathrm{C}$ for $\mathrm{Zn}_{0.9} \mathrm{Mg}_{0.1} \mathrm{O}$ grown on sapphire substrates by pulsed laser deposition (PLD) were in the range 300-1100 nm. $\mathrm{min}^{-1}$ with $\mathrm{HCl} / \mathrm{H}_{2} \mathrm{O}\left(5 \times 10^{-3}-2 \times 10^{-2} \mathrm{M}\right)$ and $120-300 \mathrm{~nm} \cdot \mathrm{min}^{-1}$ with $\mathrm{H}_{3} \mathrm{PO}_{4} / \mathrm{H}_{2} \mathrm{O}$ $\left(5 \times 10^{-3}-2 \times 10^{-2} \mathrm{M}\right)$. Both of these dilute mixtures exhibited diffusion-limited etching, with thermal activation energies of 2-3 kCal.mol ${ }^{-1}$. By sharp contrast, the etch rates for $\mathrm{ZnO}$ also grown on sapphire by PLD were much slower in similar solutions, with rates of 1.2-50 nm. $\min ^{-1}$ in $\mathrm{HCl} / \mathrm{H}_{2} \mathrm{O}(0.01-1.2 \mathrm{M})$ and $12-54 \mathrm{~nm} \cdot \mathrm{min}^{-1}$ in $\mathrm{H}_{3} \mathrm{PO}_{4} / \mathrm{H}_{2} \mathrm{O}(0.02-$ $0.15 \mathrm{M})$. The etching was reaction-limited over the temperature range $25-75^{\circ} \mathrm{C}$, with activation energies close to 6 kCal.mol ${ }^{-1}$. The resulting selectivity of $\mathrm{Zn}_{0.9} \mathrm{Mg}_{0.1} \mathrm{O}$ over $\mathrm{ZnO}$ can be a high as $\sim 400$ with $\mathrm{HCl}$ and $\sim 30$ with $\mathrm{H}_{3} \mathrm{PO}_{4}$.

Introduction: In most device fabrication schemes, wet etching is needed for isolation or mesa formation. $\mathrm{ZnO}$ is readily etched in many acid solutions, including $\mathrm{HNO}_{3} / \mathrm{HCl}$ and $\mathrm{HF}$.In most cases the etching is reaction-limited, with activation energies of $>6 \mathrm{kCal} \mathrm{mol}^{-1}$. In preliminary work, we have found that the etching of the $\mathrm{ZnO}$ is strongly dependent on material quality. If the $\mathrm{ZnO}$ is very thin, the wet etch rates are high in all acid solutions. A particular problem encountered with the wet etching of $\mathrm{ZnO} / \mathrm{AlGaN}$-based LED structures was the presence of very significant undercut (as much as around $10 \mu \mathrm{m}$ ), which occurred mainly at the end of the selective removal of the $\mathrm{ZnO}$ from the underlying AlGaN.

In this section, we report on the selective etching of $\mathrm{Zn}_{0.9} \mathrm{Mg}_{0.1} \mathrm{O}$ relative to $\mathrm{ZnO}$, both grown with similar thicknesses on sapphire substrates by pulsed laser deposition (PLD) to ensure similar crystal quality. Selectivities over 400 can be achieved with $\mathrm{HCl}$ at high dilution factors with water.

Experimental: The films were grown by PLD on c-plane $\mathrm{Al}_{2} \mathrm{O}_{3}$ substrates. Phosphorus-doped $\left(\mathrm{Zn}_{0.9} \mathrm{Mg}_{0.1}\right) \mathrm{O}$ targets were fabricated using high-purity $\mathrm{ZnO}(99.9995 \%)$ and $\mathrm{MgO}(99.998 \%)$, with $\mathrm{P}_{2} \mathrm{O}_{5}(99.998 \%)$ serving as the doping agent. The ablation targets were fabricated with a phosphorus doping level of 2 at. $\%$ (which can produce ptype conductivity if the films are annealed after growth and a $\mathrm{KrF}$ excimer laser with a repetition rate of $1 \mathrm{~Hz}$ and pulse energy density of $1-3 \mathrm{~J} / \mathrm{cm}^{2}$ was used as the ablation source. The target to substrate distance was $4 \mathrm{~cm}$. The $\mathrm{ZnO}$ growth chamber exhibits a base pressure of $10^{-6}$ Torr. Film growth was performed at $500{ }^{\circ} \mathrm{C}$ for $\mathrm{ZnMgO}$ or $400{ }^{\circ} \mathrm{C}$ for $\mathrm{ZnO}$ in an oxygen pressure of 50-150 mTorr. Both types of films were $\sim 0.5-\mu \mathrm{m}$ thick with an electron concentration of $10^{17} \mathrm{~cm}^{-3}$ and mobility $25 \mathrm{~cm}^{2} \mathrm{~V}^{-1} \mathrm{~s}^{-1}$ for the $\mathrm{ZnO}$ and a mixed conductivity(indeterminate conductivity type with carrier density around $10^{16} \mathrm{~cm}^{-3}$ ) for the $\mathrm{ZnMgO}$ layers , as determined from van der Pauw Hall measurements.

The wet etching was performed with $\mathrm{HCl} / \mathrm{H}_{2} \mathrm{O}$ or $\mathrm{H}_{3} \mathrm{PO}_{4} / \mathrm{H}_{2} \mathrm{O}$ solutions as a function of both concentration and temperature. A photoresist mask (AZ 1045) was used for creating features whose depth was measured by stylus profilometry after post-etch removal of the mask in acetone.

Results and discussion: $\quad$ Figure 2.2.1 shows the etch rates of $\mathrm{Zn}_{0.9} \mathrm{Mg}_{0.1} \mathrm{O}$ as a function of solution concentration for $\mathrm{HCl} / \mathrm{H}_{2} \mathrm{O}$ or $\mathrm{H}_{3} \mathrm{PO}_{4} / \mathrm{H}_{2} \mathrm{O}$ at $25^{\circ} \mathrm{C}$. The etch rates are significantly faster with $\mathrm{HCl} / \mathrm{H}_{2} \mathrm{O}$ at all concentrations. Note that we used high dilution factors of the acids with water in order to get controllable etch rates. The use of pure $\mathrm{HCl}$ or $\mathrm{H}_{3} \mathrm{PO}_{4}$ produced very high rates and extensive bubbling in the solutions that led to non-uniform, rough surfaces.

The etch rate of semiconductors may be limited by the diffusion of the active etchant species to the semiconductor surface, or by the diffusion away of the soluble product. In this case the etching is termed diffusionlimited, and its characteristics include a square root dependence of etch depth on etch time, an activation energy $\leq 6$ $\mathrm{kCal} . \mathrm{mol}^{-1}$ and a strong dependence of etch rate on solution agitation. This mode of etching is not desirable for device fabrication, because of the difficulty in obtaining reproducible rates. Figure 2.2.2 shows an Arrhenius plot of the etch rates of $\mathrm{ZnO}$ and $\mathrm{Zn}_{0.9} \mathrm{Mg}_{0.1} \mathrm{O}$ in the two solutions at high dilution factors with water. Under these conditions, the activation energies for etching are in the range $2-3 \mathrm{kCal}^{\mathrm{mol}}{ }^{-1}$, which is consistent with diffusionlimited etching.

Figure 2.2.3 shows the etch rates of $\mathrm{ZnMgO}$ as a function of solution concentration for $\mathrm{HCl} / \mathrm{H}_{2} \mathrm{O}$ or $\mathrm{H}_{3} \mathrm{PO}_{4} / \mathrm{H}_{2} \mathrm{O}$ at $25^{\circ} \mathrm{C}$. By contrast to the case of $\mathrm{ZnMgO}$, the etch rates are significantly faster with $\mathrm{H}_{3} \mathrm{PO}_{4} / \mathrm{H}_{2} \mathrm{O}$ at all concentrations. Note that we used lower dilution factors of the acids with water in order to get controllable $\mathrm{ZnO}$ etch rates compared to the dilutions used for $\mathrm{ZnMgO}$. Once again, the use of pure $\mathrm{HCl}$ or $\mathrm{H}_{3} \mathrm{PO}_{4}$ produced irreproducible etch rates and non-uniform, rough surfaces.

The other rate-limiting step in wet etching of semiconductors may be the chemical reactions at the surface.

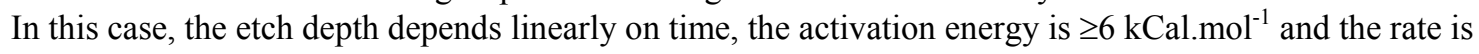
independent of solution agitation. This is the preferred mode of etching for device fabrication, since only temperature and solution composition need to be controlled. Figure 2.2.4 shows an Arrhenius plot of $\mathrm{ZnO}$ etch rate 
in the two acid/water mixtures. In this case of lower dilution factors, the activation energies ( $\sim 5.6-5.9 \pm 0.4 \mathrm{kCal}^{-\mathrm{mol}^{-}}$ ${ }^{1}$ ) are consistent with a transition to reaction-limited etching since transport of the reacting species through the etch solution is less of a factor than in the very dilute mixtures used for $\mathrm{ZnMgO}$.

The resulting selectivities for etching $\mathrm{ZnMgO}$ over $\mathrm{ZnO}$ in the two mixtures are shown in Figure 2.2.5. The $\mathrm{HCl} / \mathrm{H}_{2} \mathrm{O}$ solution provides selectivities in excess of 425 under optimum conditions. A rule of thumb in device fabrication schemes is that a selectivity of at least 10 and preferably 100 is desirable in most cases.

Using the selective etch recipes, it is possible to get clean pattern transfer when selectively etching $\mathrm{ZnMgO}$ layers from an underlying $\mathrm{ZnO}$ layer on sapphire, as shown in the scanning electron microscopy images of Figure 2.2.6. 


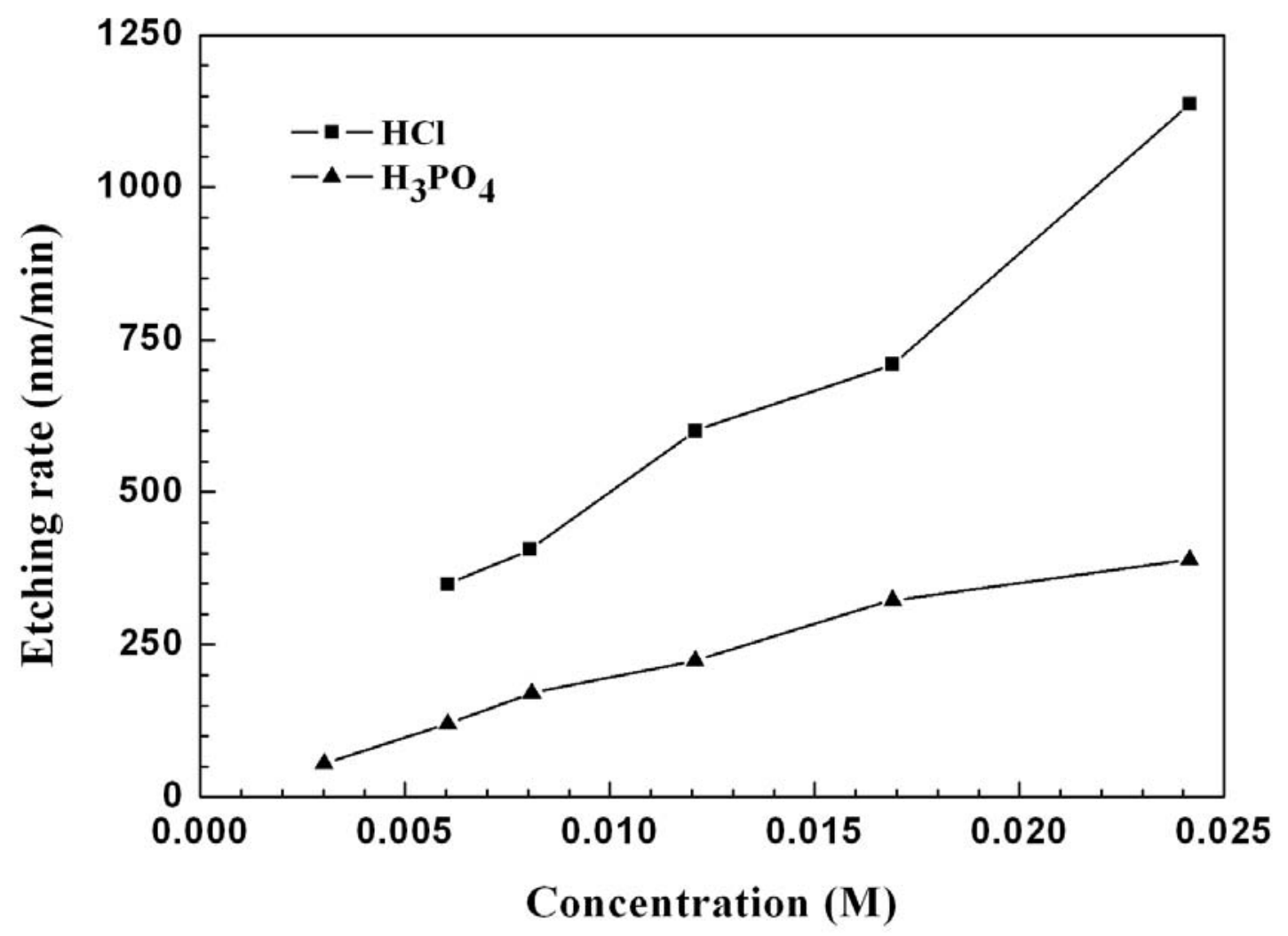

Figure 2.2.1. Etch rate of $\mathrm{Zn}_{0.9} \mathrm{Mg}_{0.1} \mathrm{O}$ in different concentrations of $\mathrm{HCl}$ and $\mathrm{H}_{3} \mathrm{PO}_{4}$ diluted with water. 


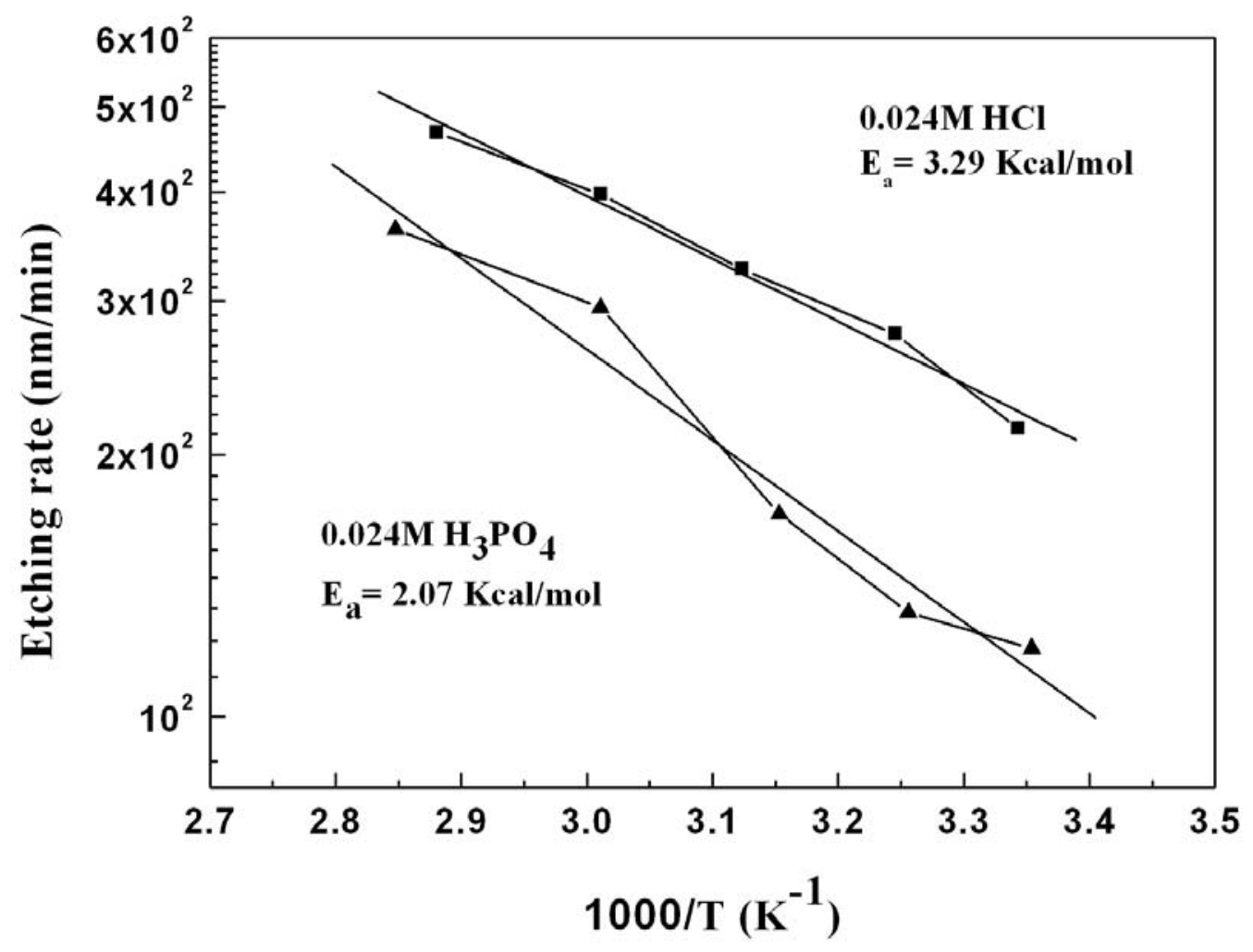

Figure 2.2.2. Arrhenius plot of etch rate of $\mathrm{Zn}_{0.9} \mathrm{Mg}_{0.1} \mathrm{O}$ in $0.024 \mathrm{M}$ concentrations of $\mathrm{HCl}$ and $\mathrm{H}_{3} \mathrm{PO}_{4}$ diluted with water. 


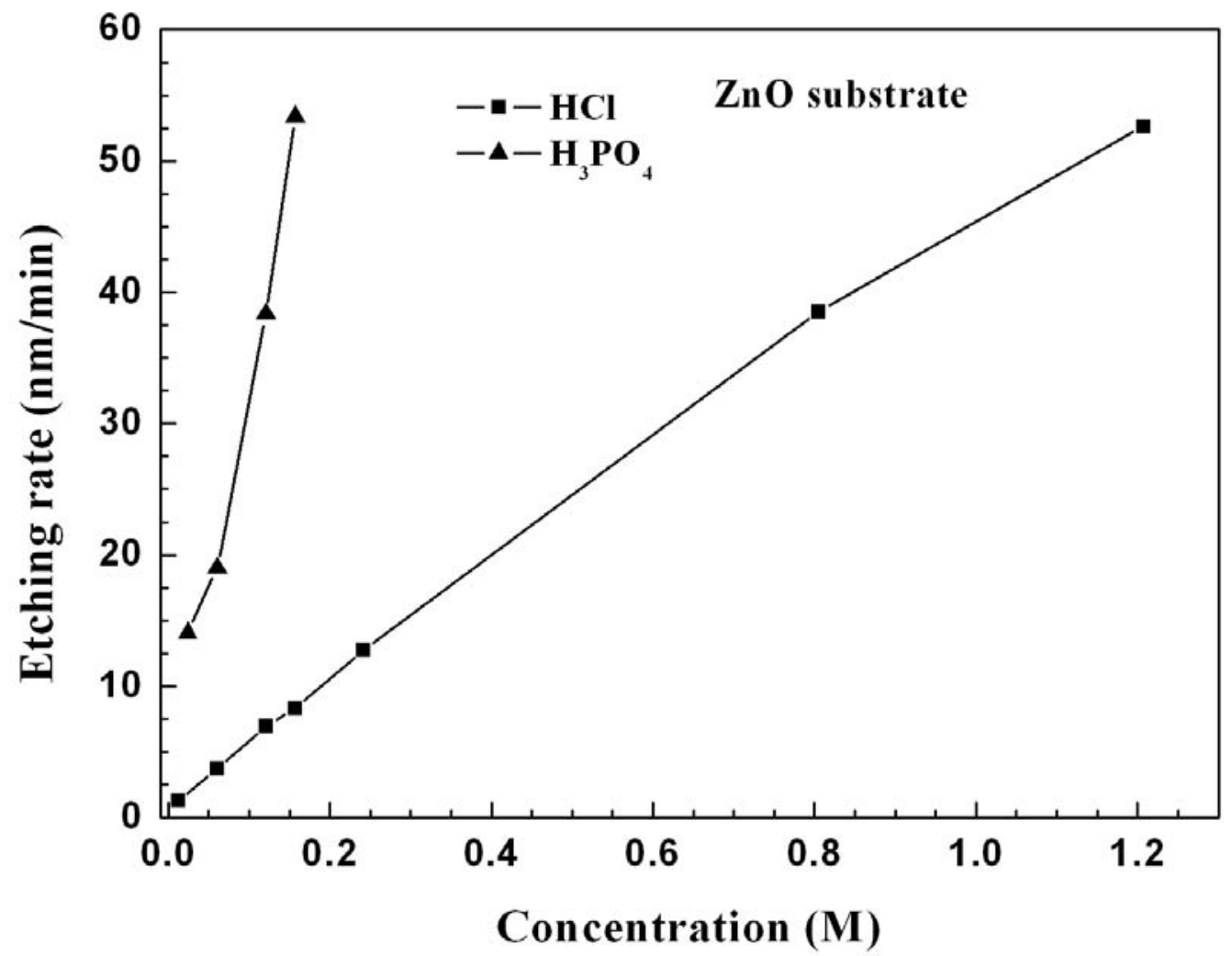

Figure 2.2.3. Etch rate of $\mathrm{ZnO}$ in different concentrations of $\mathrm{HCl}$ and $\mathrm{H}_{3} \mathrm{PO}_{4}$ diluted with water. 


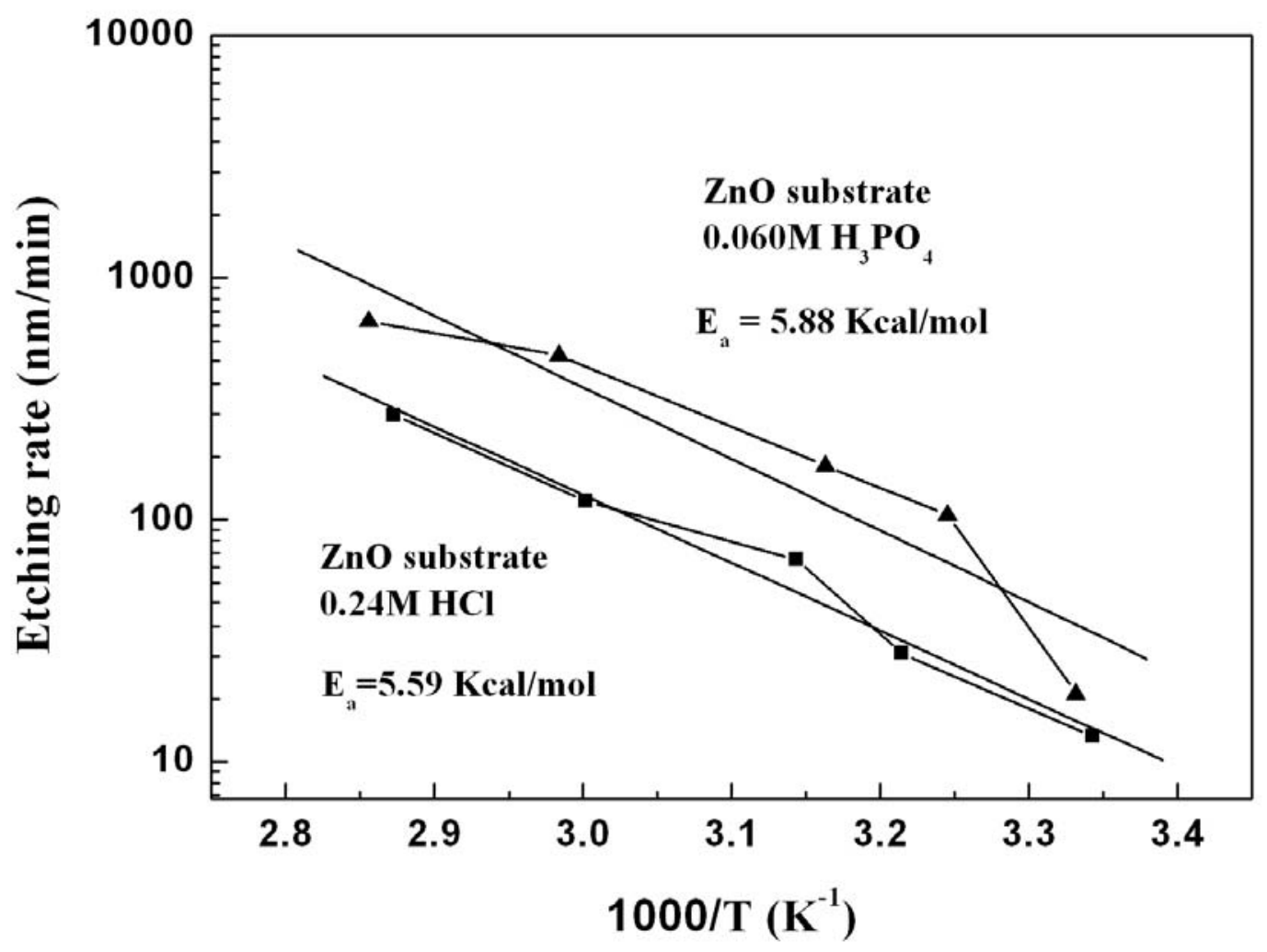

Figure 2.2.4. Arrhenius plot of etch rate of $\mathrm{ZnO}$ in $0.24 \mathrm{M} \mathrm{HCl}$ and $0.06 \mathrm{M} \mathrm{H}_{3} \mathrm{PO}_{4}$ diluted with water. 


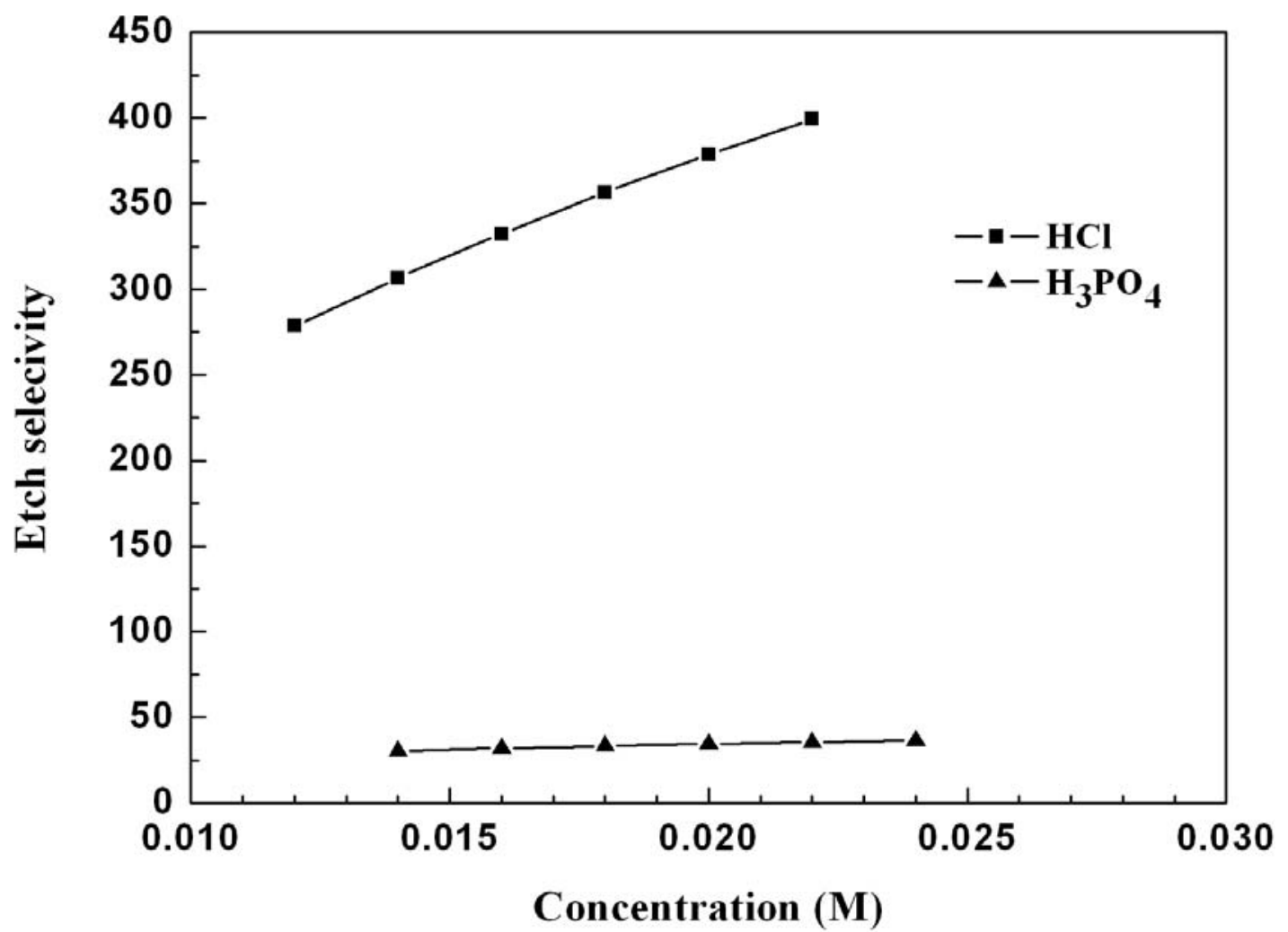

Figure 2.2.5. Etch selectivity of $\mathrm{ZnMgO}$ to $\mathrm{ZnO}$ as a function of solution concentration. 


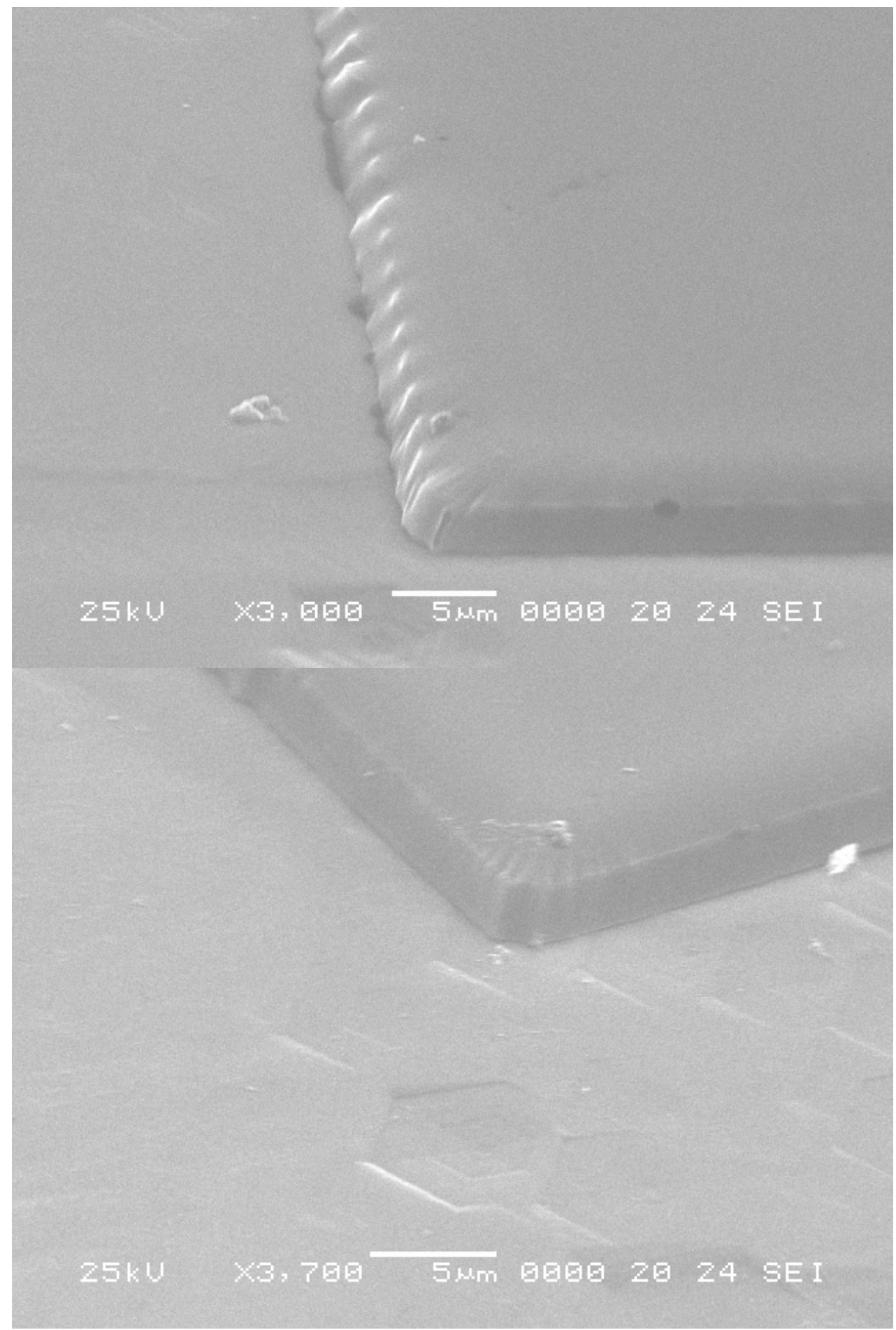

Figure 2.2.6.SEM images of $\mathrm{ZnMgO}$ selectively etched from an underlying $\mathrm{ZnO}$ layer. The photoresist mask has been removed in both cases. 
$\underline{\text { Task } 3 \text { - Fabrication of p-(Zn,Mg)O/ZnO/n-(Zn,Mg)O Heterojunctions }}$

\subsection{Synthesis and characterization of $(\mathrm{Zn}, \mathrm{Mg}) \mathrm{O}: \mathrm{P} / \mathrm{ZnO}$ heterostructures}

Summary: $\mathrm{Zn}_{0.9} \mathrm{Mg}_{0.1} \mathrm{O} / \mathrm{ZnO}$ heterostructures were grown on both sapphire and bulk $\mathrm{ZnO}$ substrates via pulsed laser deposition (PLD). Electron-beam deposited $100 \mathrm{~nm} \mathrm{Au}$ and Ti/Au (20nm/80nm) were used as the $p$-Ohmic contact and $n$-Ohmic contact, respectively. Post-annealing at above 450 of the contacts showed improved ohmic characteristics. I-V dependences showed good rectifying diode-like behaviors with threshold voltage of $1.36 \mathrm{~V}$ and $2.16 \mathrm{~V}$ for the devices fabricated on sapphire and $\mathrm{ZnO}$ substrates, respectively. 0.01 at $\% \mathrm{Al}$-doped $\mathrm{n}-\mathrm{ZnO}\left(\mathrm{n} \sim 10^{19} \mathrm{~cm}^{-}\right.$ ${ }^{3}$ ) was deposited on $\mathrm{MgO}$ buffer layer via PLD. The electrical and optical properties strongly depend on the growth temperature, working pressure and laser energy. Room temperature photoluminescence showed band edge emission at $\sim 377 \mathrm{~nm}$ with very low deep level emission. The intensity of the band edge emission increased with growth temperature and deposition laser energy. Atomic force microscopy (AFM) results also showed that the root-meansquare (RMS) roughness increases with growth temperature and oxygen partial pressure. The full-width-at-half maximum (FWHM) for the $\mathrm{ZnO}(0002)$ peak is of $0.26-0.64^{\circ}$.

Introduction: One of the critical issues in exploitation of $\mathrm{ZnO}$-related materials in optoelectronic applications is to achieve low resistivity, high carrier density p-type $\mathrm{ZnO}$. $\mathrm{ZnO}$ shows significant resistance to the formation of shallow acceptor levels. There have been several mechanisms put forward to explain these doping difficulties in wide bandgap semiconductors. First, there can be compensation by low-energy native defects such as oxygen vacancies and/or $\mathrm{Zn}$ interstitials. The defect compensates for the dopants level through the formation of a deep level complex trap. Strong lattice relaxation also can form deeper dopant energy levels within the gap. In addition, low solubility for the chosen dopant may limit the accessible extrinsic carrier density. The most promising dopants for ptype $\mathrm{ZnO}$ are group $\mathrm{V}$ elements, in particular $\mathrm{N}, \mathrm{P}$ and As. Recent breakthroughs include achieving $p$-type doping using molecular-beam epitaxy, sputtering, pulsed laser deposition and evaporation. There are several studies have been reported regarding ZnO-based LEDs. Alivov et al. reported LEDs from n-ZnO/p-AlGaN and n-ZnO/p-GaN heterostructures grown expitaxially on $\mathrm{SiC}$ substrates using hybrid vapor-phrase epitaxy combined with chemical vapor deposition. The UV LEDs emitted UV light at $389 \mathrm{~nm}$ and $430 \mathrm{~nm}$ at room temperature, respectively. Osinsky et al. also have reported electroluminescence (EL) from $\mathrm{p}-(\mathrm{Al}) \mathrm{GaN} / \mathrm{n}-\mathrm{ZnO}$ junctions. Tsukazaki et al. obtained violet $\mathrm{EL}$ from $\mathrm{ZnO}$ homojunction grown on lattice matched $\mathrm{ScAlMgO}_{4}$ substrates. Hwang et al. also reported on the diode and emission characteristics for a heterostructure of $\mathrm{p}-\mathrm{ZnO} / \mathrm{n}-\mathrm{GaN}$ fabricated via $\mathrm{RF}$ magnetic sputtering.

This section focuses on the development of $\mathrm{ZnO}$-based LEDs in the $\mathrm{ZnMgO}: \mathrm{P} / \mathrm{ZnO}$ heterostructure system. Previous study on $2 \mathrm{at} \% \mathrm{P}$-doped $\mathrm{Zn}_{0.9} \mathrm{Mg}_{0.1} \mathrm{O}$ shows oxygen partial pressure plays a significant role in converting $\mathrm{n}$-type to $\mathrm{p}$ type conductivity. The P-doped $(\mathrm{Zn}, \mathrm{Mg}) \mathrm{O}$ films grown at $150 \mathrm{mTorr}$ oxygen partial pressure were p-type and exhibited a hole concentration of $2.7 \times 10^{16} \mathrm{~cm}^{-3}$, a mobility of $8.2 \mathrm{~cm}^{2} / \mathrm{Vs}$ and a resistivity of $35 \Omega$-cm without postgrowth annealing. We have previously reported $\mathrm{ZnO}$-based p-n junctions deposited on undoped $\mathrm{ZnO}$ substrates using $\mathrm{ZnMgO}: \mathrm{P} / \mathrm{ZnO}$ heterostructure system. The use of a $\mathrm{ZnO}$ buffer on the lightly n-type $\mathrm{ZnO}$ substrate was critical in achieving acceptable rectification in the junctions. Without this buffer, the junctions showed high leakage current. In this prior work, p-type conductivity was only obtained by post-growth annealing of the P-doped $\mathrm{ZnMgO}$. In order to reduce the presence of series resistance such as the current spread resistance within the n-type $\mathrm{ZnO}$ layer, heavily Al-doped $\mathrm{ZnO}$ was grown via PLD on sapphire substrates with $\mathrm{MgO}$ buffer layer. The systematic growth condition study shows the growth temperature, oxygen working pressure and laser energy play an important role in the electrical and optical properties.

Experimental: Schematic diagrams of the $\mathrm{p}-\mathrm{ZnMgO} / \mathrm{n}-\mathrm{ZnO}$ heterostructure on both (0001) c-sapphire and $\mathrm{ZnO}$ substrate are shown in Fig. 3.1.1. The (0001) undoped grade I quality, single crystal $\mathrm{ZnO}$ substrate is obtained from Cermet. The room temperature electron concentration and mobility were $10^{17} \mathrm{~cm}^{-3}$ and $190 \mathrm{~cm}^{2} / \mathrm{Vs}$, respectively. Pulsed laser deposition was used for film growth. The 2 at $\%$ Phosphorus-doped $\mathrm{Zn}_{0.9} \mathrm{Mg}_{0.1} \mathrm{O}$ target was fabricated using high-purity $\mathrm{ZnO}(99.995 \%)$ with or without $\mathrm{MgO}$ (99.998\%), mixing with $\mathrm{P}_{2} \mathrm{O}_{5}(99.998 \%)$ as the doping agent. The addition of Mg moves the conduction band edge up in energy and potentially away from the intrinsic shallow donor state, thus increasing the activation energy of the defect donors. Sapphire and $\mathrm{ZnO}$ substrates were ultrasonically cleaned with trichloroethylene (TCE), acetone and methanol for $5 \mathrm{~min}$ and dried in $\mathrm{N}_{2}$ prior to loading into the growth chamber. The growth chamber base pressure was $1-2 \times 10^{-7}$ Torr. A KrF excimer laser with a wavelength of $248 \mathrm{~nm}$ was used as the ablation source. A laser repetition rate of $1 \mathrm{~Hz}$ was used, with a target to 
substrate distance of $4 \mathrm{~cm}$ and a laser pulse energy density of $1-3 \mathrm{~J} / \mathrm{cm}^{2}$. The $\mathrm{n}-\mathrm{ZnO}$ layer $0.6 \mu \mathrm{m}$ thick with an electron concentration of $2.53 \times 10^{18} \mathrm{~cm}^{-3}$ and mobility $36.55 \mathrm{~cm}^{2} / \mathrm{Vs}$ was grown first at $800 \mathrm{C}$ in an oxygen pressure of $100 \mathrm{mTorr}$, followed by a $0.4 \mu \mathrm{m}$ thick $\mathrm{ZnMgO}: \mathrm{P}$ layer grown at $500 \mathrm{C}$, in $150 \mathrm{mTorr} \mathrm{O}_{2}$.

Electron-bean evaporated $\mathrm{Au}(100 \mathrm{~nm})$ and $\mathrm{Ti} / \mathrm{Au}(20 \mathrm{~nm} / 80 \mathrm{~nm})$ were deposited on the $\mathrm{p}-\mathrm{ZnMgO}$ layer and $\mathrm{n}-\mathrm{ZnO}$ patterned by lift-off process. In order to improve the ohmic characteristics, the post-growth annealing at $500 \mathrm{C}$ and $450 \mathrm{C}$ in $\mathrm{N}_{2}$ for 2 min were carried out, respectively. The I-V characteristics were measured using an Agilent 4145B parameter analyzer at room temperature.

A MgO buffer layer $(\sim 200 \mathrm{~nm})$ was initially deposited at $450 \mathrm{C}$ and $10^{-4} \mathrm{mTorr}$ oxygen pressure before the growth of Al-doped $\mathrm{ZnO}$ films on sapphire substrates. The purpose of the $\mathrm{MgO}$ buffer layer is to reduce the micro-cracks resulting from the thermal expansion difference between $\mathrm{ZnMgO}$ and sapphire substrate. Table 3.1.1 shows the different growth conditions of the Al-doped $\mathrm{ZnO}$ via PLD. The film thickness of Al-doped $\mathrm{ZnO}$ is in the range of $0.75-1 \mu \mathrm{m}$. The transport properties of the as-grown films were determined using four-point Van der Pauw Hall measurements at room temperature. The photoluminescence properties of the films were also measured at room temperature using a He-Cd laser $(325 \mathrm{~nm})$. The film crystallinity and surface morphology were investigated via fourcircle X-ray Diffraction (XRD) and atomic force microscopy (AFM).

Results and discussion: Figure 3.1.2 shows the I-V curves of the Au and Ti/Au metal contacts after RTA process on $p-\mathrm{ZnMgO}$ and $n-\mathrm{ZnO}$ films measured between two square pads $(500 \times 500 \mu \mathrm{m})$ at room temperature. The I-V characteristics indicate good Ohmic contacts are formed on both electrodes. These results show that the rectifying behaviors shown in Figure 3.1.3 are due to the heterojunction of the $\mathrm{ZnMgO} / \mathrm{ZnO}$ structure and not to the semiconductor/metal contacts.

The I-V characteristics of the $\mathrm{ZnMgO}: \mathrm{P} / \mathrm{ZnO}$ heterostructure fabricated on sapphire and $\mathrm{ZnO}$ substrates are shown in Figure 3.1.3 (a) and (b), respectively. The devices show the nonlinear and rectifying diode characteristics in both structures. The extracted threshold voltages are $1.36 \mathrm{~V}$ and $2.16 \mathrm{~V}$, respectively with a low leakage current of $5 \times 10^{-}$ ${ }^{4} \mathrm{~A}$. According to the current-voltage characteristics of the real diodes equations,

$$
\begin{aligned}
& I=I_{0}\left[\exp \left(\frac{V}{n V_{i}}\right)-1\right], \\
& n=\frac{q}{k T} \frac{d V}{d \ln I},
\end{aligned}
$$

where the preexponential factor $I_{0}$ is the reverse saturation current, $V$ is the voltage at the junction, $V_{i}=k T / q$ is the thermal voltage, $\mathrm{k}$ is the Boltzmann constant, $\mathrm{T}$ is the absolute temperature, and $\mathrm{n}$ is the junction ideality factor, which is determined from the slope of the straight line of the forward bias $\log \mathrm{I}-\mathrm{V}$ characteristics. According to Eq. (2), the value of the ideality factor is about 7.6-11.8 for the $\mathrm{ZnMgO} / \mathrm{ZnO}$ heterojunction on sapphire and $\mathrm{ZnO}$ substrate, respectively. These unphysically large ideality factors may result from several current transport processes being present, including defect-assisted tunneling and conventional carrier recombination in the space-charge region via a deep level near midgap in the $\mathrm{ZnMgO}$.

Figure 3.1.4 shows the XRD data of the as-grown 0.01at\%Al-doped $\mathrm{ZnO}$ films grown under different conditions, indicating that the $\mathrm{ZnO}: \mathrm{Al}$ films are oriented with the (0001) c-axis parallel to the surface normal. The diffraction intensity of $\mathrm{ZnO}: \mathrm{Al}$ films is independent of growth conditions. To further delineate the crystallinity of the films grown under different conditions, the omega rocking curve through the (0002) plane of $\mathrm{ZnO}$ was investigated via four-circle XRD measurement. Figure 3.1.5 shows the omega rocking curve of $\mathrm{ZnO}$ :Al films grown via using 300 $\mathrm{mJ}$ laser energy. The full-width-at-half-maximum (FWHM) values of the $\mathrm{ZnO}$ :Al films are in the range of 0.26$0.64^{\circ}$.

Electrical properties of the $\mathrm{ZnO}: \mathrm{Al}$ films was investigated via using four-point Van der Pauw Hall measurement at room temperature. Table 3.1.2 shows the resistivity, electron concentration and mobility of the films grown under different conditions. The films show carrier concentration of $10^{18}-10^{19} \mathrm{~cm}^{-3}$ and mobility of $40-60 \mathrm{~cm}^{2} / \mathrm{Vs}$. Room temperature PL was used to study the optical properties of the films. Figure 7 shows the deposition laser energy 
effect on PL for the films grown at $700 \mathrm{C}$ and $800 \mathrm{C}$, respectively. The films exhibited strong band edge photoluminescence at $\sim 377 \mathrm{~nm}$ at room temperature with very low deep level emission. The band edge emission increases significantly with increasing laser energy and growth temperature. With decreasing growth temperature the deposition laser energy shows more prominent effect on the band edge emission. This might result from the improved film crystallinity with increasing the growth temperature. The oxygen partial pressure effect on the optical properties of the $\mathrm{ZnO}: \mathrm{Al}$ films is shown in Figure 3.1.7. The films grown at $800 \mathrm{C}, 50$ mTorr oxygen pressure show the highest band edge emission. Note that the band edge emission intensity does not have linear dependence on the oxygen partial pressure. For the $\mathrm{ZnO}: \mathrm{Al}$ films grown under different conditions, there is a correlation between the intensity of the band edge emission and the electron concentration. The UV luminescence increases with the electron concentration. With increasing the electron concentration, the Fermi energy will be increased closer to the conduction band. Therefore, more mid-bandgap defect levels will be filled. The probability of a band edge radiative transition will be increased. This also explains the low probability of the radiative transition into the deep defect levels.

The surface morphology of the films grown in different growth conditions is shown in figure 3.1.8. The scan area is $5 \times 5 \mu \mathrm{m}^{2}$. The root-mean-square roughness (RMS) increased as the growth temperature and oxygen partial pressure increase. 


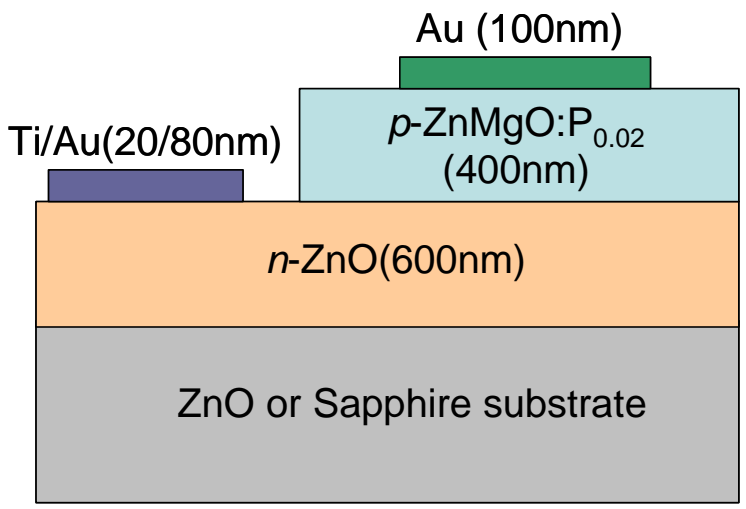

Figure 3.1.1: Schematic diagram of $\mathrm{ZnMgO}: \mathrm{P} / \mathrm{ZnO}$ heterostructure. 

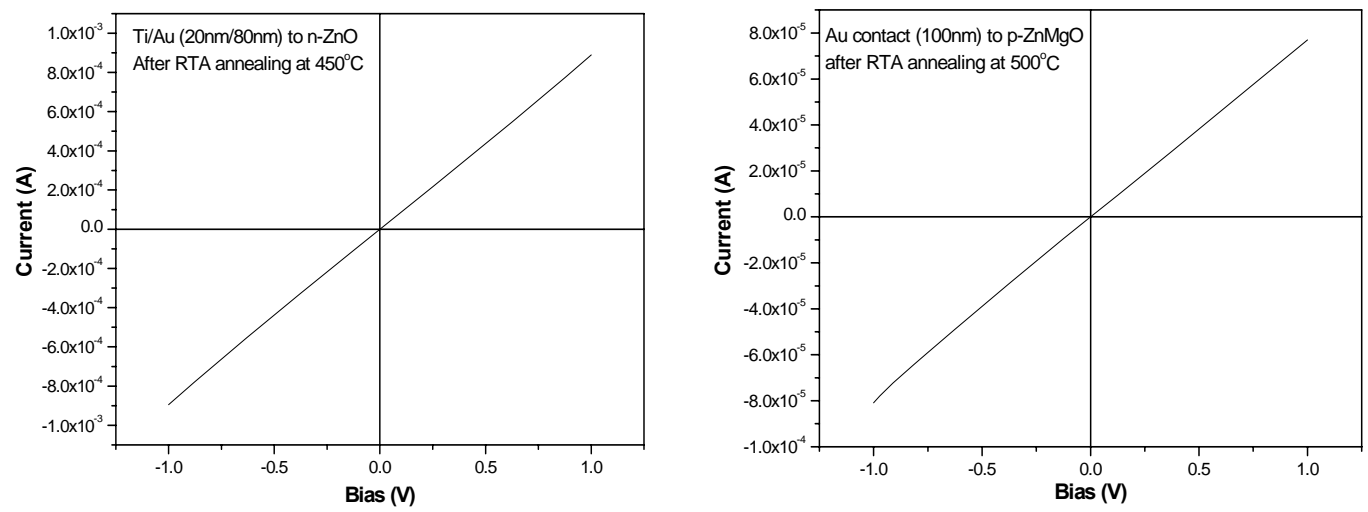

Figure 3.1.2 The I-V curve of $\mathrm{Au}$ and $\mathrm{Ti} / \mathrm{Au}$ metal contacts on $\mathrm{p}-\mathrm{ZnMgO}$ and $\mathrm{n}-\mathrm{ZnO}$ films. 


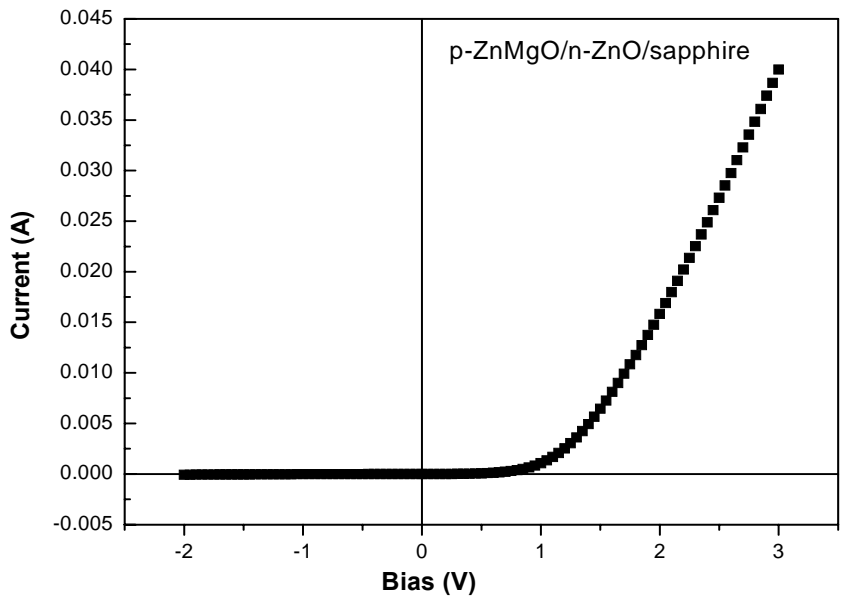

(a)

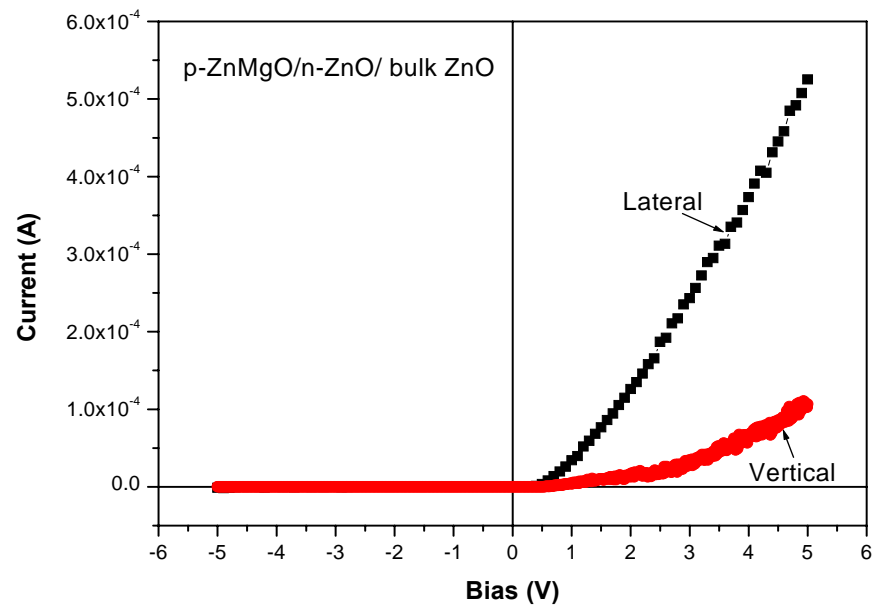

(b)

Figure 3.1.3: Current-voltage characteristics of the $\mathrm{ZnMgO} / \mathrm{ZnO}$ heterostructure on (a) sapphire, (b) $\mathrm{ZnO}$ substrate. 


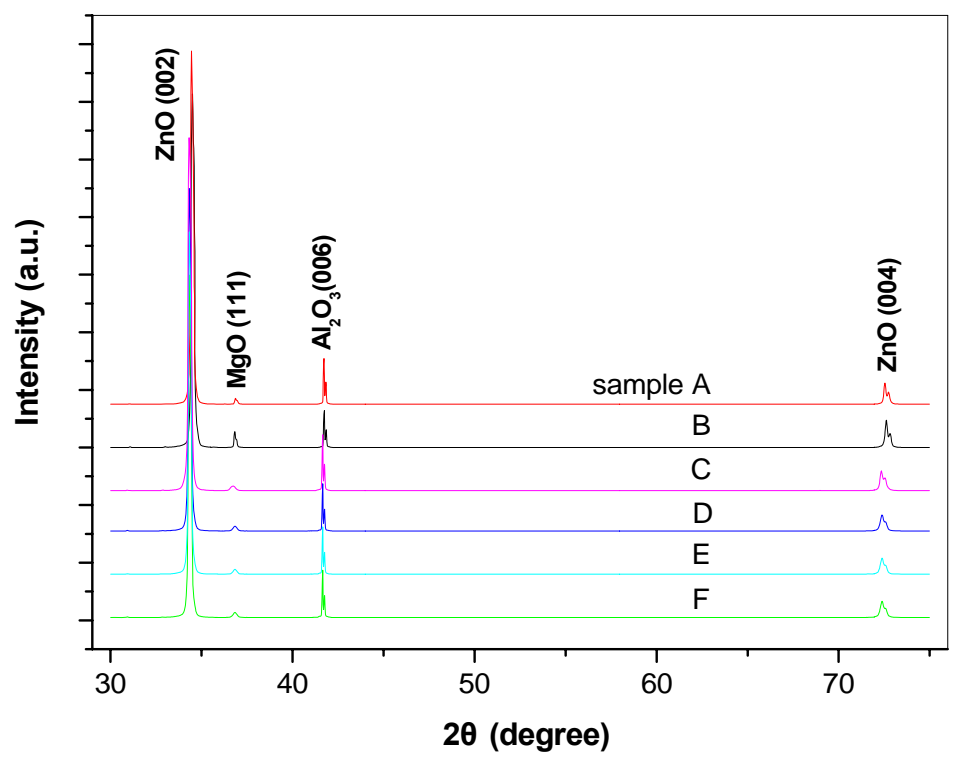

Figure 3.1.4: X-ray diffraction data for 0.01at\%Al-doped $\mathrm{ZnO}$ films grown under different conditions. 


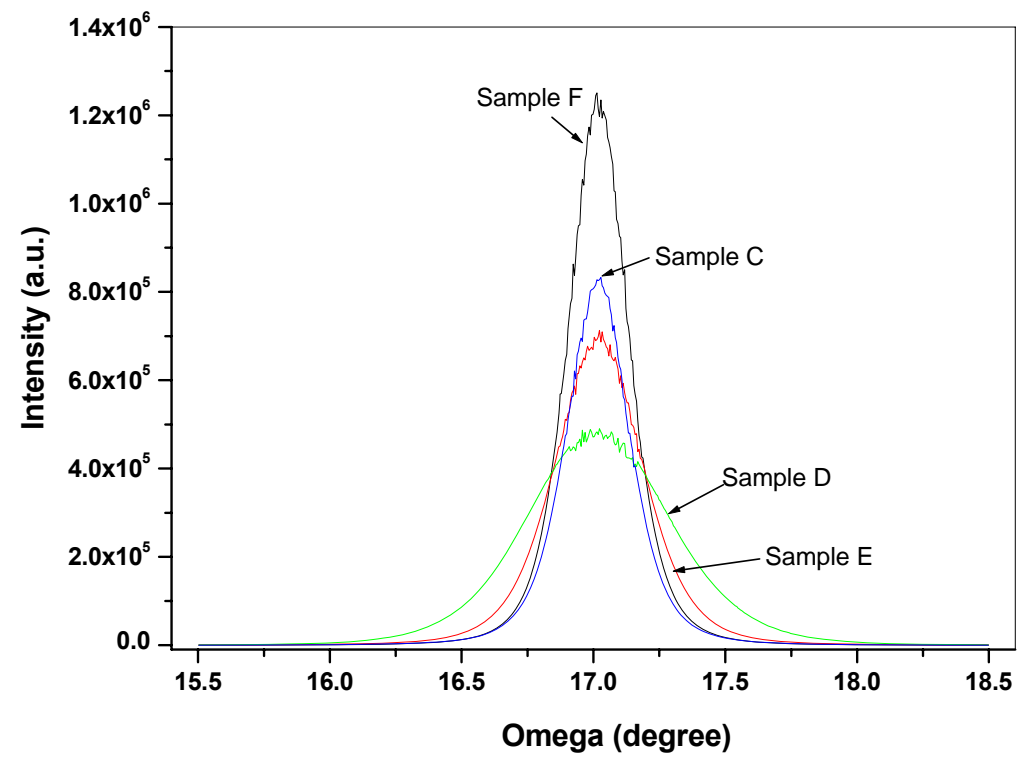

Figure 3.1.5: Omega rocking curve of $\mathrm{ZnO}$ (0002) peak for 0.01at\%Al-doped $\mathrm{ZnO}$ films grown under $300 \mathrm{~mJ}$ laser energy. 

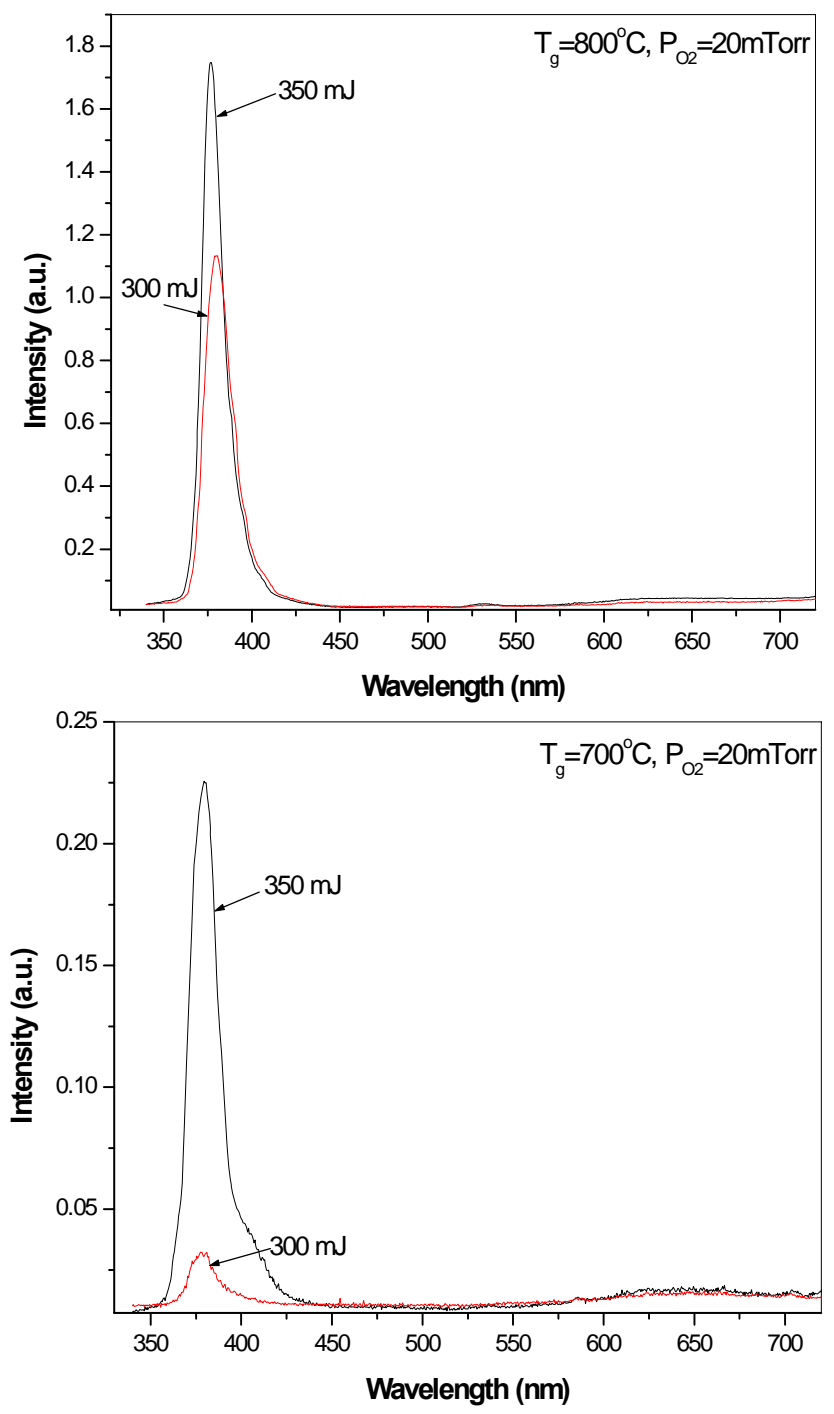

Figure 3.1.6: Laser energy effect on room temperature PL of 0.01at\%Al-doped $\mathrm{ZnO}$ films grown under different growth temperature. 


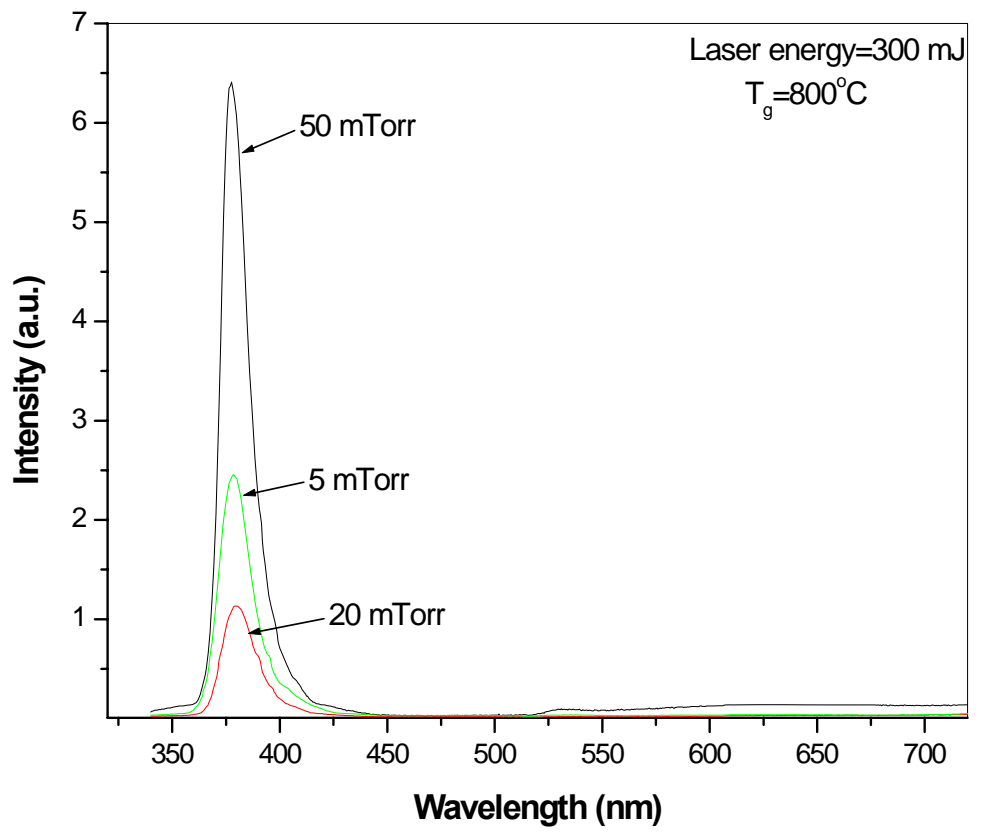

Figure 3.1.7: Oxygen partial pressure effect on room temperature PL of 0.01 at $\% \mathrm{Al}$-doped $\mathrm{ZnO}$ films. 

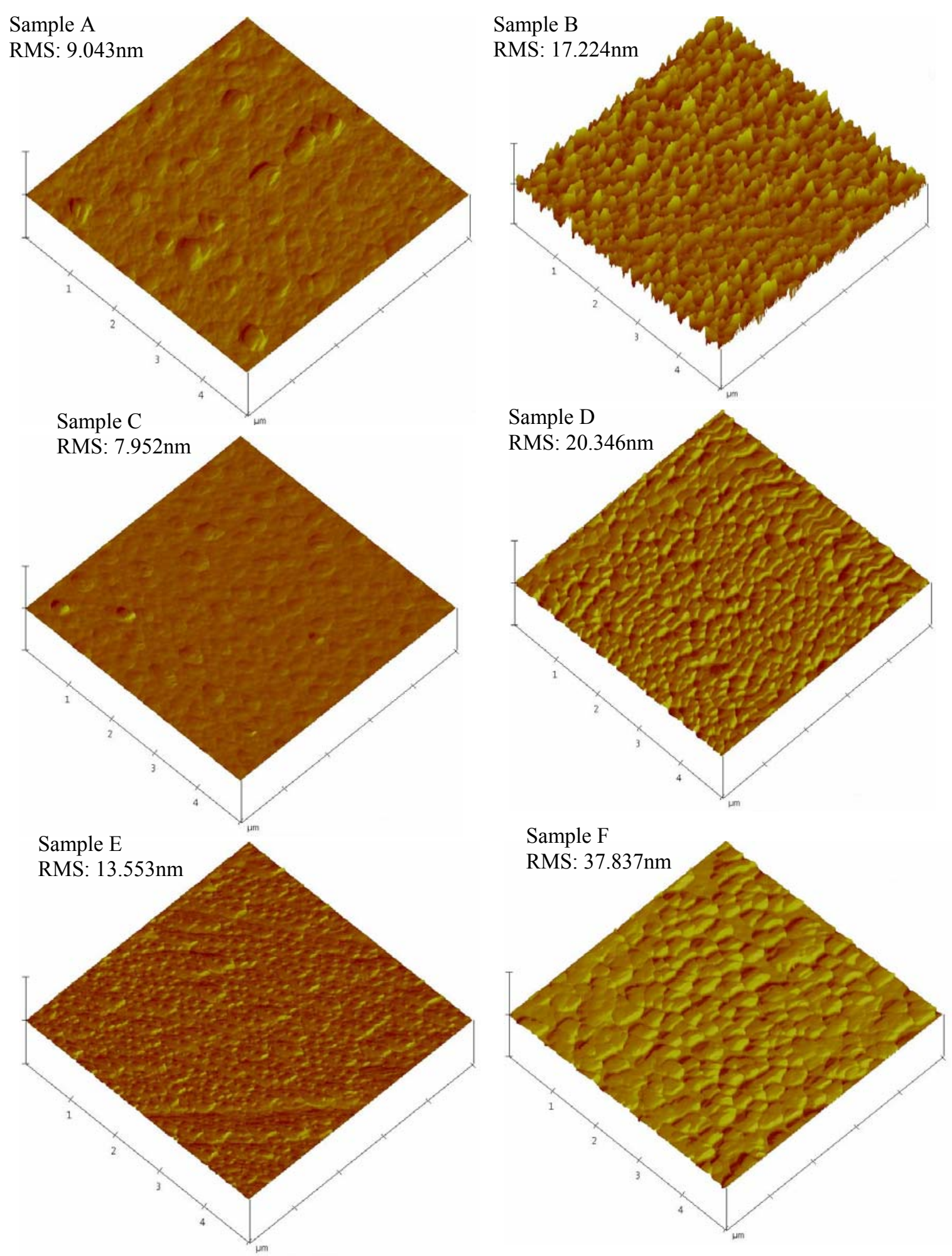

Figure 3.1.8: AFM scans of 0.01at\%Al-doped $\mathrm{ZnO}$ films grown under different conditions. The z-scale is 40 $\mathrm{nm} / \mathrm{div}$. 


\begin{tabular}{ccccc}
\hline \hline Sample & $\operatorname{Tg}(\mathrm{C})$ & $\begin{array}{c}\text { Oxygen pressure } \\
(\text { mTorr })\end{array}$ & $\begin{array}{c}\text { Laser } \\
\text { energy (mJ) }\end{array}$ & layer \\
\hline A & 700 & 20 & 350 & \\
B & 800 & 20 & 350 & MgO \\
C & 700 & 20 & 300 & \\
D & 800 & 20 & 300 & \\
E & 800 & 5 & 300 & \\
F & 800 & 50 & 300 & \\
\hline \hline
\end{tabular}

Table 3.1.1. Growth conditions of 0.01 at $\% \mathrm{Al}$-doped $\mathrm{ZnO}$ films via pulsed laser deposition. 


\begin{tabular}{clllc}
\hline \hline Sample & $\begin{array}{c}\text { Resistivity } \\
(\mathrm{ohm} \mathrm{cm})\end{array}$ & $\begin{array}{l}\text { Carrier density } \\
\left(\mathrm{cm}^{-3}\right)\end{array}$ & $\begin{array}{c}\text { Carrier } \\
\text { mobility }\left(\mathrm{cm}^{2} / \mathrm{Vs}\right)\end{array}$ & $\begin{array}{c}\text { Carrier } \\
\text { type }\end{array}$ \\
\hline $\mathrm{A}$ & $1.2376 \times 10^{-4}$ & $7.82 \times 10^{18}$ & 62.73 & $\mathrm{n}$ \\
$\mathrm{B}$ & $1.3656 \times 10^{-4}$ & $1.158 \times 10^{19}$ & 39.48 & $\mathrm{n}$ \\
$\mathrm{C}$ & $1.142 \times 10^{-1}$ & $1.399 \times 10^{18}$ & 39.12 & $\mathrm{n}$ \\
$\mathrm{D}$ & $9.375 \times 10^{-3}$ & $1.32 \times 10^{19}$ & 50.45 & $\mathrm{n}$ \\
$\mathrm{E}$ & $8.336 \times 10^{-3}$ & $1.329 \times 10^{19}$ & 56.36 & $\mathrm{n}$ \\
$\mathrm{F}$ & $1.1285 \times 10^{-2}$ & $9.094 \times 10^{18}$ & 60.85 & $\mathrm{n}$ \\
\hline \hline
\end{tabular}

Table 3.2.2. Room temperature Hall measurement of 0.01at\%Al-doped $\mathrm{ZnO}$ films under different growth conditions. 


\subsection{Design and Simulation of ZnO-based Light-Emitting Diode Structures}

Summary: Two different types of $\mathrm{ZnO}$-based light-emitting diode structures have been examined using a 1-D simulator that accounts for specific features of the hexagonal semiconductors - strong piezoeffects, existence of spontaneous electric polarization, low efficiency of acceptor activation, and high threading dislocation density (normally, $\sim 10^{7}-10^{9} \mathrm{~cm}^{-2}$ ) in the material. A hybrid $\mathrm{ZnO} / \mathrm{CdZnO} / \mathrm{AlGaN} / \mathrm{GaN}$ structure grown on sapphire avoids problems in achieving robust p-type doping in $\mathrm{ZnO}$. An all- $\mathrm{ZnO}$ approach employs a $\mathrm{MgZnO} / \mathrm{CdZnO} / \mathrm{MgZnO}$ double heterostructure grown on a $\mathrm{ZnO}$ substrate .Both structures show a strong sensitivity of emission intensity to doping and layer thicknesses within our simulations.

Introduction:

An important factor in the design of ZnO-based LED is the realization of bandgap engineering to create barrier layers and quantum wells in heterostructures. With respect to higher bandgaps, an increase up to $4.0 \mathrm{eV}$ has been achieved by the incorporation of $\mathrm{Mg}$ in the $\mathrm{ZnO}$ layer while still maintaining the wurtzite structure. Ternary $\mathrm{ZnCdO}$ seems to be an appropriate candidate for narrow bandgap because of the smaller bandgap of CdO. $(2.3 \mathrm{eV})$. In addition, when grown on c-plane sapphire, analogous to III-nitride, the total polarization of $\mathrm{ZnO}$ is aligned along the [0001] growth direction. Thus, the polarization-induced fields may influence the electronic band structure and carrier concentration profiles of $\mathrm{ZnO}$-base LEDs. Although many factors need to be considered in designing $\mathrm{ZnO}-$ based LED, no comprehensive investigation on optimized device structures and their expected performance is currently available. Therefore, there is a clear need for providing some design parameters for the LED structures in terms of layer structure, doping and composition and how they effect light emission intensity and current-voltage (IV) characteristics.

In this section, we describe some simulation results for both the hybrid $\mathrm{ZnO} / \mathrm{ZnCdO} / \mathrm{ZnO} / \mathrm{AlGaN} /$ $\mathrm{GaN} /$ sapphire substrate structures and the $\mathrm{ZnMgO} / \mathrm{ZnCdO} / \mathrm{ZnO} / \mathrm{ZnMgO}$ substrate LEDs. These results will be used to identify the most important parameters for achieving high brightness and high performance.

Experimental:

The simulation program used in this study was SiLENSe ${ }^{\mathrm{TM}}$ code. This is a 1-D simulator which can build a band diagram, carrier injection and recombination, and light emission profiles in wide bandgap LED heterostructures. The SiLENSe 2.1 version is capable of simulating heterostructures made not only of group-III nitrides, but also of other wurtzite semiconductors (for example, $\mathrm{ZnMgO}$ alloys) including hybrid structures. The LED operation of the heterostructure is considered within the framework of the 1-D drift diffusion model of carrier transport that accounts for specific features of the nitride semiconductors - strong piezoeffect, existence of spontaneous electric polarization, low efficiency of acceptor activation, and high threading dislocation density (normally, $\sim 10^{7}-10^{9} \mathrm{~cm}^{-2}$ ). Along with bimolecular radiative electron and hole recombination, an original model of non-radiative carrier recombination at threading dislocation cores is also considered. The latter allows an analysis of the interaction between the radiative and non-radiative recombination channels and predicts the internal emission efficiency of the LED structure as a function of threading dislocation density. The spectrum of light emission from a single- or multiple-quantum-well active region can be calculated to account for the complex valence band structure of wurtzite semiconductors by using the $8 \times 8$ Kane Hamiltonian. Energies and wave functions of localized carrier states are found by a numerical solution of the Schrödinger equation within the effective-mass approximation. Generation of the grid for each QW is totally automated.

The model implemented into the code incorporates the following: (i) localized and distributed polarization charges in the LED structure induced by both spontaneous and piezo-polarization in nitride semiconductors; (ii) Fermi statistics for electrons and holes for both degenerate and non-degenerate semiconductors; (iii) partial ionization of donors and acceptors depends on the respective quasi-Fermi level positions; (iv) strain calculations in the LED structure assume coherent growth of all epilayers on an underlying buffer layer; (v) bimolecular radiative electron and hole recombination neglects quantum-confined effects on the recombination rate; and (vi) non-radiative carrier recombination in the principal channel and on threading dislocation cores. The LED I-V characteristics are calculated by the software at a given serial resistance that is assumed to account for both the lateral current spreading in the LED chip and Ohmic contact resistances. Moreover, the light emission spectra are determined with a post-processing module that uses the calculated band profiles of the LED structure and takes into account the 
complex structure of the valence band of nitride materials and the contribution of the confined electronic states.

In our simulations we used the available $\mathrm{ZnMgCdO}$ material parameters, but not all the required parameters are available. For example, the band-offsets between $\mathrm{ZnMgO} / \mathrm{ZnO}$ and $\mathrm{ZnCdO} / \mathrm{ZnO}$ are not known. Whenever the required parameter was unavailable we used preliminary values obtained from X-Ray Photoelectron Spectroscopy for samples grown by MBE on c-plane sapphire. Given the preliminary nature of the available data, the simulated results should be used as a guide for identifying important parameters in the LED design rather than as definitive.

Results and discussion

(a) Hybrid $\mathrm{ZnO} / \mathrm{GaN}$ LEDs

In our previous work, we observed that hybrid $\mathrm{ZnMgO} / \mathrm{ZnO} / \mathrm{AlGaN} / \mathrm{GaN}$ LEDs grown on sapphire substrates showed clean interfaces between the various layers as shown in the transmission electron microscopy images of Fig. 3.2.1(a). Moreover, the fabricated LED with this structure operated above $650 \mathrm{~K}$, as observed in temperature dependent electroluminescence spectrum. (Fig. 3.2.1(b)). The band structures of various $\mathrm{MgZnO} / \mathrm{AlGaN} / \mathrm{GaN}$ heterojunctions were also simulated, revealing strong hole confinement near the $\mathrm{n}-\mathrm{ZnO} / \mathrm{p}-\mathrm{AlGaN}$ interface with a hole sheet density up to $1.8 \times 10^{13} \mathrm{~cm}^{-2}$. The formation of a hole accumulation layer and a triangular well near the hybrid heterointerface can increase the probability of radiative recombination under forward bias. To achieve a broader range of emission wavelengths, $\mathrm{ZnCdO}$ active regions have been considered essential due to the controllability of bandgap. Thus, we designed $\mathrm{n}-\mathrm{ZnO} / \mathrm{p}-\mathrm{AlGaN}$ structure with $\mathrm{ZnCdO}$ active region.

The schematic cross-sectional diagram of hybrid $\mathrm{ZnO} / \mathrm{GaN}$ structure and its band diagram are displayed in Fig. 3.2.2. The range of the various parameters used in this simulation study is summarized in Table 3.2.1. The active region is sandwiched by triangular wells arising from the polarization contribution at the interfaces. This implies that the carriers are effectively confined in the active region which can increase the probability of radiative recombination under forward bias. Introduction of the $\mathrm{ZnMgO} / \mathrm{ZnO}$ heterojunction provides an additional confinement for electrons injected into the $\mathrm{ZnCdO}$ active region.

The simulated $I-V$ characteristics did not show any significant dependence on either the thickness (in the range $50 \sim 250 \mathrm{~nm}$ ) or Cd composition of the active layer (in the range 0.03 0.07). However, the doping level in the active region had a clear influence, as shown in Fig. 3.2.3. At very low doping levels $\left(\sim 10^{16} \mathrm{~cm}^{-3}\right)$, the active region is depleted and the additional resistance pushes out the $I-V$ characteristic.

Figure 3.2.4 shows the emission spectra as a function of the active layer thickness (Fig. 3.2.4(a)) and doping (Fig. 3.2.4(b)) for the $\mathrm{ZnO} / \mathrm{ZnCdO} / \mathrm{ZnO} / \mathrm{AlGaN} / \mathrm{GaN}$ structure. These results indicate that there is a significant increase in emission intensity for highly doped active regions, but only a small dependence on the active layer thickness above the limit for quantum wells. The simulated emission wavelength at $\sim 370 \mathrm{~nm}$ is shorter than expected, due to the uncertainty concerning $\mathrm{ZnCdO}$ material parameters, including discontinuities and bowing parameter. The experimental band gap of our $\mathrm{ZnCdO}$ is $\sim 2.9 \mathrm{eV}$ and, therefore, we would expect the emission wavelength to be $\sim 2.9 \mathrm{eV}$ or shorter due to triangular wells arising from the polarization contribution at the interfaces. However, in previous work on $\mathrm{ZnCdO}$ alloy films, the actual energy band gap of $5 \% \mathrm{Cd}$ alloyed $\mathrm{ZnCdO}$ film was determined to be $\sim 3.07 \mathrm{eV}$ and a reliable bowing parameter between $\mathrm{ZnO}$ and $\mathrm{CdO}$ is not available in the literature. In our simulations we used experimental data from ref 18 , and assumed that the emission intensity is a function of material parameters.

Some additional parameters that had a significant effect on ZnO LED characteristics were obviously the Cd composition of the active layer (Fig. 3.2.5 (a)) and the thickness and composition of the top and bottom cladding layers (Fig. 3.2.5 (b) and 3.2.5 (c)). The light output is red-shifted as the Cd concentration increases, leading to a smaller bandgap of the $\mathrm{ZnCdO}$. On the other hand, the $I-V$ characteristics were degraded by increasing the bandgap of the top and bottom cladding layers through $\mathrm{Mg}$ doping. These layers reduced the light output at fixed bias relative to the output when pure $\mathrm{ZnO}$ cladding layers were used. This implies that increasing the bandgap of the cladding layer is beneficial only when quantum wells are used to achieve better carrier confinement.

\section{(b) ZnMgO/ZnCdO LEDs}

Figure 3.2.6 shows a schematic of the $\mathrm{MgZnO} / \mathrm{ZnCdO} / \mathrm{MgZnO}$ structure on a $\mathrm{ZnO}$ substrate and a corresponding band diagram simulated with this structure. The bias condition in the band diagram was $0 \mathrm{~V}$. The range of the various parameters for the simulations is summarized in Table 3.2.2. The triangular wells arising from the polarization contribution at the interfaces were observed, but their magnitudes are much smaller than those for the hybrid $\mathrm{ZnO} / \mathrm{GaN}$ structure. Our preliminary results have yielded only small band offsets in the $\mathrm{ZnMgO} / \mathrm{ZnO}$ system $(\sim 0.14 \mathrm{eV}$ in the conduction band and $0.02 \mathrm{eV}$ in the valence band at $\sim 5$ at. $\% \mathrm{Mg})$. Thus, we expect that the use of $\mathrm{Cd}$ to reduce the bandgap should increase these offsets.

The simulated emission spectra from $\mathrm{MgZnO} / \mathrm{ZnCdO} / \mathrm{MgZnO}$ as a function of active layer parameters are 
shown in Fig. 3.2.7. There is an increase in light output intensity with both active layer thickness and Cd composition, as well as the expected red shift of the wavelength with increasing $\mathrm{Cd}$ content. Alternatively, the dependence of doping concentration on emission intensity was not significant when compared to that for thickness and doping. The series resistance of the active layer had no observable effect on the $I-V$ characteristics. This indicates that the LED optical properties are very sensitive to the physical parameters of the active region, so that optimization of the active layer design needs to focus on the emission properties rather than the electrical ones.

The simulated emission wavelength is obviously strongly dependent on the active layer composition and the choice of bowing parameters. Figure 3.2.8 shows both experimental data for the emission wavelength of $\mathrm{CdZnO}$ as a function of composition determined by Rutherford Backscattering measurements and peak emission taken from the simulated spectral data for DHSs with different mole fraction of $\mathrm{Cd}$ as a function of Cd mole fraction. Since there is no phase separation in the $\mathrm{CdZnO}$ films, as confirmed by $\mathrm{CL}$ emission mapping, this fit is a practical calibration for adjustment of bowing parameters for $\mathrm{CdZnO}$ band gap dependence. In our case we use a bowing parameter of around 6 for a Cd composition of 5\%.

As the $\mathrm{ZnMgO}$ cladding layer thickness was increased, the $I-V$ characteristics showed somewhat greater series resistance. On the other hand, the cladding layer thickness did not have much influence on the emission intensity. The most important effect of the cladding layers was the effect that the $\mathrm{Mg}$ composition had on the $I-V$ characteristics (Fig. 3.2.9(a)) because of the increased series resistance at high $\mathrm{Mg}$ content which also affected the emission intensity. (Fig. 3.2.9(b)). The doping of the cladding layer also affected the $I-V$ characteristics (Fig. 3.2.9(c)), but had only a minor impact on emission intensity. 
Table 3.2.1. Simulated parameters conducted in $\mathrm{ZnO} / \mathrm{ZnCdO} / \mathrm{ZnO} / \mathrm{AlGaN} / \mathrm{GaN}$ structure. Bolded conditions in the table correspond to the referenced ones in Fig.2.

\begin{tabular}{|c|c|}
\hline Parameters & Conditions \\
\hline Active layer thickness & $50,100, \mathbf{1 5 0}, 200(\mathrm{~nm})$ \\
\hline Active layer doping & $10^{16}, 10^{17}, \mathbf{1 0}^{18}, 10^{19}\left(\mathrm{~cm}^{-3}\right)$ \\
\hline Active layer composition & $\mathrm{Cd}$ composition: $0.03, \mathbf{0 . 0 5}, 0.07$ \\
\hline Top cladding layer composition \& & $\mathbf{1 0}, 20,30(\mathrm{~nm})$, \\
thickness & $\mathrm{Mg}: 0.1,0.2$ \\
\hline Bottom cladding layer composition \& & $\mathbf{2 0}, 30,40(\mathrm{~nm})$, \\
thickness & $\mathrm{Mg}: 0.1,0.2$ \\
\hline
\end{tabular}


Table 3.2.2. Simulated parameters conducted in $\mathrm{MgZnO} / \mathrm{ZnCdO} / \mathrm{MgZnO}$ structure. Bolded conditions in the table correspond to the referenced ones in Fig.3.2.6.

\begin{tabular}{|c|c|}
\hline Parameters & Conditions \\
\hline Active layer thickness & $30,50,75, \mathbf{1 0 0}, 150,200(\mathrm{~nm})$ \\
\hline Active layer doping & Undoped, $10^{15}, 10^{16}, 10^{17}, 10^{18}, 10^{19}\left(\mathrm{~cm}^{-3}\right)$ \\
\hline Active layer composition & Cd composition: $0.03, \mathbf{0 . 0 5}, 0.07$ \\
\hline Cladding layer thickness & $300, \mathbf{4 0 0}, 500(\mathrm{~nm})$ \\
\hline Cladding layer doping & $10^{16}, 10^{17}, \mathbf{1 0} \mathbf{1 0}^{18}, 10^{19}\left(\mathrm{~cm}^{-3}\right)$ \\
\hline Cladding layer composition & Mg composition: $0.05, \mathbf{0 . 1}, 0.15,0.2,0.3$ \\
\hline
\end{tabular}




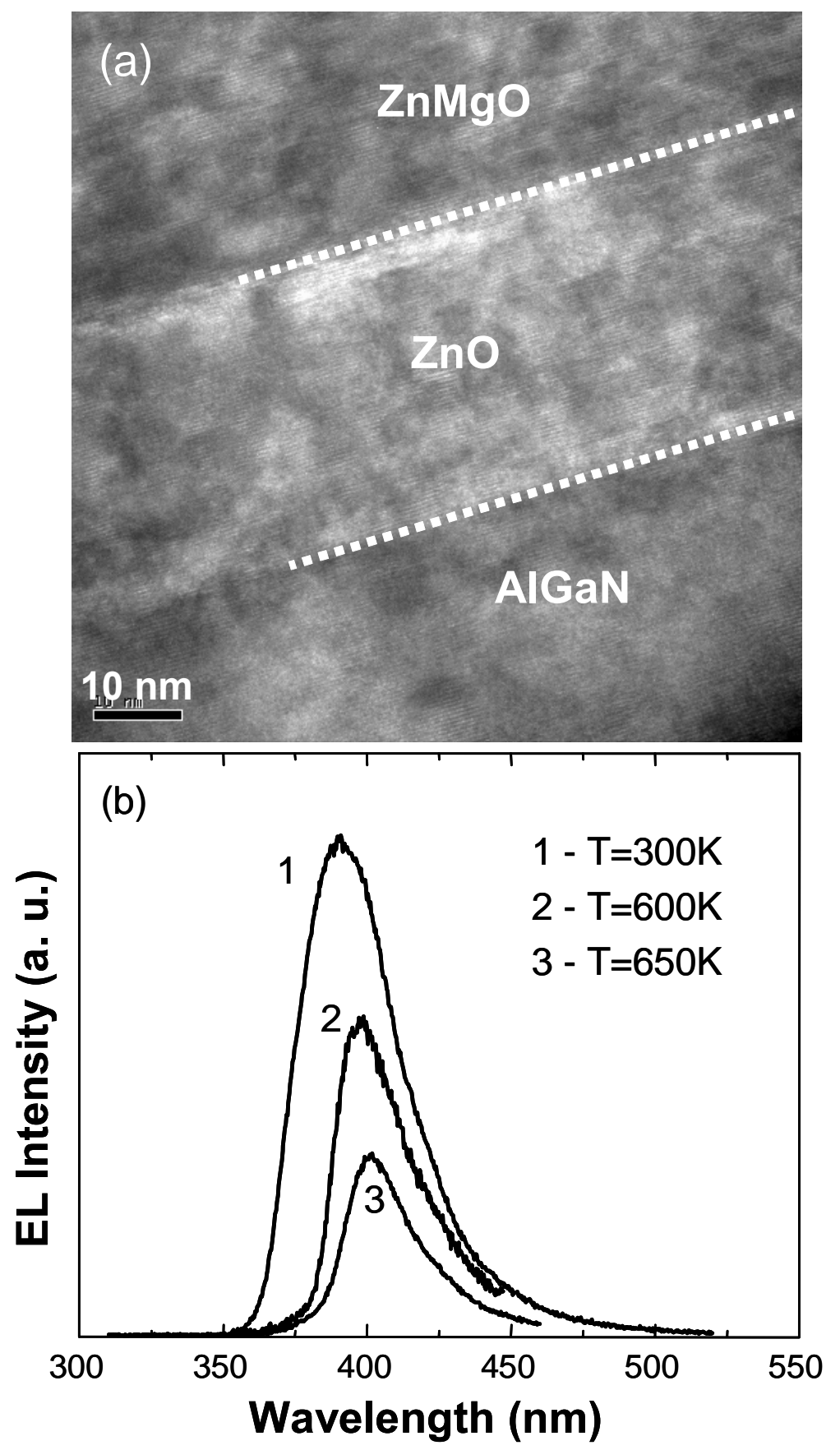

Figure 3.2.1. (a) Cross-sectinnal TEM image and (b) temperature dependent EL spectrum in $\mathrm{ZnMgO} / \mathrm{ZnO} / \mathrm{AlGaN}$ /GaN LED. 
(a)

\begin{tabular}{|c|}
\hline $\begin{array}{c}100 \mathrm{~nm} \mathrm{ZnO},(\mathrm{Ga}) \\
\mathrm{n} \sim 10^{19} \mathrm{~cm}^{-3}\end{array}$ \\
\hline $\begin{array}{c}300 \mathrm{~nm} \mathrm{ZnO},(\mathrm{Ga}) \\
\mathrm{n} \sim 10^{18} \mathrm{~cm}^{-3}\end{array}$ \\
\hline $\begin{array}{l}10 \mathrm{~nm} \mathrm{ZnO} \\
\mathrm{n} \sim 10^{17} \mathrm{~cm}^{-3}\end{array}$ \\
\hline $\begin{array}{c}150 \mathrm{~nm} \mathrm{ZnCdO}, \\
\mathrm{n} \sim 10^{18} \mathrm{~cm}^{-3}\end{array}$ \\
\hline $\begin{array}{l}20 \mathrm{~nm} \mathrm{ZnO} \\
\mathrm{n} \sim 10^{17} \mathrm{~cm}^{-3}\end{array}$ \\
\hline $\begin{array}{c}30 \mathrm{~nm} \mathrm{Al}_{0.12} \mathrm{Ga}_{0.88} \mathrm{~N},(\mathrm{Mg}) \\
\mathrm{p} \sim 10^{17} \mathrm{~cm}^{-3}\end{array}$ \\
\hline $\begin{array}{c}1000 \mathrm{~nm} \mathrm{GaN},(\mathrm{Mg}) \\
\mathrm{p} \sim 10^{17} \mathrm{~cm}^{-3}\end{array}$ \\
\hline $600 \mathrm{~nm}$ undoped GaN \\
\hline $30 \mathrm{~nm}$ AIN \\
\hline 2" c-plane sapphire \\
\hline
\end{tabular}

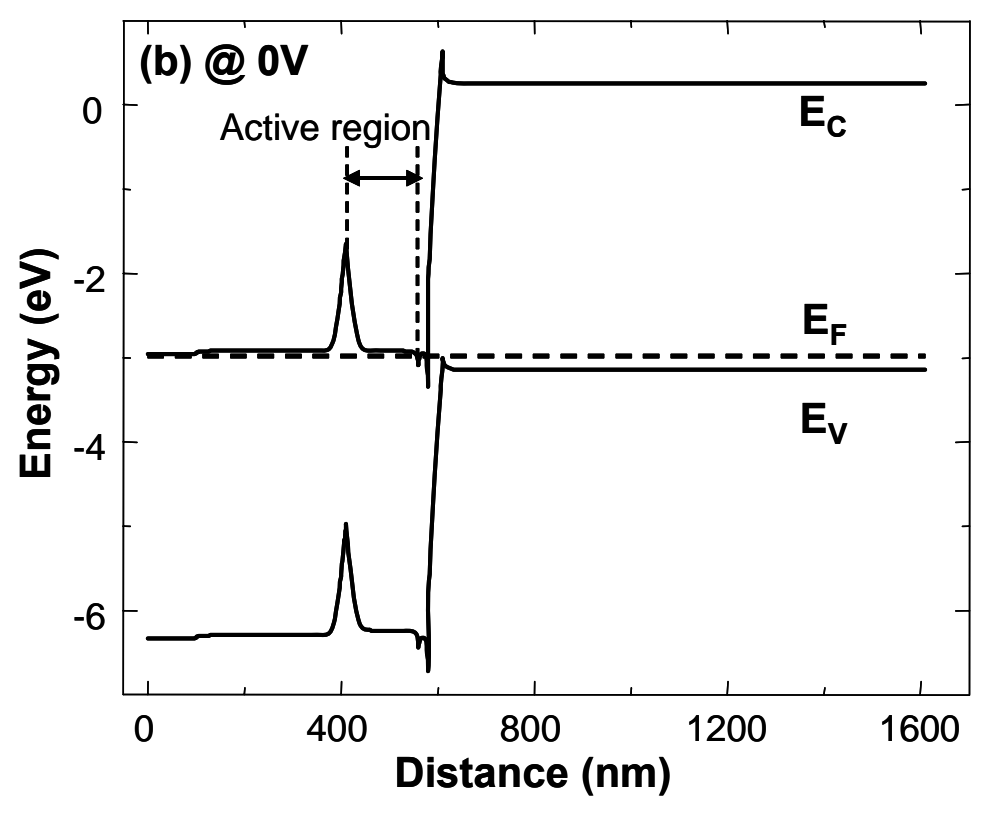

Figure 3.2.2. (a) Schematic of $\mathrm{ZnO} / \mathrm{ZnCdO} / \mathrm{ZnO} / \mathrm{AlGaN} / \mathrm{GaN}$ structure simulated and (b) its band diagram. 


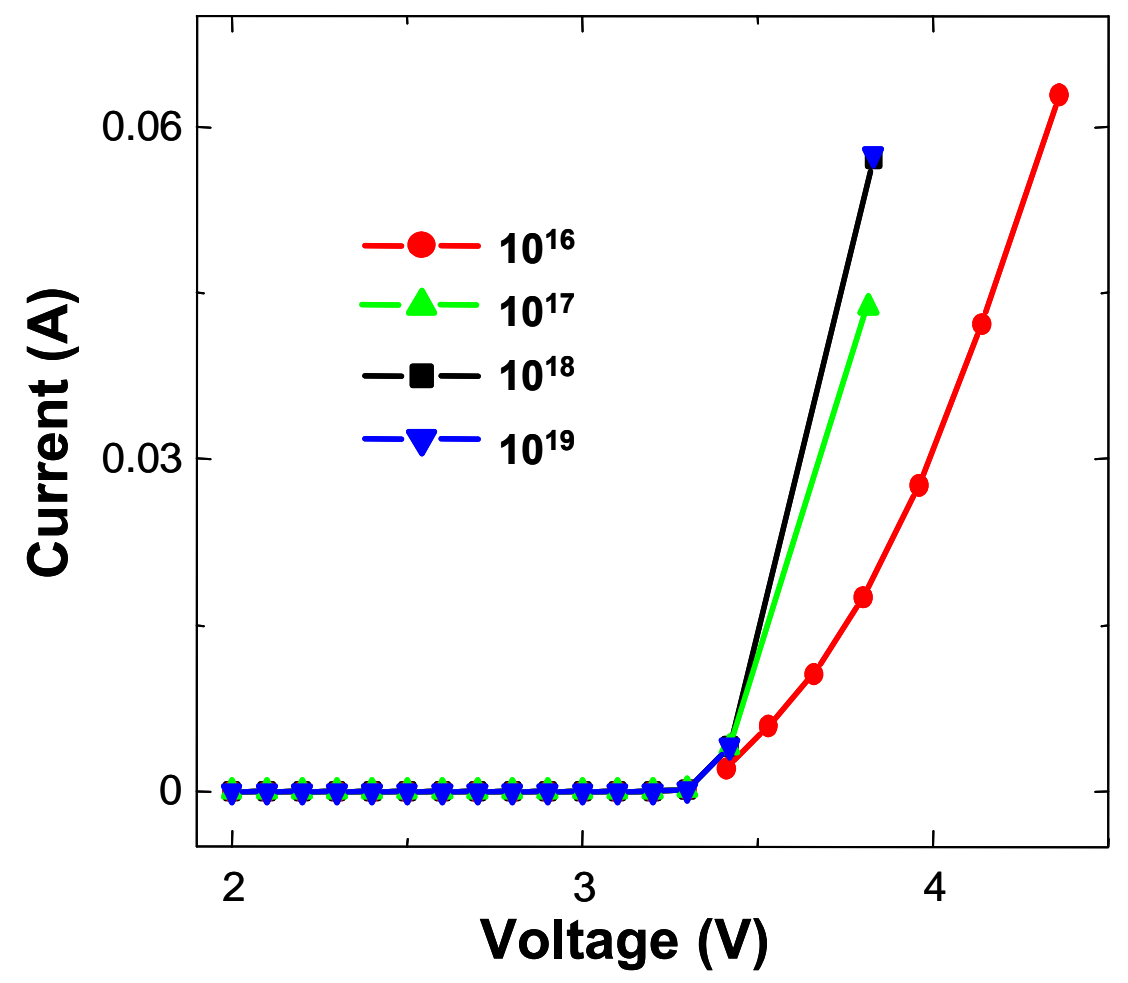

Figure 3.2.3. Simulated $I-V$ characteristics of $\mathrm{ZnO} / \mathrm{ZnCdO} / \mathrm{ZnO} / \mathrm{AlGaN} / \mathrm{GaN}$ structure as a function of active layer doping at fixed Cd composition of 0.05 . 

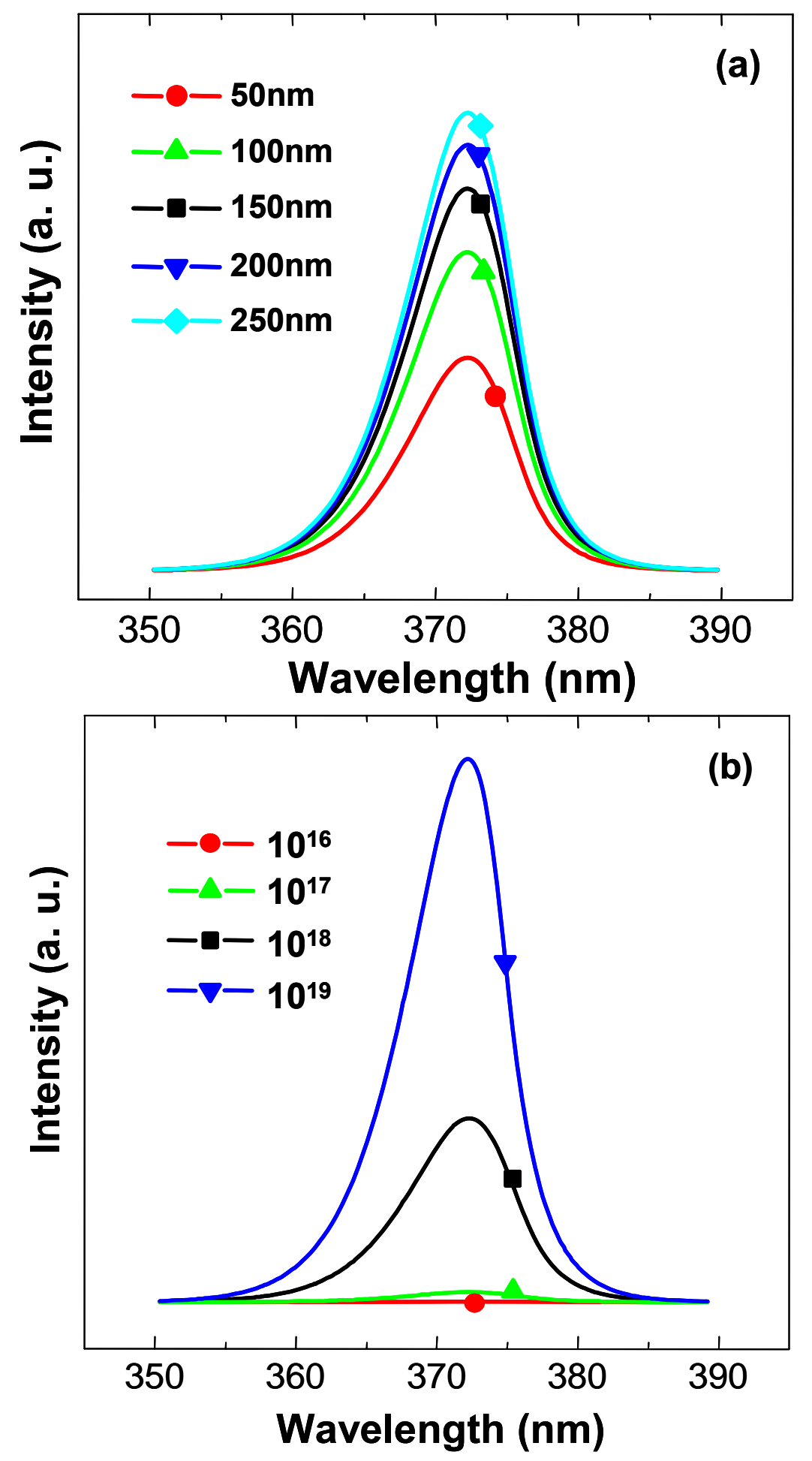

Figure 3.2.4. Simulated emission spectra from $\mathrm{ZnO} / \mathrm{ZnCdO} / \mathrm{ZnO} / \mathrm{AlGaN} / \mathrm{GaN}$ structure as a function of either (a) active layer thickness and (b) doping concentration. 


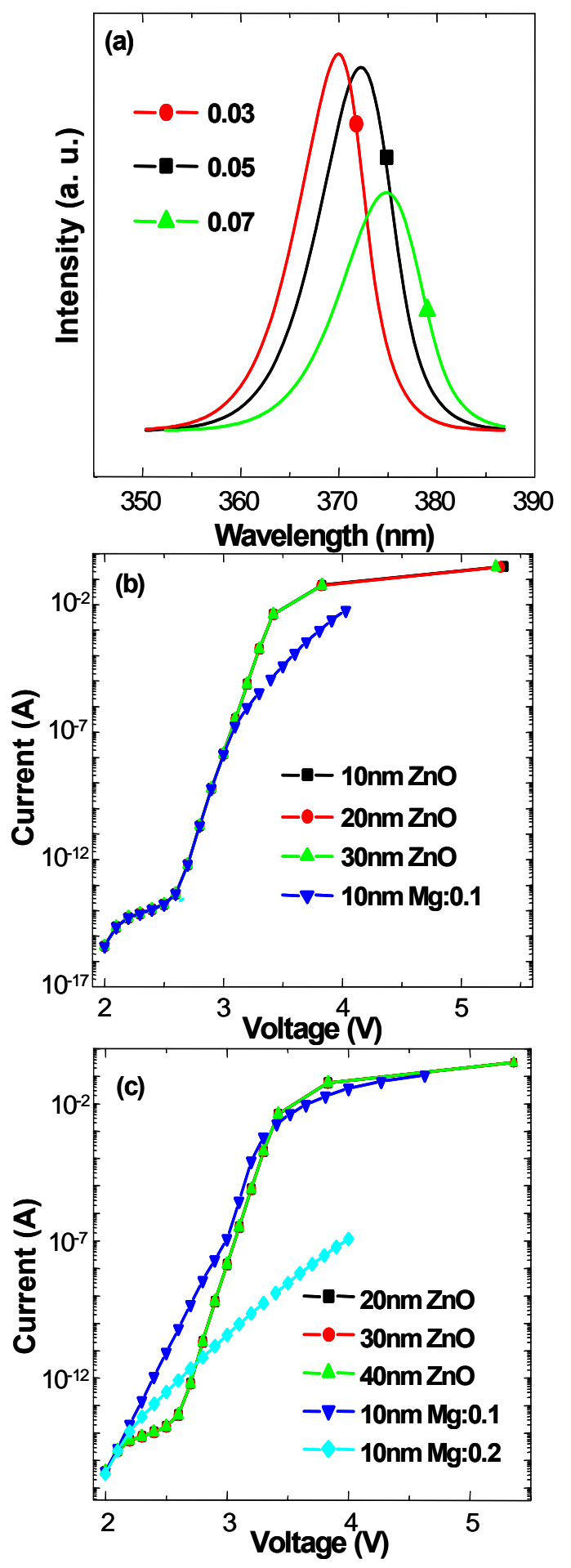

Figure 3.2.5. (a) Simulated emission spectra from $\mathrm{ZnO} / \mathrm{ZnCdO} / \mathrm{ZnO} / \mathrm{AlGaN} / \mathrm{GaN}$ structure as a function of $\mathrm{Cd}$ composition. $I-V$ characteristics as a function of (b) top $\mathrm{ZnO}$ clad layer thickness and composition and (c) bottom $\mathrm{ZnO}$ clad layer thickness and composition. 


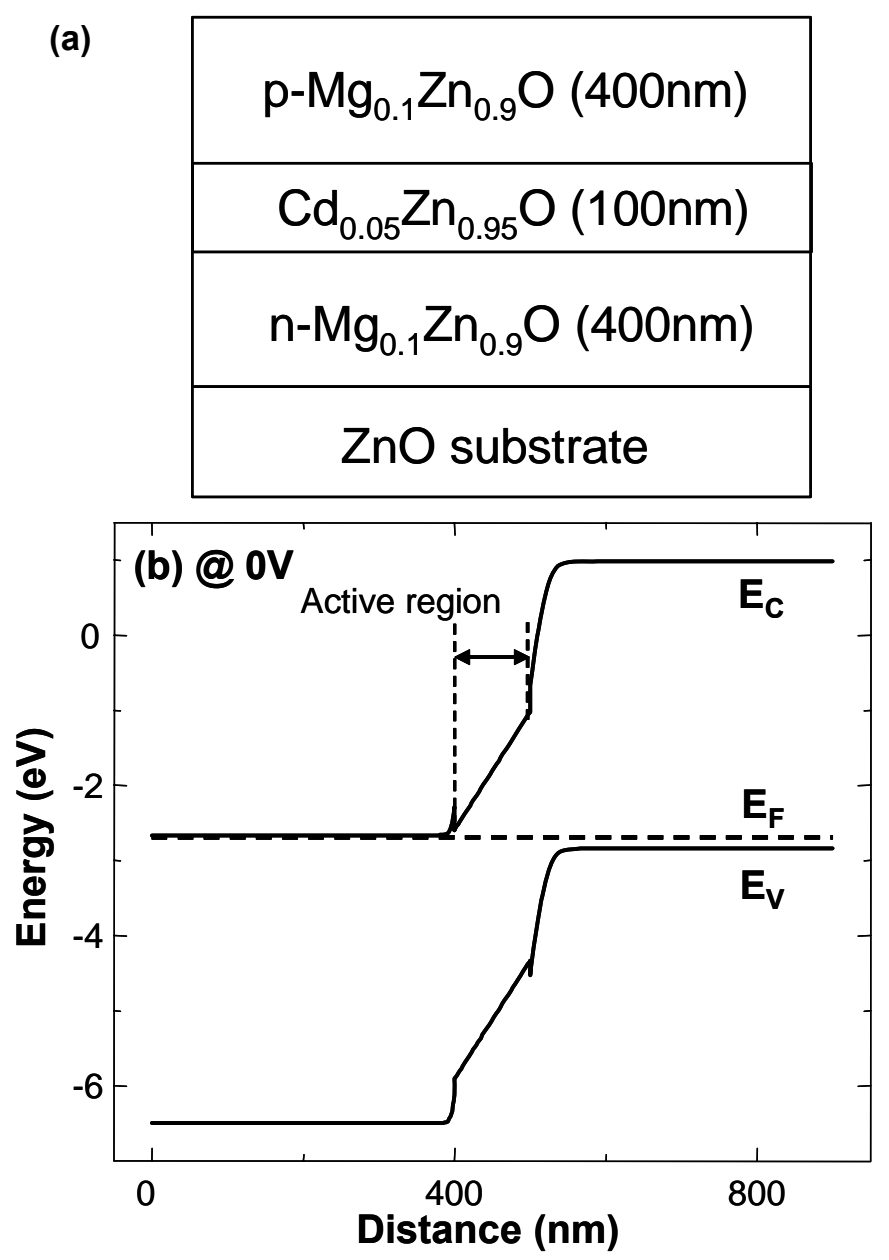

Figure 3.2.6. (a) Schematic of $\mathrm{MgZnO} / \mathrm{ZnCdO} / \mathrm{MgZnO}$ structure simulated and (b) its band diagram. 

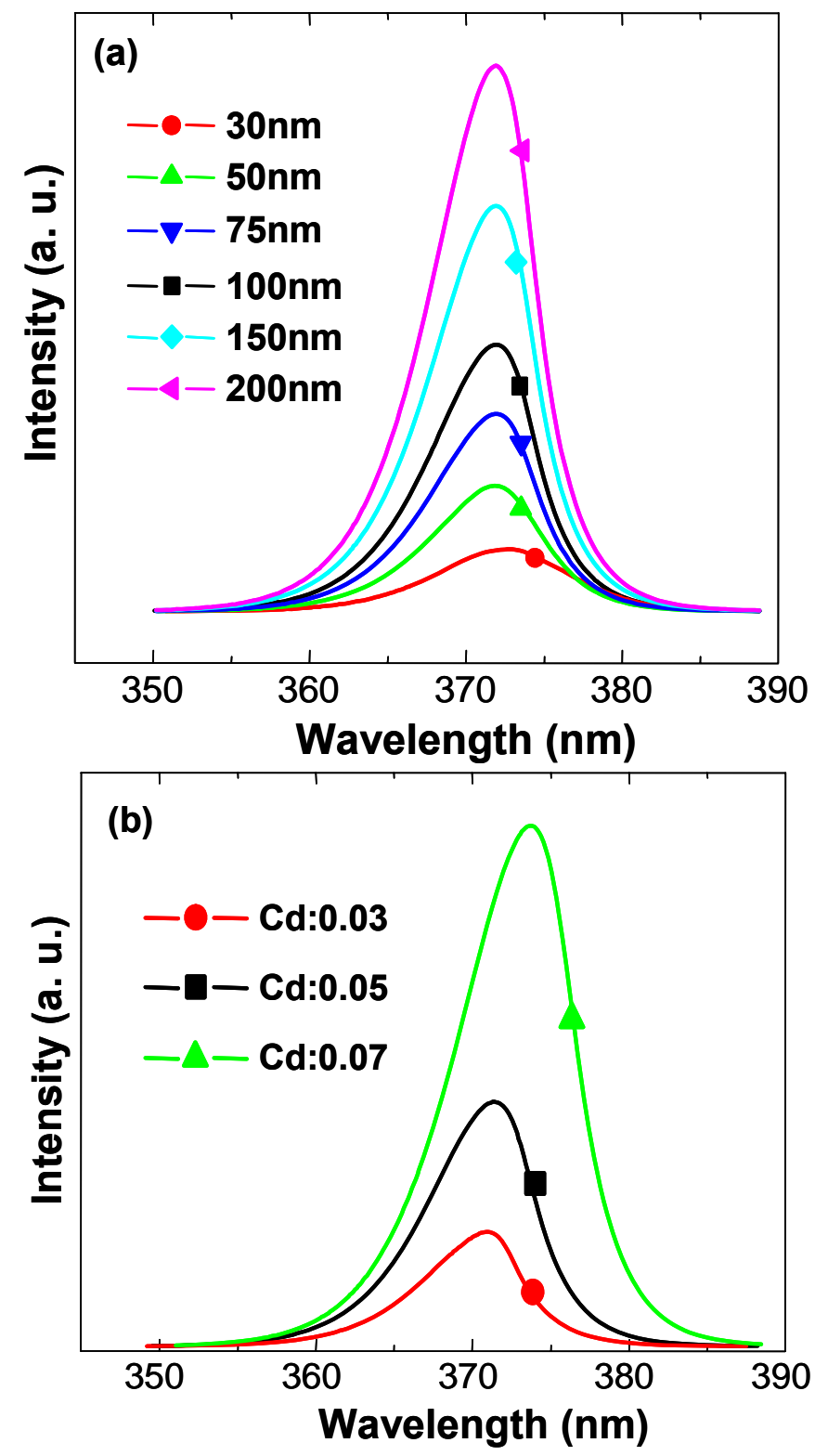

Figure 3.2.7. Simulated emission spectra from $\mathrm{MgZnO} / \mathrm{ZnCdO} / \mathrm{MgZnO}$ structure as a function of both active layer (a) thickness and (b) Cd composition. 


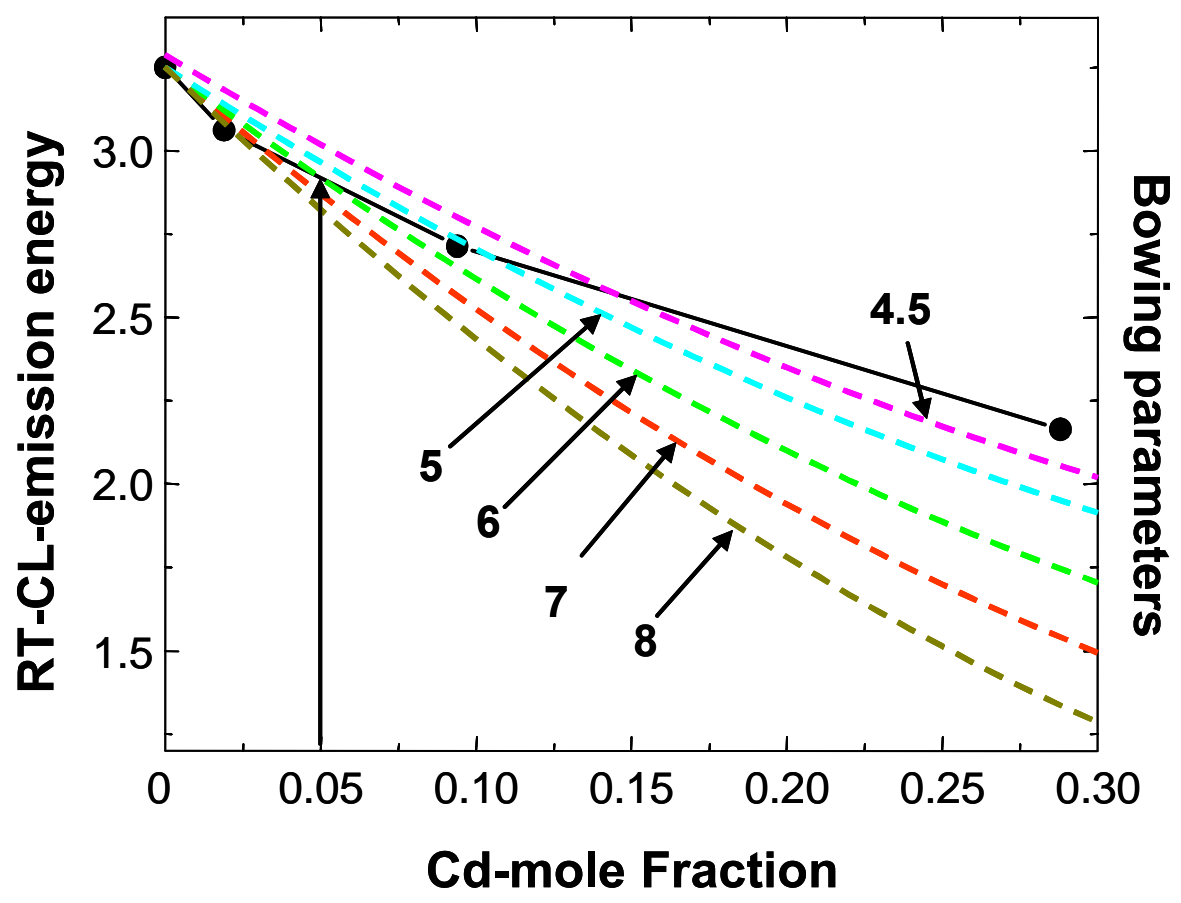

Figure 3.2.8. Experimentally observed change of room-temperature cathodoluminescence emission energy (solid circles) and simulated bowing parameters (dashed lines) as a function of $\mathrm{Cd}$ mole fraction. 

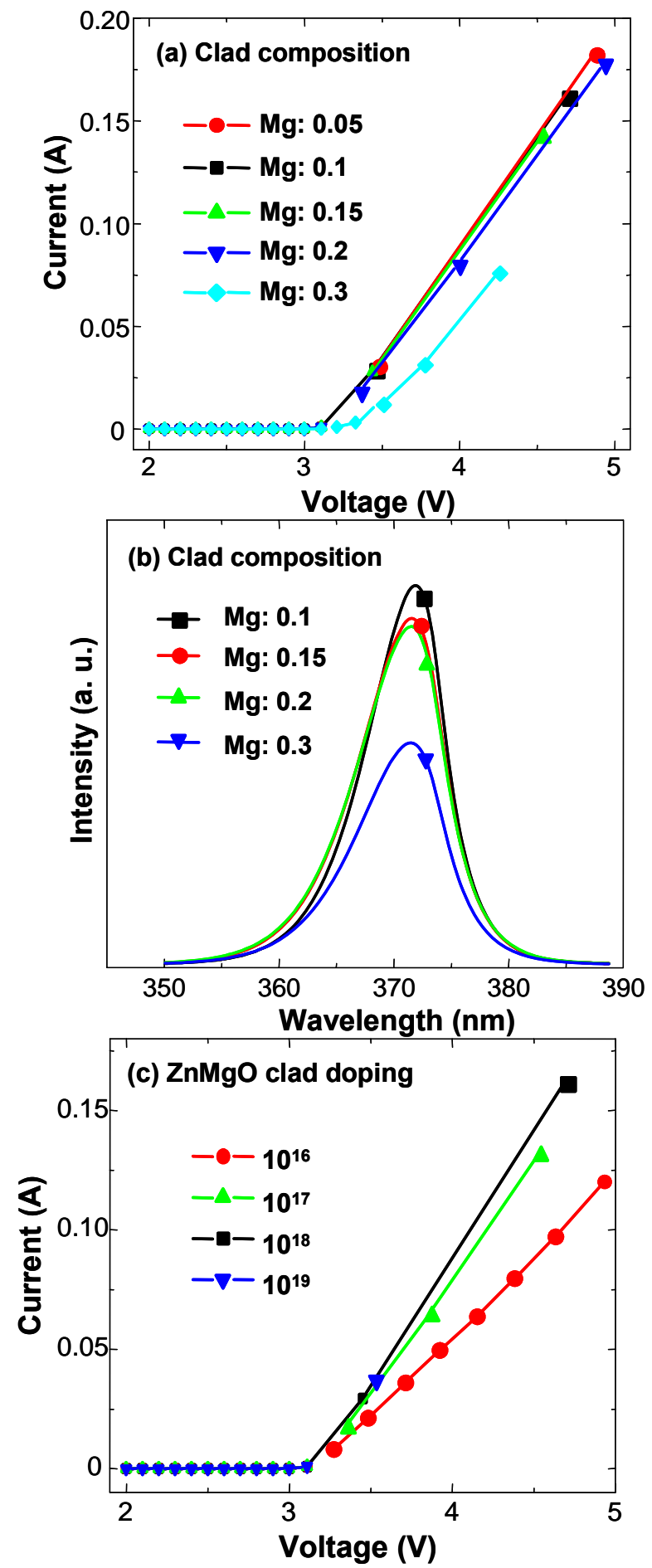

Figure 3.2.9. Simulated (a) $I-V$ characteristics and (b) emission spectrum of $\mathrm{MgZnO} / \mathrm{ZnCdO} / \mathrm{MgZnO}$ structure as a function of clad layer composition. (c) $I-V$ characteristic as a function of clad layer doping. 


\title{
$\underline{\text { Task } 4 \text { - Fabrication of n-ZnO/p-CuGaO }} 2$ pn Heterojunctions
}

\author{
4.1 Electrical Transport and Structural Study of $\mathrm{CuCr}_{1-\mathrm{x}} \mathrm{Mg}_{\mathrm{x}} \mathrm{O}_{2}$ Delafossite Thin Films Grown by Pulsed Laser \\ Deposition
}

Summary: The class of I-III-O2 ternary oxides, known collectively as delafossites, show the combined properties of a high conductivities, p-type behavior, and optical transparency. This work seeks to characterize the effects of various growth conditions upon the electrical and structural properties of $\mathrm{CuCr}_{1-\mathrm{x}} \mathrm{Mg}_{\mathrm{x}} \mathrm{O}_{2}$ grown by PLD (Pulsed Laser Depostion). We have successfully grown highly conductive, optically transparent, single crystal films of $\mathrm{CuCr}_{1-\mathrm{x}} \mathrm{Mg}_{\mathrm{x}} \mathrm{O}_{2}$ upon c-sapphire by using various $\mathrm{O} 2$ pressures and growth temperatures. Further study needs to be done to separate the effects of the highly conductive minority spinel phase $\mathrm{Cu}_{1-\mathrm{x}} \mathrm{Mg}_{\mathrm{x}} \mathrm{Cr}_{2} \mathrm{O}_{4}$ upon the aforementioned properties.

Introduction

Delafossites are a relatively recently studied class of metal oxides. As a group they form a large class of ternary oxides with the basic formula $\mathrm{A}_{\mathrm{I}} \mathrm{M}_{\mathrm{III}} \mathrm{O}_{2}$ where $\mathrm{A}_{\mathrm{I}}$ can be palladium, platinum, silver, or copper and $\mathrm{M}_{\mathrm{III}}$ can be essentially any trivalent metal with a diameter larger than aluminum and smaller than lanthanum. Those composed of palladium and platinum act as metals while those composed of silver or copper act as semiconductors. The layered nature of the crystal structure acts like a MQW (multi-quantum well) with the smaller bandgap $\mathrm{Cu}_{2} \mathrm{O}$ layers sandwiched between large bandgap $\mathrm{Cr}_{2} \mathrm{O}_{3}$ as seen in Figure 4.1.1. This dilates the bandgap to more than 3.1 $\mathrm{eV}$. Others have more adequately explained this phenomenon. Our interests lie in the ability of several copper delafossites to act as transparent p-type semiconductors.

While TCO's (Transparent Conductive Oxides) have been used and researched for several years, there has been an inability to create robust p-type materials to complement the common n-type TCO's. This inability to create the basic pn-junction has limited the commercialization of transparent electronics. Understandably, the announcement of a p-type and transparent $\mathrm{CuAlO}_{2}$ delafossite in 1997 received much attention. Major obstacles in utilizing delafossites more extensively have been relatively low conductiveties, low mobilities, and the inability to dope the delafossite as both p- and n-types to create a pn-homojunction with the notably exception of the Ohta et. al. report of $\mathrm{CuInO}_{2}$ doped with $\mathrm{Sn}$ and $\mathrm{Ca}$ acting as donors and acceptors respectively. Recent reports of polycrystalline $\mathrm{CuCr}_{1-\mathrm{x}} \mathrm{Mg}_{\mathrm{x}} \mathrm{O}_{2}$ have been shown to exhibit a conductivity as high as $220 \mathrm{Scm}^{-1}$, with p-type conduction and optical transparencies of $>40 \%$.

\section{Experimental Setup}

This paper details thin epitaxial films of $\mathrm{CuCr}_{1-\mathrm{x}} \mathrm{Mg}_{\mathrm{x}} \mathrm{O} 2$ grown by PLD (Pulsed Laser Deposition) on cplane $\mathrm{Al}_{2} \mathrm{O}_{3}$. Targets were made by massing, mixing, and hand grinding with a mortar and pestle stoichiometric amounts of $\mathrm{Cu}_{2} \mathrm{O}, \mathrm{MgO}$, and $\mathrm{Cr}_{2} \mathrm{O}_{3}$ to create the desired alloying percentage. The powder mixture was then uniaxially pressed and sintered at $1300{ }^{\circ} \mathrm{C}$ for 12 hours. The resulting target was black in color.

Double sided sapphire substrates were cleaned in sonicated baths of trichloroethylene, acetone, and methanol each for 5 minutes and subsequently blown dry with nitrogen. These substrates were then attached to the chamber heater surface by silver paint alongside a second "dummy" sample partially coated in silver paint for later thickness measurements. Once in the chamber the pressure was pumped down below $1.0 \times 10^{-5}$ Torr. Next the oxygen pressure was regulated to attain the desired pressure (either $1 \mathrm{mTorr}, 10 \mathrm{mTorr}$, or $50 \mathrm{mTorr}$ ) and the temperature was slowly raised $(\mathrm{dT} / \mathrm{dt}<10 \mathrm{C} / \mathrm{min})$ to the desired temperature and held for 30 minutes to ensure temperature consistency between the sapphire surface and the heater/thermocouple. A Compex KrF with a laser energy of $248 \mathrm{~nm}$ was used at a rate of $5 \mathrm{~Hz}$ during growth. After growth, the chamber temperature was subsequently lowered $(\mathrm{dT} / \mathrm{dt}<10 \mathrm{C} / \mathrm{min})$ and the films removed for characterization.

$\underline{\text { Results }}$

Each sample "dummy" was measured with a profilometer to attain film thickness. Powder XRD $\Omega-2 \Theta$ scans were taken for each sample. While the film shows a dominant delafossite phase presence there exists a spinel phase, $(\mathrm{Cu}, \mathrm{Mg}) \mathrm{Cr}_{2} \mathrm{O}_{4}$, represented by spinel (101), (202), and (303) peaks. Despite various growth temperatures and oxygen pressures the spinel phase was only rarely absent in the thin films and never reproducibly removed.

By increasing the alloying percentage of the $\mathrm{Mg}$ atom the amount of spinel phase increased as well. Clearly, the three spinel peaks (101), (202), and (303) increase in intensity with an increase in Mg percentage from $0.5 \%$ to $5.0 \%$. The relative spread and double peak for the spinel (202) peak illustrates the heterogeneity of the spinel phase. Both the copper and magnesium components can act as bi-valent ions in the spinel crystal lattice. The sample $\mathrm{CuCr}_{0.97} \mathrm{Mg}_{0.03} \mathrm{O}_{2}$ is especially instructive in the precipitation of the $\mathrm{Cr}_{2} \mathrm{O}_{3}, \mathrm{Cu}_{2} \mathrm{O}$, and $\mathrm{CuO}$ within the film. 
The epitaxy and crystalline quality of $\mathrm{CuCr}_{0.95} \mathrm{Mg}_{0.05} \mathrm{O}_{2}$ was established with an $\Omega$-rocking curve and $\Phi$ scan. For both the sapphire substrate and $\mathrm{CuCr}_{0.95} \mathrm{Mg}_{0.05} \mathrm{O}_{2}$ overlaying thin film the (104) crystal planes were examined in the $\Phi$-scan. Though epitaxial, the delafossite was rotated $30^{\circ}$ on the $\mathrm{Al}_{2} \mathrm{O}_{3}$ surface. Obvious twinning resulted without a domination of either of the twinned domains. The expected 3 -fold geometry of the delafossite (104) plane is seen twinned into its 6-fold twinned analogue. This is an apparently common phenomenon with thin film delafossites. The nature of tilted (104) was a highly textured single crystal with a $\Omega$-rocking curve FWHM (full width half max) of $1.133^{\circ}$. An $\Omega$-rocking curve of the c-oriented spinel (202) plane was also analyzed to determine its crystalline nature.

Hall measurements were performed for the various $\mathrm{CuCr}_{1-\mathrm{x}} \mathrm{Mg}_{\mathrm{x}} \mathrm{O}_{2}$ thin films. The van der Pauw configuration was used for the 4-point probe Hall geometry. Contacts on the surface were created with indium metal using a soldering gun. Though measurements of the carrier type using Hall measurements proved to be difficult due to low mobilities, resistivities generally increase with an increase in growth temperature. Conversely, carrier concentrations tumbled with an increase in growth temperature. Carrier type could not be ascertained for this set of films. Predictably, the resistivities of the films decreased with an increase of Mg alloying. Measurements show the carrier concentration decreasing with an addition of $\mathrm{Mg}$ while the mobility increases. This could be explained by an increase in the prevalence of the minority spinel phase previously discussed. This phase could be present in a sufficient quantity to dominate the transport characteristics of the film.

To determine the position of the $\mathrm{Mg}$ ion in the $\mathrm{CuCrO}_{2}$ lattice XPS measurements for $\mathrm{CuCr}_{1-\mathrm{x}} \mathrm{Mg}_{\mathrm{x}} \mathrm{O}_{2}$ $(\mathrm{x}=0.005,0.01,0.03,0.05)$ were performed with special attention paid to the $\mathrm{Cu}, \mathrm{Cr}$ and $\mathrm{Mg}$ binding energies. Figure 8 shows the profile for the region of the $\mathrm{Mg} 2 \mathrm{p}$ peak. Typical values for the binding energy of $\mathrm{Mg}$ as native metal or as $\mathrm{MgO}$ are very close to $49.8 \mathrm{eV}$ with $\mathrm{MgO}$ having a binding energy slightly higher. It appears that the plot only reveals a peak at $50 \mathrm{eV}$ for $\mathrm{CuCr}_{0.95} \mathrm{Mg}_{0.05} \mathrm{O}_{2}$. The peak energy to the left of "typical" $\mathrm{Mg}$ peak could be $\mathrm{Mg}$ acting to replace $\mathrm{Cr}$ in the $\mathrm{CuCrO}_{2}$ lattice. More study will be required to determine how the $\mathrm{Mg}$ lies within the lattice.

The surface texture of the films was examined using tapping mode AFM (atomic force microscopy). Films grow were rough, typically on the order of $10 \mathrm{~nm}$ RMS (root mean square) roughness. One interesting aspect of the AFM imaging is the 3-D fold symmetry demonstrated. Figure 4.1.2 shows the triangular appearance of the sample surface. The crystallite sizes are typically close to $400 \mathrm{~nm}$ in length and $100 \mathrm{~nm}$ in girth.

Optical transparency of the films was tested by optical transmission using $900 \mathrm{~nm}$ to $200 \mathrm{~nm}$ (infrared to UV light). Notably, the Tauc plots show direct bandgap behavior with the band gaps ranging from $3.19 \mathrm{eV}$ to $3.02 \mathrm{eV}$ for $0.5 \% \mathrm{Mg}$ and $1.0 \%$ samples. 


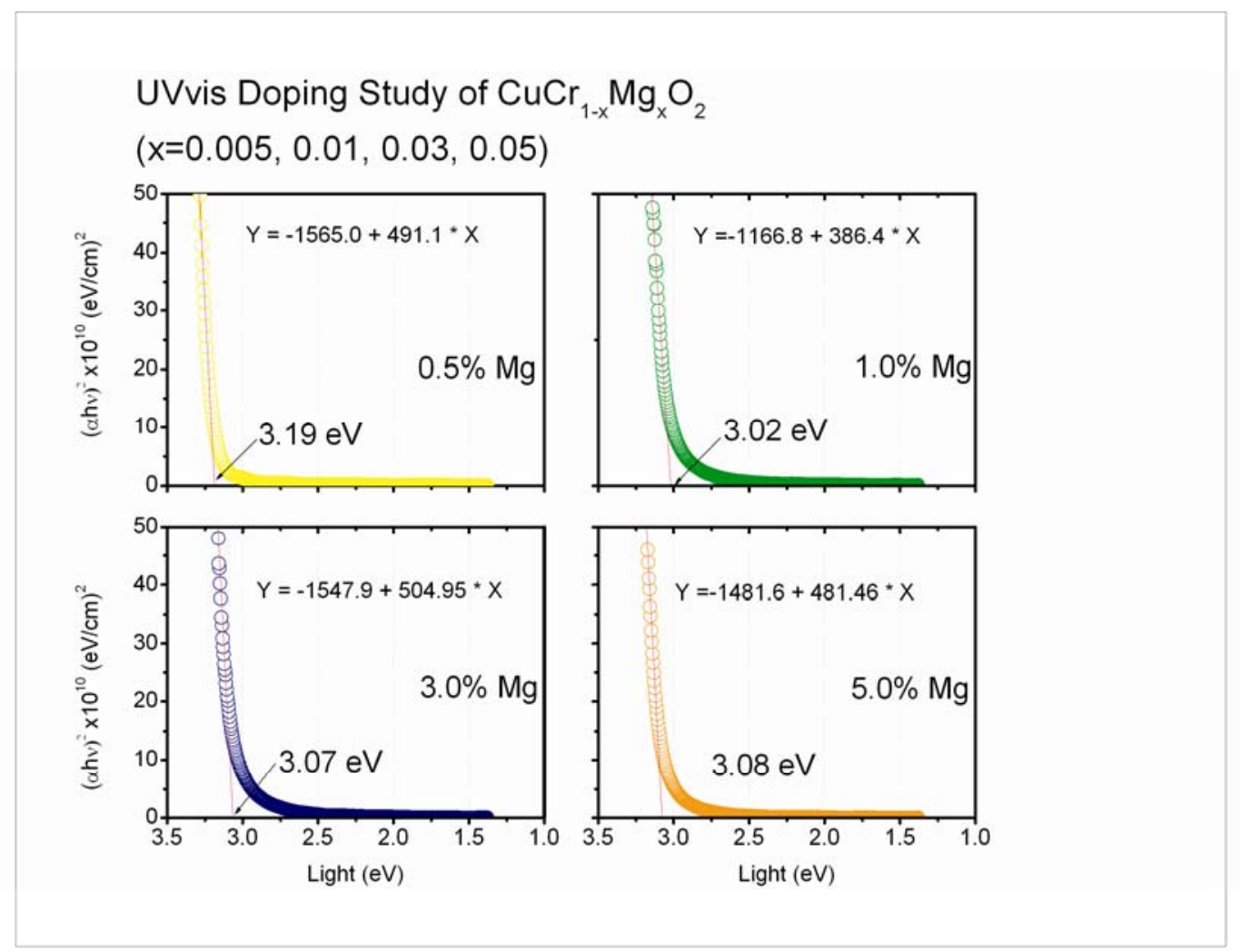

Figure 4.1.1 Optical absorption data for $\mathrm{CuCr}_{1-\mathrm{x}} \mathrm{Mg}_{\mathrm{x}} \mathrm{O}$ films 


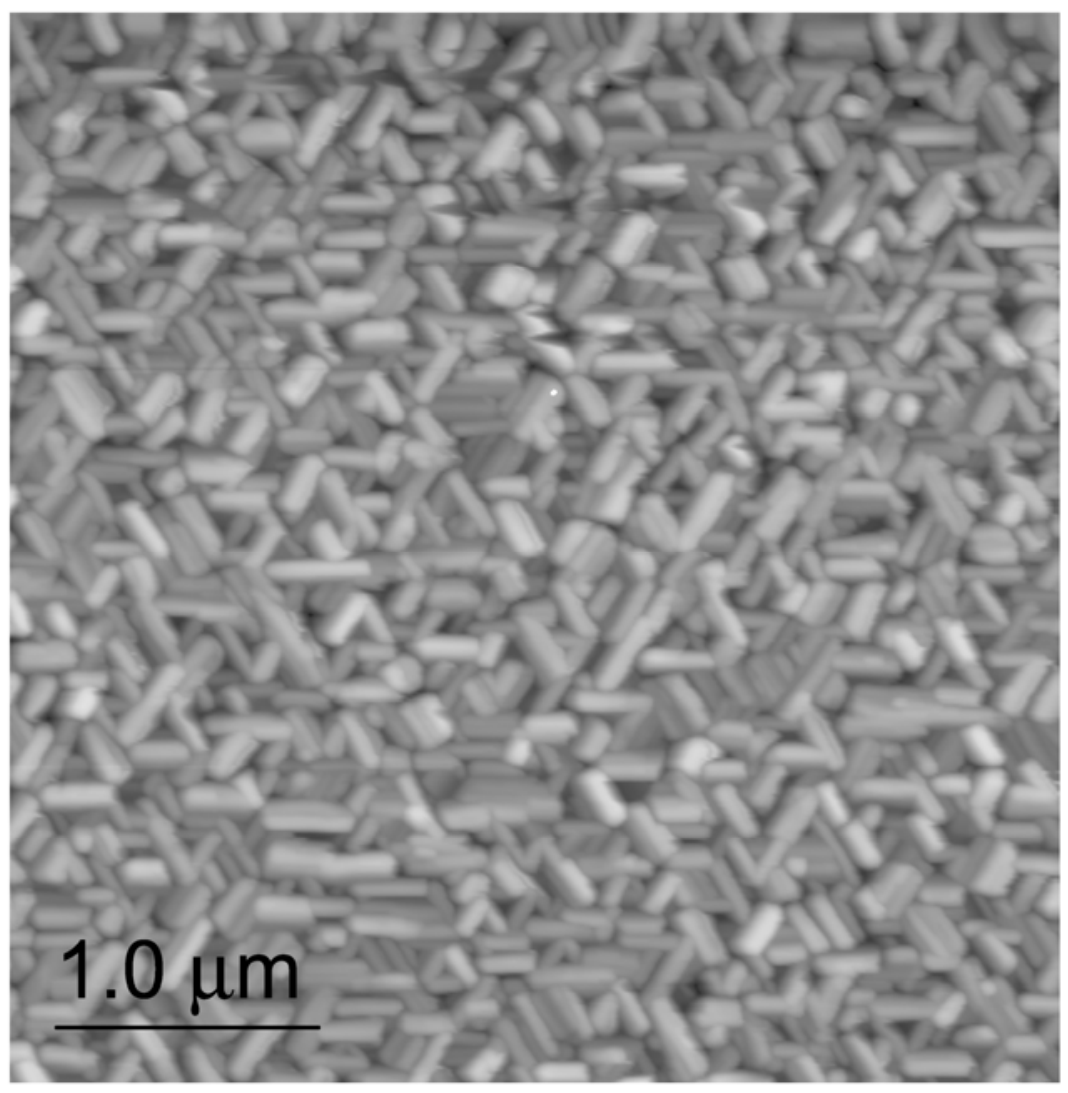

Figure 4.1.2 $\quad \mathrm{SEM}$ of $\mathrm{Cu}(\mathrm{Mg}, \mathrm{Cr}) \mathrm{O}_{2}$ film 


\section{Task 5 - Characterization of Thin Film and pn Junction Device Properties}

\subsection{Materials and Process Development for ZnMgO/ZnO Light-Emitting Diodes}

Summary: We report on the fabrication of UV light-emitting diodes (LEDs) based on a $p$ - $n$ junction p$\mathrm{ZnMgO} / \mathrm{n}-\mathrm{ZnO} / \mathrm{n}-\mathrm{ZnMgO}$ double heterostructure. Pulsed laser deposition was used to grow the complete heterostructure on $c$-plane sapphire templates. The LEDs were patterned by simple wet etching. Band-edge electroluminescence emission most likely associated with $\mathrm{ZnO}$ excitonic transitions was observed at room temperature. However, the devices show sensitivity to the presence of hydrogen in the measurement ambient due to formation of a surface conduction layer. The results show the potential of ZnO-based materials for UV emitters of potentially lower cost and with comparable or higher emission intensity than $\mathrm{AlGaN} / \mathrm{GaN}$ devices provided adequate surface passivation techniques are developed.

Introduction

In this section, we report on the growth, fabrication and characterization of $\mathrm{P}-\mathrm{ZnMgO} / \mathrm{ZnO} / \mathrm{n}-\mathrm{ZnMgO} p-n$ junction LEDs. Band edge emission is observed at forward biases of $\sim 7 \mathrm{~V}$. The devices degrade during measurement and must be annealed at $350^{\circ} \mathrm{C}$ in $\mathrm{O}_{2}$ to restore the initial current-voltage and light emission properties.

Experimental Procedure

The starting substrates were c-plane sapphire. Pulsed-laser deposition (PLD) was used for film growth on these substrates. Phosphorus-doped $\left(\mathrm{Zn}_{0.9} \mathrm{Mg}_{0.1}\right) \mathrm{O}$ or $\left(\mathrm{Zn}_{0.95} \mathrm{Mg}_{0.05}\right) \mathrm{O}$ targets were fabricated using high-purity $\mathrm{ZnO}$ (99.9995\%) and $\mathrm{MgO}$ (99.998\%), with $\mathrm{P}_{2} \mathrm{O}_{5}$ (99.998\%) serving as the doping agent. Use of the ( $\left.\mathrm{Zn}, \mathrm{Mg}\right) \mathrm{O}$ alloy reduces the residual n-type conductivity due to shallow defect donor states. A $\mathrm{KrF}$ excimer laser with repetition rate of $1 \mathrm{~Hz}$ and pulse energy density of 1-3 J/ $\mathrm{cm}^{2}$ was used as the ablation source. The target-to-substrate distance was 4 $\mathrm{cm}$. The $\mathrm{ZnO}$ growth chamber had a base pressure of $10^{-6}$ Torr. Film growth of the layer structure was performed at $500{ }^{\circ} \mathrm{C}$ for $\mathrm{ZnMgO}$ or $400^{\circ} \mathrm{C}$ for $\mathrm{ZnO}$ in an oxygen pressure of 50-150 mTorr. An n-type, Ga-doped $\mathrm{ZnO}$ layer 0.45 $\mu \mathrm{m}$ thick with electron concentration of $5 \times 10^{19} \mathrm{~cm}^{-3}$ was grown first. The active region of the LED consisted of a $\sim 40 \mathrm{~nm}$ thick intentionally undoped $\mathrm{ZnO}$ layer sandwiched between $40 \mathrm{~nm}$ thick wide band gap $n-\mathrm{Zn}_{0.9} \mathrm{Mg}_{0.1} \mathrm{O}$ clad $\left(\mathrm{n}=1.1 \times 10^{17} \mathrm{~cm}^{-3}\right)$ and a $40 \mathrm{~nm}$ thick $p-\mathrm{Zn}_{0.9} \mathrm{Mg}_{0.1} \mathrm{O}$ clad $\left(\mathrm{p} \sim 3 \times 10^{16} \mathrm{~cm}^{-3}\right)$ followed by a $0.25 \mu$ m thick $\mathrm{p}-\mathrm{ZnO}$ hole injection layer clad layer with hole concentration of $\sim 5 \times 10^{16} \mathrm{~cm}^{-3}$ and mobility $6 \mathrm{~cm}^{2} . \mathrm{V}^{-1} \cdot \mathrm{s}^{-1}$ as determined from van der Pauw Hall measurements carried out on separate single-layer calibration samples. Figure 5.1.1 shows how the P-doping of the $\mathrm{ZnO}$ produces p-type material after annealing at $900^{\circ} \mathrm{C}$. The LED was annealed under an $\mathrm{O}_{2}$ ambient at this temperature to activate the p-type doping prior to device fabrication.

LED devices were fabricated using a one step etching technique. The overall process is shown schematically in Figure 5.1.2. The mesa structure was formed by using wet etching of $\mathrm{ZnMgO} / \mathrm{ZnO}$. First, the top $p-\mathrm{ZnMgO} / \mathrm{ZnO}$ layers were etched down to the $n-\mathrm{ZnO}$ with a dilute phosphoric acid solution. Figure 5.1.3 (top) shows the etch rate of $\mathrm{ZnO}$ as a function of the solution molarity in two common etch solutions and also the selectivity of $\mathrm{ZnMgO}$ over $\mathrm{ZnO}$ (bottom). Note that very dilute solutions must be used in order to achieve controllable etch rates. The etch rate was also a strong function of material quality and was faster if the $\mathrm{ZnO}$ was grown on glass, for example, at lower temperatures than used here for the growth on sapphire.

The p-side of the structure was contacted with Ni/Au (200/800 $\AA$ ) deposited by e-beam evaporation and patterned by lift-off with contact diameters ranging from $50 \mu \mathrm{m}$ to $375 \mu \mathrm{m}$. We measured the current-voltage (I-V) characteristics of these contacts between pads in a transmission line pattern for anneal temperatures up to $350^{\circ} \mathrm{C}$. The n-type $\mathrm{ZnO}$ was given a Ti/Au (200/800 $\AA$ ) contact that was not annealed. The current-voltage (I-V) characteristics of the resulting pn junction diodes were measured using an Agilent 4145B parameter analyzer. The EL spectrum and output power were measured using a spectrometer and Si photodiode, respectively.

\section{Results and Discussion}

The I-V characteristics from the two types of contacts are shown in Figure 5.1.4 for different anneal temperatures. The Ti/Au contact to $n-\mathrm{ZnMgO}$ shows a good Ohmic behavior even in the non-alloyed, as-deposited condition and remains Ohmic during annealing at $350^{\circ} \mathrm{C}$. By contrast, the $\mathrm{Ni} / \mathrm{Au}$ on the $p$-type $\mathrm{ZnO}$ showed linear I$\mathrm{V}$ characteristics only over a limited voltage range with a specific contact resistivity in the $10^{-2} \Omega . \mathrm{cm}^{2}$ range and this was degraded by annealing for extended times at $350^{\circ} \mathrm{C}$. Thus, we kept the post-testing anneals to this temperature for short periods so as not to degrade the p-contact too much. Figure 5.1.5(top) shows an optical micrograph of the completed device. Note that the contact metallurgy remains reasonably smooth after annealing at $350^{\circ} \mathrm{C}$.

The electrical and optical characteristics of fabricated $\mathrm{ZnMgO} / \mathrm{ZnO} p-n$ diodes were measured at the wafer 
level using standard electrical and optical characterization methods. A typical chip is shown at the bottom of Figure 5.1.5. The measurements were conducted in the stage temperature range of $22^{\circ} \mathrm{C}$ to $-70^{\circ} \mathrm{C}$ for LEDs operating in $\mathrm{CW}$ mode. Electroluminescence (EL) spectra measured at room temperature (top) or $\sim-70^{\circ} \mathrm{C}$ (bottom) for different forward biases are shown in Figure 5.1.6. The devices show band edge emission beginning at biases of $7 \mathrm{~V}$ at room temperature and $6 \mathrm{~V}$ at $-70^{\circ} \mathrm{C}$. The emission band with a peak at $\sim 390 \mathrm{~nm}$ originates from the near-interband transition in the $\mathrm{ZnO}$ active region. The origin of the optical emission may be the annihilation of free or bound excitons, as suggested by optical absorption, photocurrent and CL spectral measurements The light emission intensity was low for current values below the threshold. It is likely that non-radiative recombination was a predominant mechanism responsible for transitions structure below the threshold current values. The origin of the non-radiative recombination mechanism needs additional study. The linearity of the optical power dependence above the threshold provided additional evidence that the optical emission was interband-related rather than impurity-related.

We noted that the LEDs showed poor stability when measured in air ambient. Figure 5.1.7(top) shows the I-V characteristics and light intensity curves from devices that were measured several times over a period of a few hours. The initial rectifying characteristics disappear in this time frame and the light output also significantly degraded. We were able to re-activate the rectifying I-V characteristics and light emission by annealing the LED at $350^{\circ} \mathrm{C}$ under an $\mathrm{O}_{2}$ ambient for brief periods, as shown in Figure 5.1.7(bottom). Lower anneal temperatures were not effective. We found that the LEDs would degrade in light output even for water rinsing, which might be a result of hydroxyl groups forming on the surface. This data points to the need for a stable passivation technique for the $\mathrm{ZnO}$ surface. Others have reported formation of conducting surfaces on lightly -doped $\mathrm{ZnO}$ during exposure to water vapor or annealing in vacuum that were largely reversible by subsequent air exposure, while Look et al. found that H-related donors are the most likely cause of the surface conductance. It is clear that a very important aspect of the development of $\mathrm{ZnO}$ LEDs will be the need for surface encapsulation techniques that prevent changes in nearsurface conductivity. Common methods such as plasma enhanced chemical vapor deposition of $\mathrm{SiO}_{2}$ or $\mathrm{SiN}_{\mathrm{X}}$ are problematic because of the hydrogen-containing precurors. Other oxides such as $\mathrm{Sc}_{2} \mathrm{O}_{3}$ have proven promising for producing low defect density interfaces on $\mathrm{GaN}$ and might be one approach worth pursuing. 


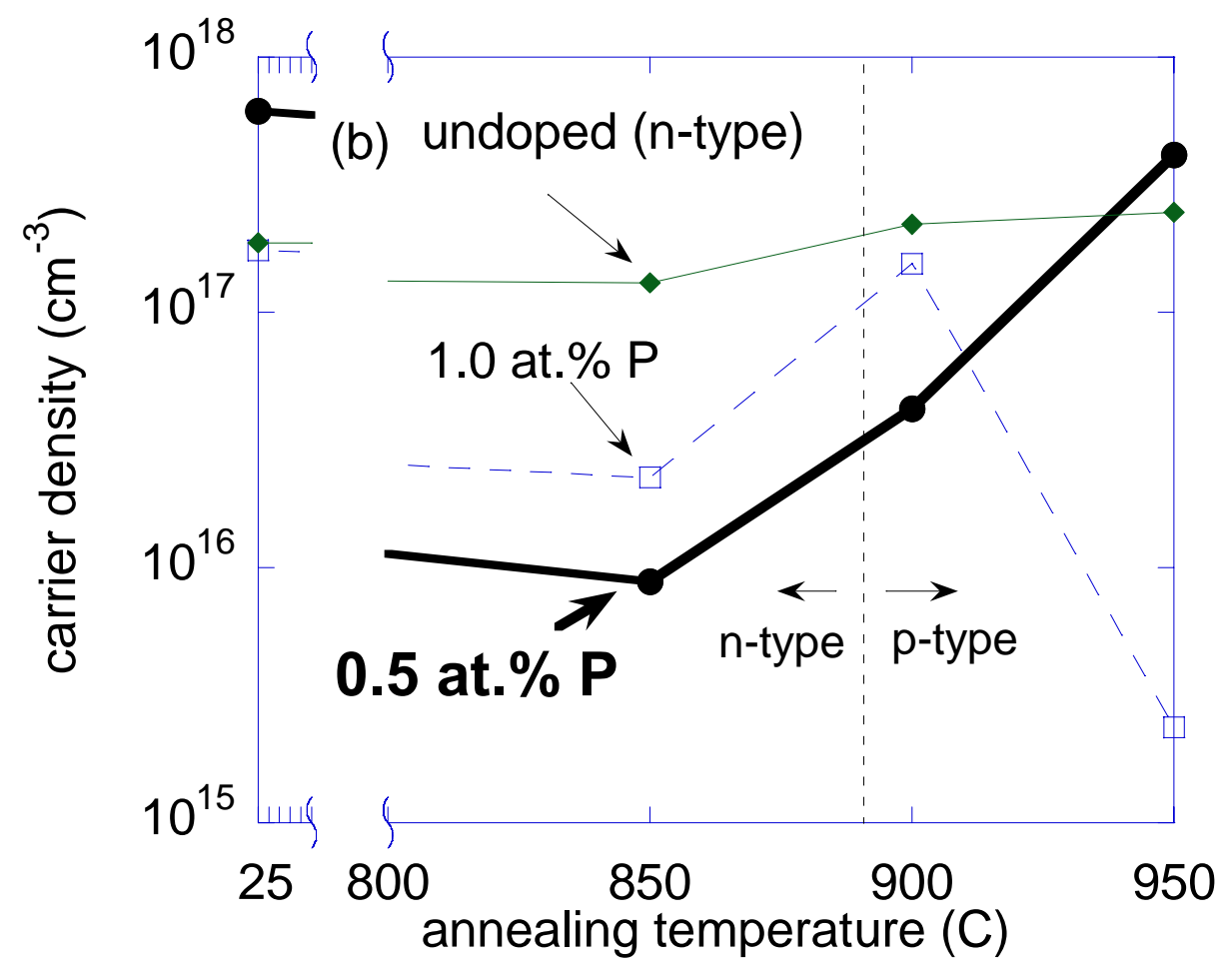

Figure 5.1.1. Carrier concentration in $\mathrm{P}$-doped $\mathrm{ZnO}$ as a function of post-growth annealing, showing typeconversion to p-type above $900^{\circ} \mathrm{C}$. 


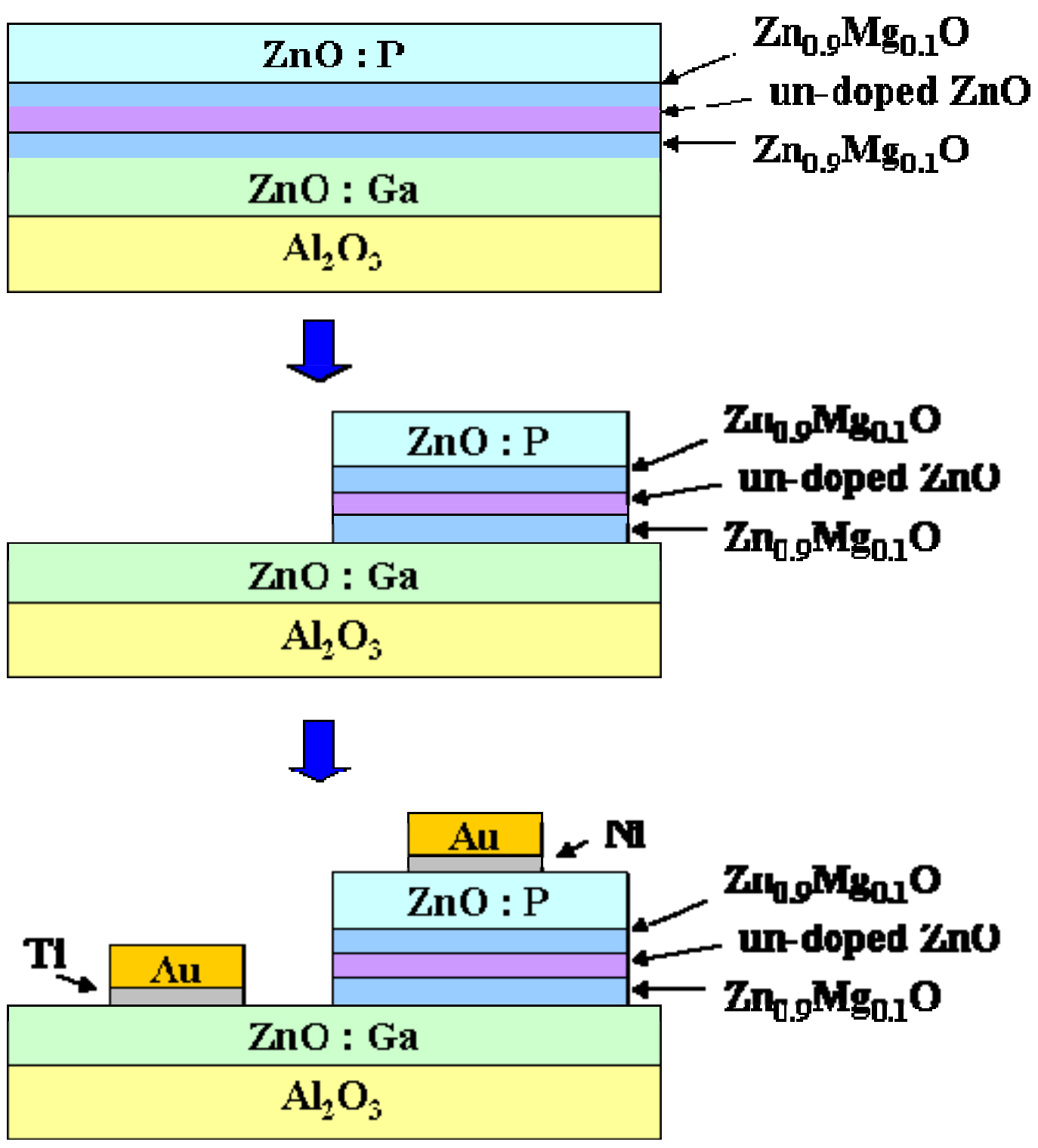

Figure 5.1.2. Schematic of processing sequence for LED, starting with the as-grown structure, followed by wet etching of $\mathrm{ZnMgO}$ and $\mathrm{ZnO}$, and finally formation of $\mathrm{p}$ - and $\mathrm{n}$-contacts. 

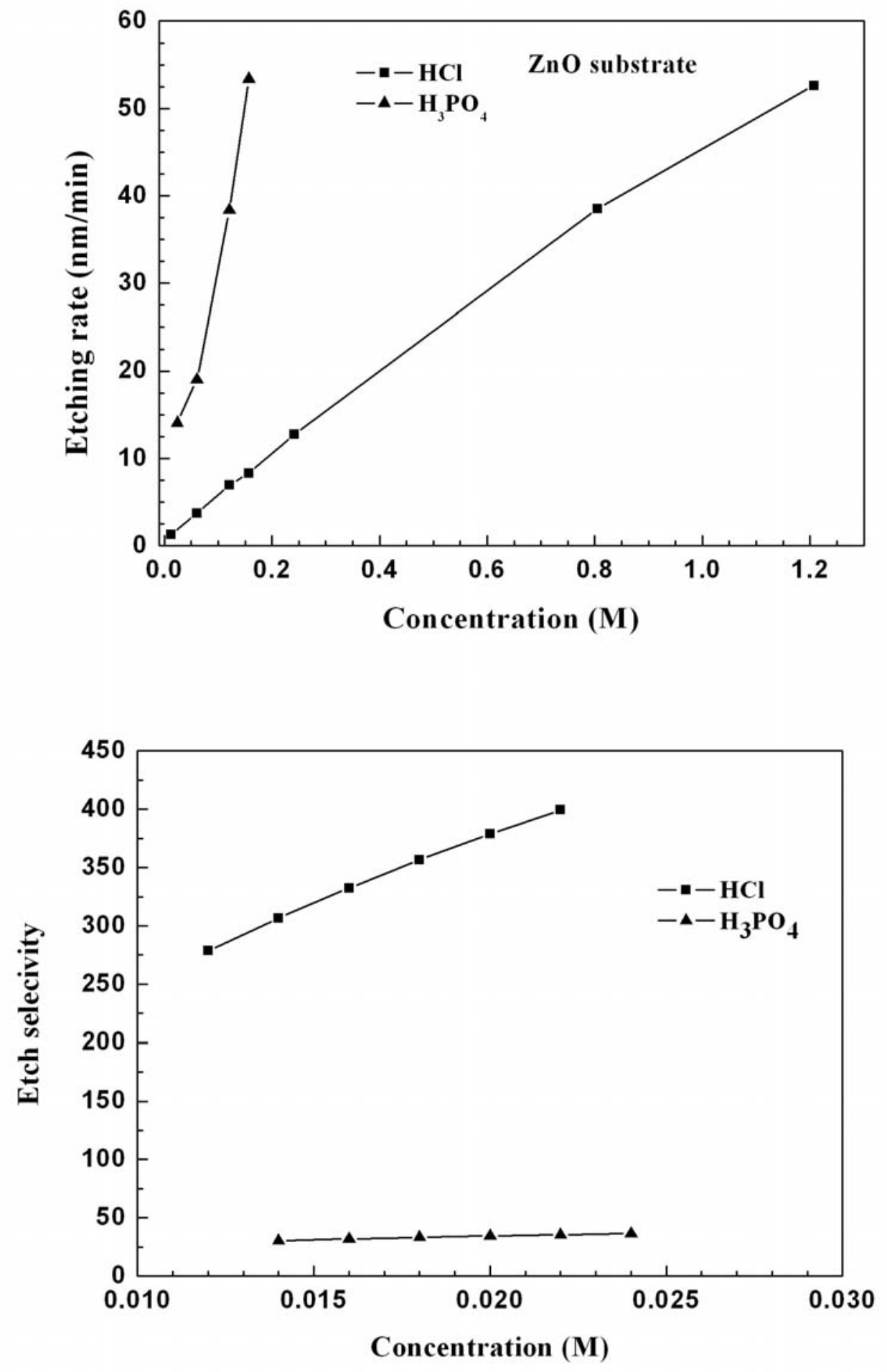

Figure 5.1.3. Wet etch rates of $\mathrm{ZnO}$ in dilute $\mathrm{H}_{3} \mathrm{PO}_{4}$ or $\mathrm{HCl}$ mixtures with water(top) and selectivity of $\mathrm{ZnMgO}$ over $\mathrm{ZnO}$ under the same conditions (bottom). 


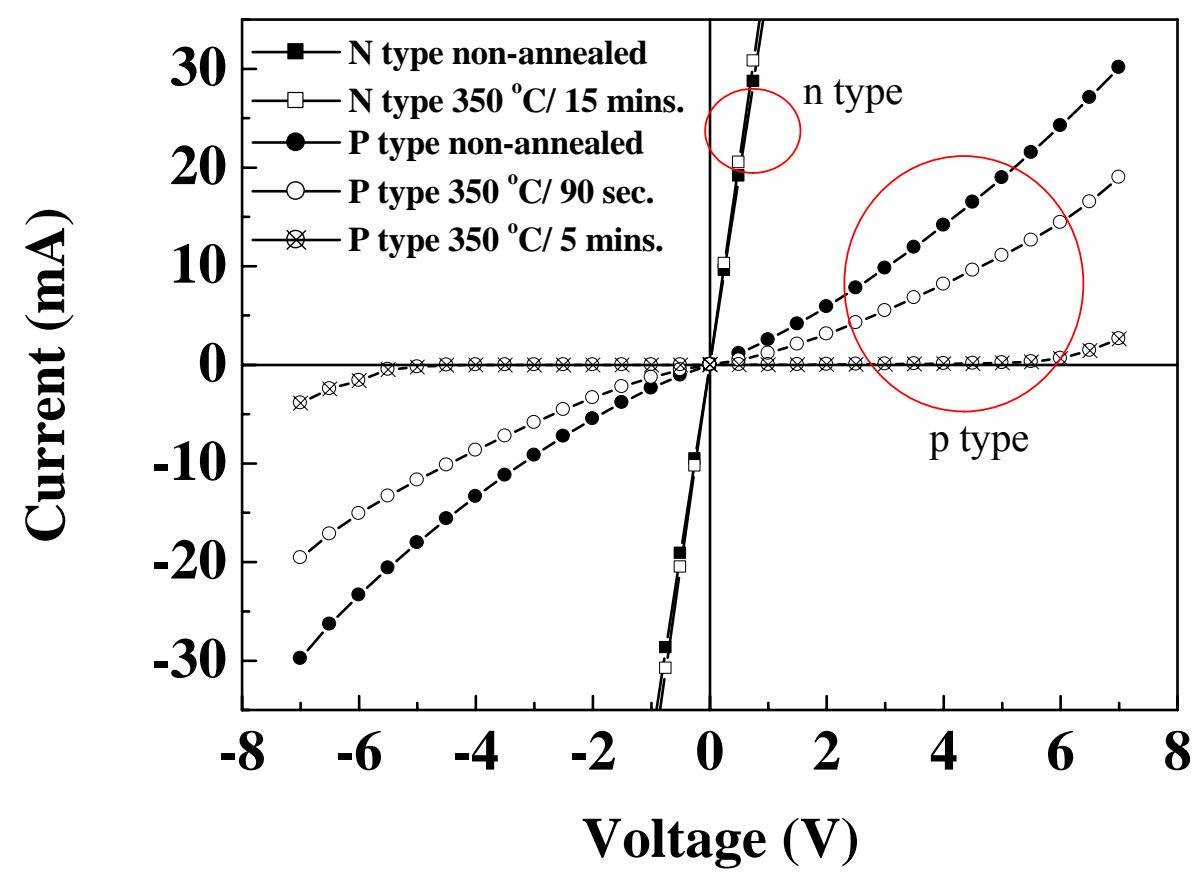

Figure 5.1.4. I-V characteristics from both $n-\mathrm{Ohmic} \mathrm{Ti} / \mathrm{Au}$ on $\mathrm{ZnMgO}$ and from $p$-Ohmic $\mathrm{Ni} / \mathrm{Au}$ contact on $\mathrm{ZnO}$ before and after annealing in air at $350^{\circ} \mathrm{C}$. 

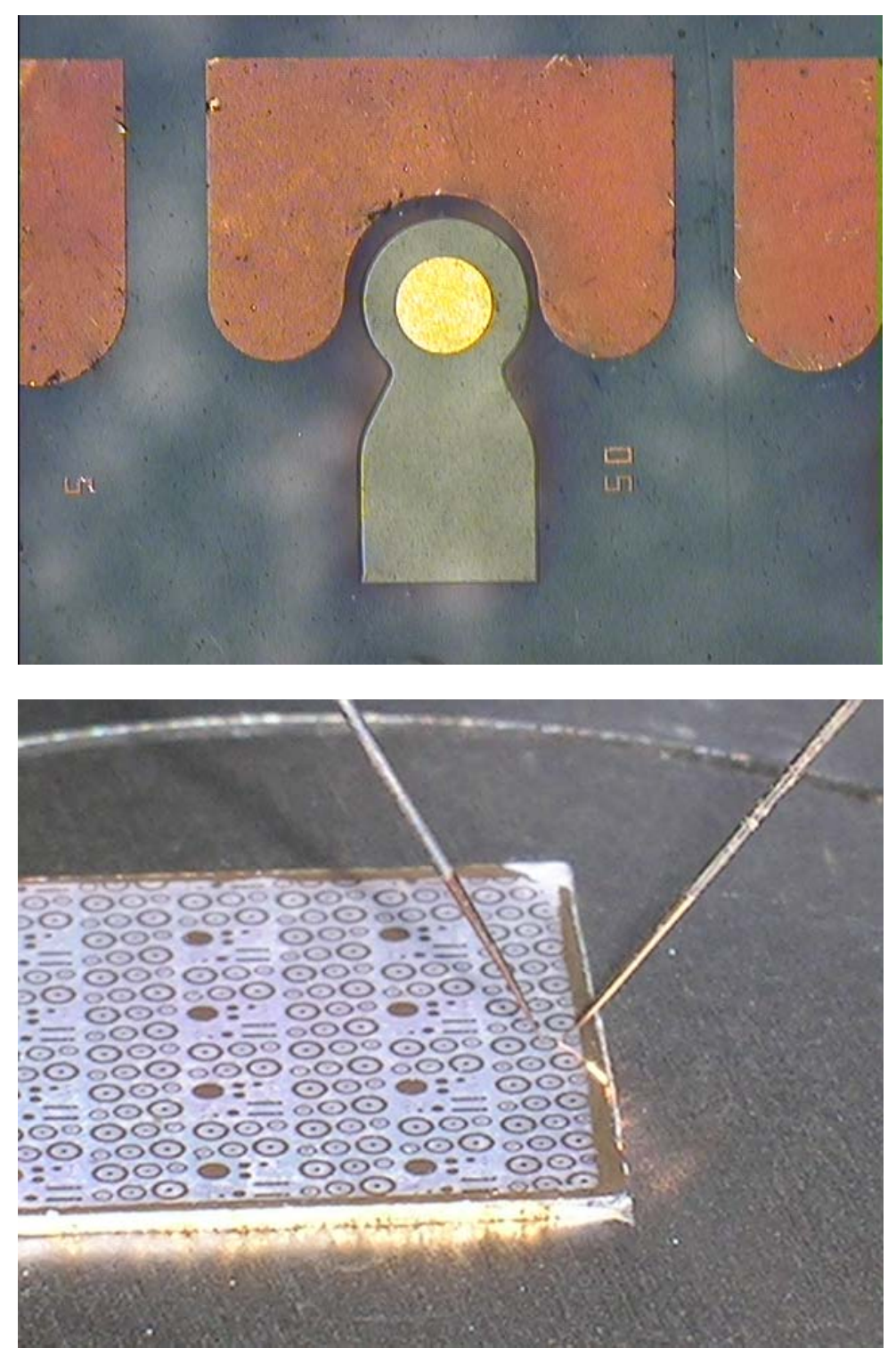

Figure 5.1.5. Optical micrograph of the completed device (top) and chip-level testing (bottom). 

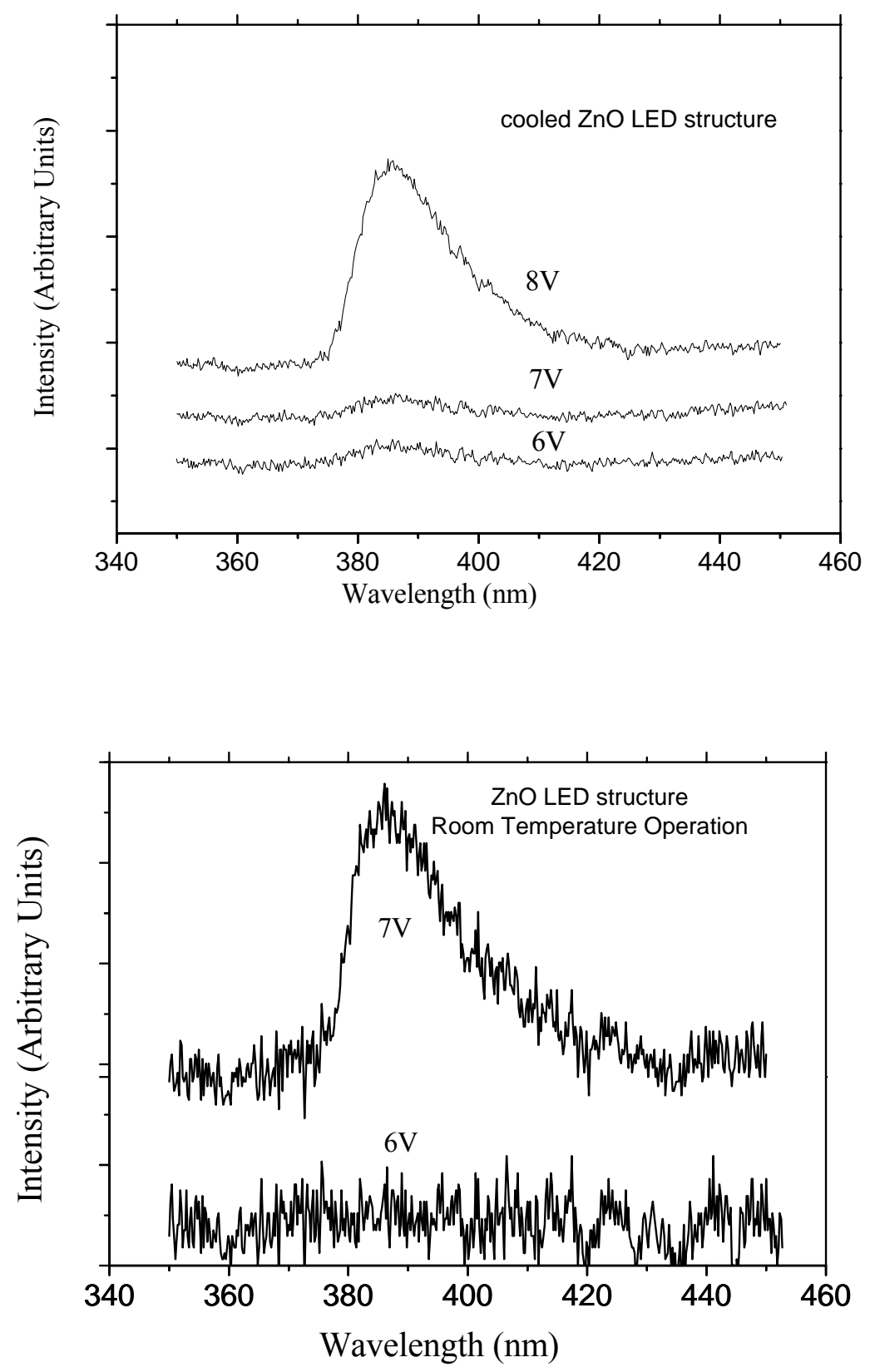

Figure 5.1.6. EL spectrum of an LED measured as a function of forward bias at room temperature (top) or $\sim-70^{\circ} \mathrm{C}$ (bottom). 

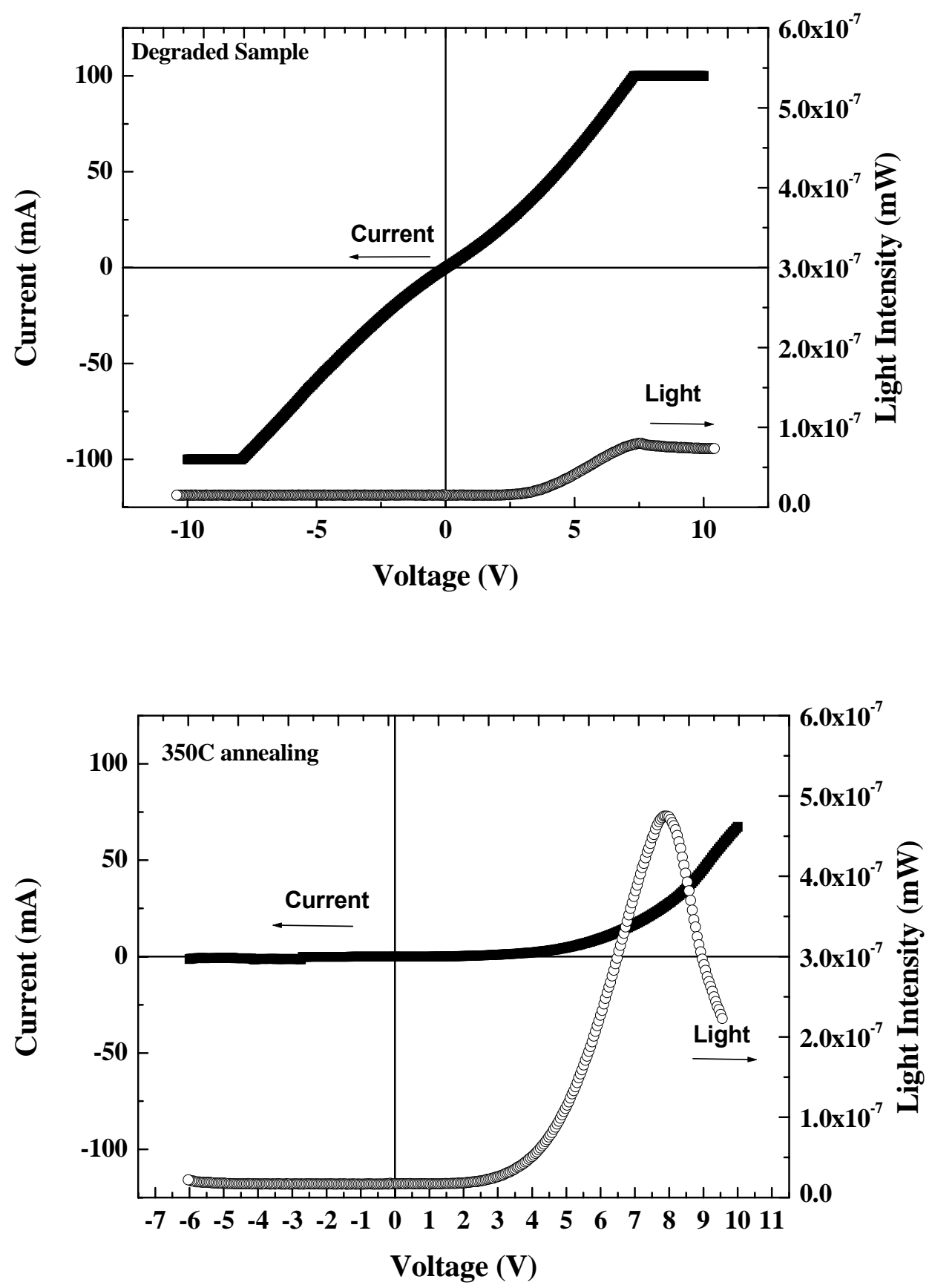

Figure 5.1.7.I-V and light intensity characteristics from degraded LED(top) and after annealing at $350 \mathrm{C}$ in $\mathrm{O}_{2}$ ambient(bottom). 


\section{Peer-Reviewed Journal Articles:}

1. Polyakov, AY; Smirnov, NB; Govorkov, AV; et al., Electrical properties of $\mathrm{ZnO}(\mathrm{P})$ and $\mathrm{ZnMgO}(\mathrm{P})$ films grown by pulsed laser deposition, JOURNAL OF THE ELECTROCHEMICAL SOCIETY, 154 (9): H825H829 2007

2. Buyanova, IA; Bergman, JP; Pozina, G; et al., Mechanism for radiative recombination in $\mathrm{ZnCdO}$ alloys, APPLIED PHYSICS LETTERS, 90 (26): Art. No. 261907 JUN 252007

3. Wright, JS; Stafford, L; Gila, BP; et al., Effect of cryogenic temperature deposition of various metal contacts on bulk single-crystal n-type ZnO, JOURNAL OF ELECTRONIC MATERIALS, 36 (4): 488-493 APR 2007

4. Lim, WT; Sadik, PW; Norton, DP; et al., Reaction-limited wet etching of $\mathrm{CuCrO} 2$ ELECTROCHEMICAL AND SOLID STATE LETTERS, 10 (6): H178-H180 2007

5. Lim, WT; Stafford, L; Sadik, PW; et al., Ni/Au ohmic contacts to p-type Mg-doped CuCrO2 epitaxial layers, APPLIED PHYSICS LETTERS, 90 (14): Art. No. 142101 APR 22007

6. Wright, JS; Khanna, R; Voss, LF; et al., Effect of cryogenic temperature deposition on Au contacts to bulk, single-crystal n-type ZnO, APPLIED SURFACE SCIENCE, 253 (8): 3766-3772 FEB 152007

7. Wang, YL; Ren, F; Kim, HS; et al., Incorporation and drift of hydrogen at low temperatures in ZnO, APPLIED PHYSICS LETTERS, 90 (9): Art. No. 092116 FEB 262007

8. Wright, JS; Khanna, R; Stafford, L; et al., Ir/Au ohmic contacts on bulk, single-crystal n-type ZnO, JOURNAL OF THE ELECTROCHEMICAL SOCIETY, 154 (3): H161-H165 2007

9. Wright, JS; Khanna, R; Ramani, K; et al., ZrB2/Pt/Au ohmic contacts on bulk, single-crystal ZnO, APPLIED SURFACE SCIENCE, 253 (5): 2465-2469 DEC 302006

10. Lim, W; Voss, L; Khanna, R; et al., Comparison of CH4/H-2 and $\mathrm{C} 2 \mathrm{H} 6 / \mathrm{H}-2$ inductively coupled plasma etching of ZnO, APPLIED SURFACE SCIENCE, 253 (3): 1269-1273 NOV 302006

11. Chen, JJ; Jang, S; Ren, F; et al., Thermal stability of Ti/Al/Pt/Au and Ti/Au ohmic contacts on n-type ZnCdO, APPLIED SURFACE SCIENCE, 253 (2): 746-752 NOV 152006

12. Lim, W; Voss, L; Khanna, R; et al., Dry etching of bulk single-crystal $\mathrm{ZnO}$ in $\mathrm{CH} 4 / \mathrm{H}-2$-based plasma chemistries, APPLIED SURFACE SCIENCE, 253 (2): 889-894 NOV 152006

13. Wang, XJ; Buyanova, IA; Chen, WM; et al., Band gap properties of $\mathrm{Zn} 1-\mathrm{xCdxO}$ alloys grown by molecular-beam epitaxy, APPLIED PHYSICS LETTERS, 89 (15): Art. No. 151909 OCT 92006

14. Heo, YW; Ip, K; Pearton, SJ; et al., Growth of $\mathrm{ZnO}$ thin films on c-plane Al2O3 by molecular beam epitaxy using ozone as an oxygen source, APPLIED SURFACE SCIENCE, 252 (20): 7442-7448 AUG 15 2006

15. Varadarajan, $\mathrm{V}$; Norton, $\mathrm{DP}, \mathrm{CuGaO} 2$ thin film synthesis using hydrogen-assisted pulsed laser deposition, APPLIED PHYSICS A-MATERIALS SCIENCE \& PROCESSING, 85 (2): 117-120 NOV 2006

16. Kang, BS; Chen, JJ; Ren, F; et al., ITO/Ti/Au ohmic contacts on n-type ZnO, APPLIED PHYSICS LETTERS, 88 (18): Art. No. 182101 MAY 12006

17. Jang, S; Chen, JJ; Ren, F; et al., Simulation of vertical and lateral ZnO light-emitting diodes, JOURNAL OF VACUUM SCIENCE \& TECHNOLOGY B, 24 (2): 690-694 MAR-APR 2006

18. Chang, CY; Tsao, FC; Pan, CJ; et al., Electroluminescence from $\mathrm{ZnO}$ nanowire/polymer composite $\mathrm{p}-\mathrm{n}$ junction, APPLIED PHYSICS LETTERS, 88 (17): Art. No. 173503 APR 242006

19. Chen, JJ; Jang, SW; Ren, F; et al., Selective and nonselective wet etching of $\mathrm{Zn} 0.9 \mathrm{Mg} 0.1 \mathrm{O} / \mathrm{ZnO}$, JOURNAL OF ELECTRONIC MATERIALS, 35 (4): 516-519 APR 2006

20. Li, YJ; Heo, YW; Erie, JM; et al., Synthesis and characterization of phosphorus-doped $\mathrm{ZnO}$ and $(\mathrm{Zn}, \mathrm{Mg}) \mathrm{O}$ thin films via pulsed laser deposition, JOURNAL OF ELECTRONIC MATERIALS, 35 (4): 530-537 APR 2006

21. Polyakov, AY; Smirnov, NB; Govorkov, AV; et al., Electrical properties of undoped bulk ZnO substrates, JOURNAL OF ELECTRONIC MATERIALS, 35 (4): 663-669 APR 2006

22. Chen, JJ; Anderson, TJ; Jang, S; et al., Ti/Au ohmic contacts to Al-doped n-ZnO grown by pulsed laser deposition, JOURNAL OF THE ELECTROCHEMICAL SOCIETY, 153 (5): G462-G464 2006

23. Wright, JS; Khanna, R; Norton, DP; et al., Thermally stable TiB2 ohmic contacts on n-ZnO, ELECTROCHEMICAL AND SOLID STATE LETTERS, 9 (5): G164-G166 2006

24. Chen, JJ; Jang, S; Anderson, TJ; et al., Low specific contact resistance Ti/Au contacts on ZnO, APPLIED PHYSICS LETTERS, 88 (12): Art. No. 122107 MAR 202006 
25. Wang, HT; Kang, BS; Chen, JJ; et al., Band-edge electroluminescence from N+-implanted bulk ZnO, APPLIED PHYSICS LETTERS, 88 (10): Art. No. 102107 MAR 62006

26. Ip, K; Thaler, GT; Yang, HS; et al., Contacts to ZnO, JOURNAL OF CRYSTAL GROWTH, 287 (1): 149156 JAN 182006

27. Chen, JJ; Jang, S; Ren, F; et al., Comparison of Ti/Al/Pt/Au and Ti/Au Ohmic contacts on n-type $\mathrm{ZnCdO}$, APPLIED PHYSICS LETTERS, 88 (1): Art. No. 012109 JAN 22006

28. Norton, DP; Ivill, M; Li, Y; et al., Charge carrier and spin doping in $\mathrm{ZnO}$ thin films, THIN SOLID FILMS, 496 (1): 160-168 FEB 12006

29. Ip, K; Khanna, R; Norton, DP; et al., Thermal stability of W2B and W2B5 contacts on ZnO, APPLIED SURFACE SCIENCE, 252 (5): 1846-1853 DEC 152005

30. Jang, S; Chen, JJ; Kang, BS; et al., Formation of p-n homojunctions in n-ZnO bulk single crystals by diffusion from a Zn3P2 source, APPLIED PHYSICS LETTERS, 87 (22): Art. No. 222113 NOV 282005

31. Yang, HS; Norton, DP; Pearton, SJ; et al., Ti/Au n-type Ohmic contacts to bulk ZnO substrates, APPLIED PHYSICS LETTERS, 87 (21): Art. No. 212106 NOV 212005

32. Chen, JJ; Ren, F; Li, YJ; et al., Measurement of Zn0.95Cd0.05O/ZnO (0001) heterojunction band offsets by x-ray photoelectron spectroscopy, APPLIED PHYSICS LETTERS, 87 (19): Art. No. 192106 NOV 7 2005

33. Ip, K; Khanna, R; Norton, DP; et al., Improved thermal stability CrB2 contacts on ZnO, JAPANESE JOURNAL OF APPLIED PHYSICS PART 1-REGULAR PAPERS BRIEF COMMUNICATIONS \& REVIEW PAPERS, 44 (10): 7291-7295 OCT 2005

34. Yang, HS; Han, SY; Heo, YW; et al., Fabrication of hybrid n-ZnMgO/n-ZnO/p-AlGaN/p-GaN lightemitting diodes, JAPANESE JOURNAL OF APPLIED PHYSICS PART 1-REGULAR PAPERS BRIEF COMMUNICATIONS \& REVIEW PAPERS, 44 (10): 7296-7300 OCT 2005

35. Heo, YW; Norton, DP; Pearton, SJ, Origin of green luminescence in $\mathrm{ZnO}$ thin film grown by molecularbeam epitaxy, JOURNAL OF APPLIED PHYSICS, 98 (7): Art. No. 073502 OCT 12005

36. Chen, JJ; Ren, F; Norton, DP; et al., Diffusion-controlled selective wet etching of ZnCdO over ZnO, ELECTROCHEMICAL AND SOLID STATE LETTERS, 8 (12): G359-G361 2005

37. Ip, K; Li, YJ; Norton, DP; et al., Low-resistance au and Au/Ni/Au ohmic contacts to p-ZnMgO, APPLIED PHYSICS LETTERS, 87 (7): Art. No. 071906 AUG 152005

38. Li, YJ; Heo, YW; Kwon, Y; et al., Transport properties of p-type phosphorus-doped $(\mathrm{Zn}, \mathrm{Mg}) \mathrm{O}$ grown by pulsed-laser deposition, APPLIED PHYSICS LETTERS, 87 (7): Art. No. 072101 AUG 152005

39. Varadarajan, V; Norton, DP; Budai, JD, Phase stability and orientation of $\mathrm{SrCu} 2 \mathrm{O} 2$ films grown by pulsed laser deposition, THIN SOLID FILMS, 488 (1-2): 173-177 SEP 222005

40. Yang, HS; Li, Y; Norton, DP; et al., Low-resistance ohmic contacts to $\mathrm{p}-\mathrm{ZnMgO}$ grown by pulsed-laser deposition, APPLIED PHYSICS LETTERS, 86 (19): Art. No. 192103 MAY 92005

41. Yang, $\mathrm{H}$; Li, Y; Norton, DP; et al., Characteristics of unannealed $\mathrm{ZnMgO} / \mathrm{ZnO}$ p-n junctions on bulk (100) ZnO substrates, APPLIED PHYSICS LETTERS, 86 (17): Art. No. 172103 APR 252005

42. Heo, YW; Kwon, YW; Li, Y; et al., Properties of phosphorus-doped ( $\mathrm{Zn}, \mathrm{Mg}) \mathrm{O}$ thin films and device structures, JOURNAL OF ELECTRONIC MATERIALS, 34 (4): 409-415 APR 2005

43. Dong, JW; Osinsky, A; Hertog, B; et al., Development of MgZnO-ZnO-AlGaN heterostructures for ultraviolet light emitting applications, JOURNAL OF ELECTRONIC MATERIALS, 34 (4): 416-423 APR 2005

44. Lopatiuk, O; Burdett, W; Chernyak, L; et al., Minority carrier transport in p-type Zn0.9Mg0.1O doped with phosphorus, APPLIED PHYSICS LETTERS, 86 (1): Art. No. 012105 JAN 32005

45. Pearton, SJ; Norton, DP; Ip, K; et al., Recent progress in processing and properties of ZnO, PROGRESS IN MATERIALS SCIENCE, 50 (3): 293-340 MAR 2005

46. Khanna, R; Ip, K; Heo, YW; et al., Thermal degradation of electrical properties and morphology of bulk single-crystal ZnO surfaces, APPLIED PHYSICS LETTERS, 85 (16): 3468-3470 OCT 182004

47. Ip, K; Gila, BP; Onstine, AH; et al., Effect of ozone cleaning on Pt/Au and W/Pt/Au Schottky contacts to ntype ZnO, APPLIED SURFACE SCIENCE, 236 (1-4): 387-393 SEP 152004

\section{Book Chapters}

1. K. Ip, S. J. Pearton, D. P. Norton, and F. Ren, “Advances in Processing of ZnO,” in Zinc Oxide Bulk, Thin Films, and Nanostructures, C. Jagadish and S. J. Pearton, Ed., Elsevier, pp. 313-338, 2006.

\section{Refereed Conference Proceedings Publications}


1. Effect of cryogenic temperature deposition of various metal contacts to bulk, single-crystal n-type $\mathrm{ZnO}$. Wright, Jon; Stafford, L.; Gila, B. P.; Norton, D. P.; Pearton, S. J.; Wang, Hung-Ta; Ren, F., Materials Research Society Symposium Proceedings (2007), 957(Zinc Oxide and Related Materials), 143-148. Publisher: Materials Research Society,

2. Development of thin film and nanorod ZnO-based LEDs and sensors. Pearton, S. J.; Tien, L. C.; Kim, H. S.; Norton, D. P.; Chen, J. J.; Wang, H. T.; Kang, B. S.; Ren, F.; Lim, W. T.; Wright, J.; Khanna, R.; Voss, L. F.; Stafford, L.; Jun, J.; Lin, Jenshan, Materials Research Society Symposium Proceedings (2007), 957(Zinc Oxide and Related Materials), 3-14.

3. Effect of argon annealing of phosphorus-doped $\mathrm{ZnO}$ and $(\mathrm{Zn}, \mathrm{Mg}) \mathrm{O}$ thin-films grown pulsed laser deposition. $\quad$ Li, Yuanjie; Kim, Hyun-Sik; Erie, Jean-Marie; Ren, Fan; Pearton, Stephen J.; Norton, David P., Proceedings of SPIE-The International Society for Optical Engineering (2006), 6337(Sixth International Conference on Solid State Lighting, 2006), 633708/1-633708/9. Publisher: SPIE-The International Society for Optical Engineering,

4. Growth of a-plane ZnO thin films on r-plane sapphire by plasma-assisted MBE. Xie, J. Q.; Dong, J. W.; Osinsky, A.; Chow, P. P.; Heo, Y. W.; Norton, D. P.; Pearton, S. J.; Dong, X. Y.; Adelmann, C.; Palmstrom, C. J., Materials Research Society Symposium Proceedings (2006), Volume Date 2005, 891(Progress in Semiconductor Materials V--Novel Materials and Electronic and Optoelectronic Applications), 407-412. Publisher: Materials Research Society

5. $\mathrm{ZnCdO} / \mathrm{ZnMgO}$ and $\mathrm{ZnO} / \mathrm{AlGaN}$ heterostructures for $\mathrm{UV}$ and visible light emitters. Osinsky, $\mathrm{A}$. $\mathrm{V}$.; Dong, J. W.; Xie, J. Q.; Hertog, B.; Dabiran, A. M.; Chow, P. P.; Pearton, S. J.; Norton, D. P.; Look, D. C.; Schoenfeld, W.; Lopatiuk, O.; Chernyak, L.; Cheung, M.; Cartwright, A. N.; Gerhold, M., Materials Research Society Symposium Proceedings (2006), Volume Date 2005, 891(Progress in Semiconductor Materials V--Novel Materials and Electronic and Optoelectronic Applications), 371-379. Publisher: Materials Research Society,

6. $\mathrm{ZnCdO} / \mathrm{ZnMgO}$ and $\mathrm{ZnO} / \mathrm{AlGaN}$ heterostructures for $\mathrm{UV}$ and visible light emitters. Osinsky, $\mathrm{A}$. $\mathrm{V}$.; Dong, J. W.; Xie, J. Q.; Hertog, B.; Dabiran, A. M.; Chow, P. P.; Pearton, S. J.; Norton, D. P.; Look, D. C.; Schoenfeld, W.; Lopatiuk, O.; Chernyak, L.; Cheung, M.; Cartwright, A. N.; Gerhold, M.,. $\quad$ Materials Research Society Symposium Proceedings (2006), 892(GaN, AlN, InN and Related Materials), 429-437. Publisher: Materials Research Society,

7. Synthesis and characterization of $(\mathrm{Zn}, \mathrm{Mg}) \mathrm{O}: \mathrm{P} / \mathrm{ZnO}$ heterostructures. Li, Yuanjie; Erie, J. M.; Kim, H. S.; Pearton, S. J.; Norton, D. P.; Chen, J. J.; Ren, F., Proceedings of SPIE-The International Society for Optical Engineering (2006), 6122(Zinc Oxide Materials and Devices), 61220R/1-61220R/10. Publisher: SPIE-The International Society for Optical Engineering,

\section{Presentations At Professional Conferences/Meetings}

\section{Invited Presentations}

1. "P-Type Doping in ZnO Thin Films: Current Status," $14^{\text {th }}$ International Workshop on Oxide Electronics, Jeju Island, South Korea, Oct. 2007

2. "ZnO Thin Films and Nanowires for Photonics, Spintronics, and Sensors," 5th International Symposium on Transparent Oxide Thin Films for Electronics and Optics, Kanagawa, Japan, May 2007

3. "ZnO PN Junctions for Highly-Efficient, Low-Cost Light Emitting Diodes," DOE Solid State Lighting Workshop, Phoenix, AR, January 2007

4. "Development of Thin Film and Nanorod ZnO-Based LEDs and Sensors," 2006 Fall Meeting of the Materials Research Society, Boston, MA, November 2006

5. "Charge Carrier And Spin Doping In ZnO Thin Films For Device Applications", 2005 Fall MRS Meeting, Boston, MA December 2006

6. "P-type doping and electroluminescence for ZnO," SPIE Meeting, San Diego, CA, August 2006

7. "Charge- and Spin-Based Devices in ZnO Thin Films and Nanostructures," American Physical Society March Meeting, Baltimore, MD, March 2006

8. "Pulsed laser deposition of acceptor doped ZnO," European-MRS, E-MRS, Strasbourg,France, May 2005 
9. "Charge carrier and spin doping in $\mathrm{ZnO}$ thin films," 4th International Symposium on Transparent Oxide Thin Films for Electronics and Optics, Tokyo, Japan, April 2005

10. "Charge and Spin-Based Electronics using ZnO Thin Films," 206nd ECS Meeting, The Electrochemical Society, Honolulu, Hawaii, October 2004

\section{Contributed Conference Presentations}

1. "Investigation of carrier type conversion of post annealed $\mathrm{ZnO}: \mathrm{P}$ thin films as a function of the substrate temperature," 2007 TMS Electronic Materials Conference, South Bend, Indiana, June 2007

2. "CdZnO/MgZnO multilayer structures for photonic applications: growth and devices," 2007 TMS Electronic Materials Conference, South Bend, Indiana, June 2007

3. "Wet Chemical Etching of Wide Bandgap Semiconductors- GaN, ZnO and SiC," Meeting: $211^{\text {th }}$ Meeting of the Electrochemical Society, Chicago, IL, May 2007

4. "High Density Inductively Coupled Plasma Etching of Zinc-Oxide and Indium-Zinc Oxide," $211^{\text {th }}$ Meeting of the Electrochemical Society, Chicago, IL, May 2007

5. $211^{\text {th }}$ Meeting of the Electrochemical Society "Thermally Stable Novel Metal Contacts on Bulk, SingleCrystal n-type ZnO," Chicago, IL, May 2007

6. "Ir/Au ohmic contacts on bulk, single crystal n-type ZnO," 2007 Spring Meeting of the Materials Research Society, San Francisco, CA, April 2007

7. "P-type doping and electroluminescence in $\mathrm{ZnO}$ thin films," March Meeting of the American Physical Society, Denver, CO, March 2007

8. "Examination Of CuCr1-XMgxO2 Thin Film Delafossites Grown By Pulsed Laser Deposition," Florida Chapter American Vacuum Society Meeting, Orlando, FL, March 2007

9. “Carrier Type Conversion In Post Annealed ZnO:P Thin Films," Florida Chapter American Vacuum Society Meeting, Orlando, FL, March 2007

10. "Investigation of carrier type conversion of post annealed $\mathrm{ZnO}: \mathrm{P}$ thin films as a function of the substrate temperature," TMS 2007 Annual Meeting \& Exhibition, Orlando, FL, February 2007

11. "Effect of Cryogenic Temperature Deposition of Various Metal Contacts to Bulk, Single-Crystal n-type ZnO," 2006 Fall Meeting of the Materials Research Society, Boston, MA, November 2006

12. "High-density Plasma Etching of Zinc-Oxide and Indium-Zinc-Oxide in $\mathrm{Cl}_{2} / \mathrm{Ar}$ and $\mathrm{CH}_{4} / \mathrm{H}_{2} / \mathrm{Ar}$ Chemistires," 2006 Fall Meeting of the Materials Research Society, Boston, MA, November 2006

13. "Electroluminescence from ZnO Nanowire/Polymer Composite p-n Junction," $53^{\text {rd }}$ Annual Meeting of the American Vacuum Society, San Francisco, CA, November 2006

14. "X-ray Excited Optical Luminescence Studies of ZnO Nanowires and ZnO/MgxZn(1-x)O Core-Shell Nanowires," $3^{\text {rd }}$ Annual Meeting of the American Vacuum Society, San Francisco, CA, November 2006

15. "Changes in Electrical Characteristics of p-Type Zinc Oxide Thin

16. Films Due to Light and Gas Ambient," TMS Electronic Materials Conference, State College, PA, June 2006

17. "Determination Of $\mathrm{MgO} / \mathrm{GaN}$ And $\mathrm{Zn0.95Cd0.05o/ZnO} \mathrm{Heterojunction} \mathrm{Band} \mathrm{Offsets} \mathrm{By} \mathrm{X-Ray}$ Photoelectron Spectroscopy” Florida Chapter American Vacuum Society Meeting, Orlando, FL, March 2006

18. "Simulation of ZnO-based UV and Visible Light-Emitting Diode Structures" Southeast Section of the American Physical Society Meeting, Gainesville, FL, November 2005

19. "Synthesis and characterization of P-doped $\mathrm{ZnO}$ and $(\mathrm{Zn}, \mathrm{Mg}) \mathrm{O}$ thin films for optoelectronic applications" Southeast Section of the American Physical Society Meeting, Gainesville, FL, November 2005

20. "Electrical, optical and structural properties of Arsenic-doped ( $\mathrm{Zn}, \mathrm{Mg}) \mathrm{O}$ films" 52nd American Vacuum Society Meeting, Boston, MA, November 2005

21. "Improved $\mathrm{Pt} / \mathrm{Au}$ and W/Pt/Au Schottky Contacts on n-type ZnO Using Ozone Cleaning", 2005 Annual Joint Symposium of Florida Chapter of the AVS and Florida Society for Microscopy, Florida AVS, Orlando, FL, March 2005

22. "Fabrication of ZnO-based P-N junction diodes", 2005 Annual Joint Symposium of Florida Chapter of the AVS and Florida Society for Microscopy, Florida AVS, Orlando, FL, March 2005

23. "Thermal Stability of Tungsten-Based Schottky Contacts to N-Type ZnO”, 207nd ECS Meeting, The Electrochemical Society, Quebec City, Canada, May 2005

24. "Fabrication of ZnMgO:P/ZnO p-n Junctions on ZnO Substrates", 2005 Electronic Materials Conference (EMC), TMS, Santa Barbara, CA, June 2005

25. "Realization of phosphorus-doped p-type ( $\mathrm{Zn}, \mathrm{Mg}) \mathrm{O}$ thin films via pulsed laser deposition", 2005 Electronic 
Materials Conference (EMC), TMS, Santa Barbara, CA, June 2005

\section{Awards/Recognition}

- David Norton elected Fellow of the American Physical Society

- David Norton elected Fellow of the American Vacuum Society

- Fan Ren elected Fellow of the American Vacuum Society

(2006) 